\title{
Adhesion and Durability of Latex Paint on Wood Fiber Reinforced Polyethylene
}

by

\author{
Afsaneh Akhtarkhavari
}

A thesis submitted in conformity with the requirements for the degree of Master of Applied Science

Graduate department of Chemical Engineering University of Toronto

@C Copyright by Afsaneh Akhtarkhavari Year 2000 
National Library

of Canada

Acquisitions and Bibliographic Services

395 Wellington Street Ottawa ON K1A ON4 Canada
Bibliothèque nationale du Canada

\section{Acquisitions et} services bibliographiques

395, rue Wellington

Ottawa ON K1A ON4

Canada
The author has granted a nonexclusive licence allowing the National Library of Canada to reproduce, loan, distribute or sell copies of this thesis in microform, paper or electronic formats.
L'auteur a accordé une licence non exclusive permettant à la Bibliothèque nationale du Canada de reproduire, prêter, distribuer ou vendre des copies de cette thèse sous la forme de microfiche/film, de reproduction sur papier ou sur format électronique.

The author retains ownership of the copyright in this thesis. Neither the thesis nor substantial extracts from it may be printed or otherwise reproduced without the author's permission.
L'auteur conserve la propriété du droit d'auteur qui protège cette thèse. $\mathrm{Ni}$ la thèse ni des extraits substantiels de celle-ci ne doivent être imprimés ou autrement reproduits sans son autorisation. 


\title{
Adhesion and Durability of Latex Paint on Wood Fiber Reinforced
}

\author{
Polyethylene \\ Master of Applied Science Year 2000 \\ Afsaneh Akhtrarkhavari

\section{Department of Chemical engineering and Applied Chemistry \\ University of Toronto}

\begin{abstract}
The low surface free energy of polyethylene is a barrier for painting wood fiber reinforced polyethylene, particularly with water borne paints. In this study, the surface characteristics of compression molded WFRP. containing $50 \% \mathrm{w} / \mathrm{w}$ wood fiber, were investigated by means of optical and scanning electron microscopy. Image analysis was employed to measure the amount of exposed wood fiber as a function of mold temperature. The WFRP surface was modified using mechanical treatments and corona discharge.
\end{abstract}

To evaluate the efficiency of the pretreatment methods, contact angle measurements were used to characterize the surface energy of the specimens. In addition, a scratch test and $45^{\circ}$ peel test were employed to measure the paint/substrate adhesion on both treated and untreated WFRP surfaces. The results indicated that, for the conditions used in this study, corona treatment improved the wettability of the WFRP surface and increased the paint/substrate adhesion better than mechanical treatments. The exposed wood fiber enhanced the paint/substrate adhesion and long term performance of the painted WFRP. 


\section{Acknowledgments}

I really appreciate the guidance, help and continued encouragement of my supervisors, Professor M.T. Kortschot and Professor J.K. Spelt. I am also grateful to Professor J.J. Balatinecz whose precious advice was a great motivation for this research.

I would like to thank the great assistance and advice of my dear colleagues Shiang Law and Imran Farid. I am also thankful to my fellow graduate students and friends, Steve Hu, Ryo Okada, Wei Ding, Saeed Doroudiani, and Abdullah Garmsiri, for their inspiration and intellectual discussions.

I am thankful to Material and Manufacturing Ontario (MMO), Royal Eco Products and Northern Fibers for their financial support.

At the end, I would like to thank my dear parents and sisters for their understanding, moral support and encouragement during the course of this research. 


\section{Table of Contents}

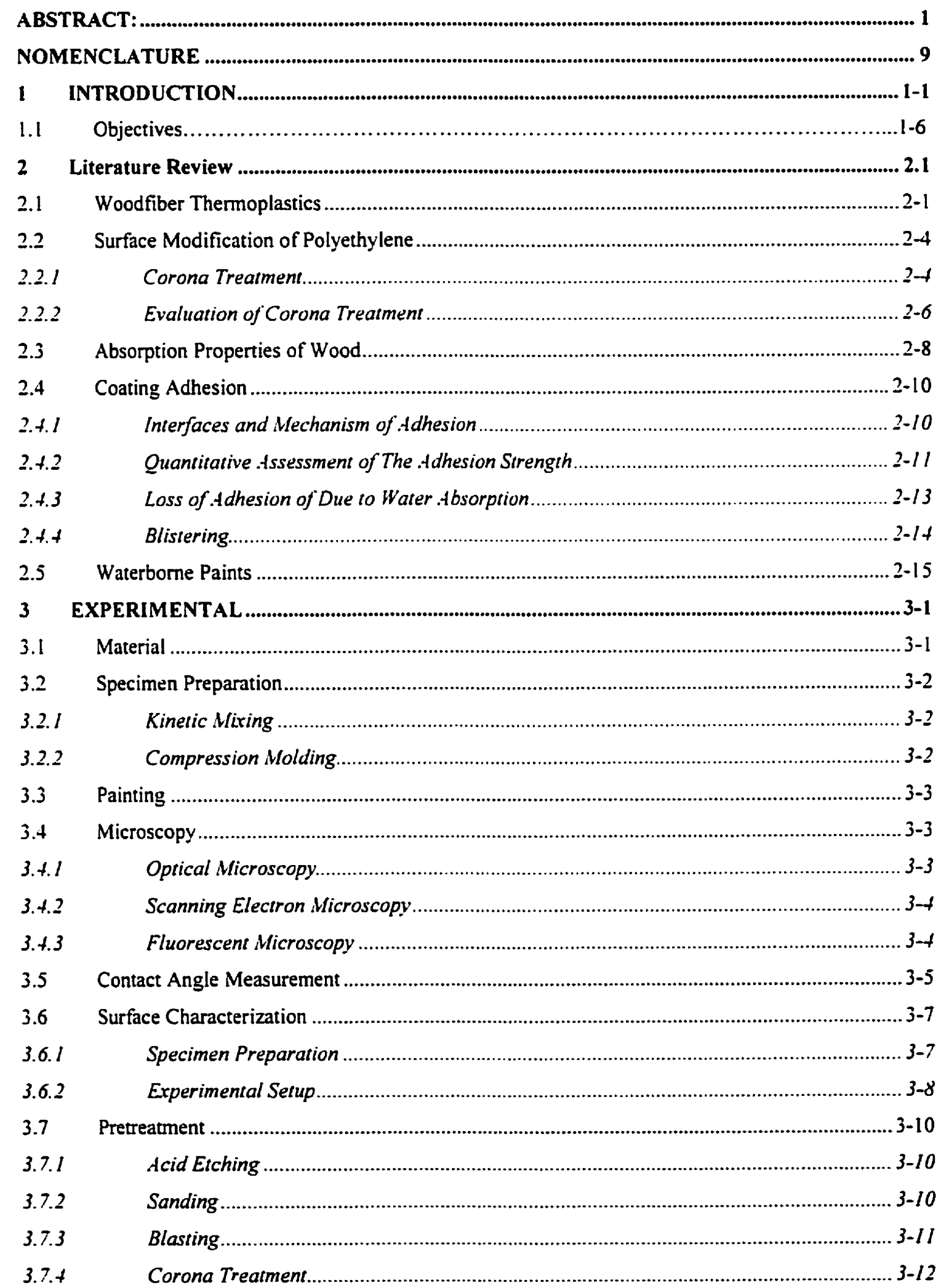




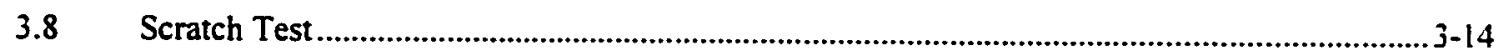

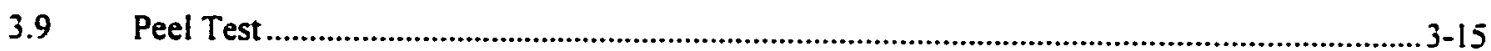

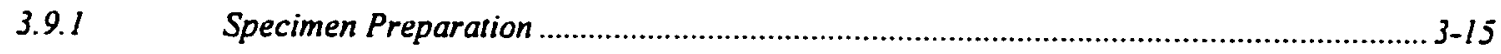

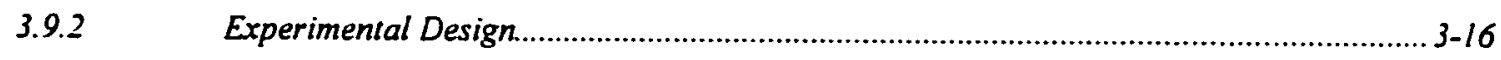

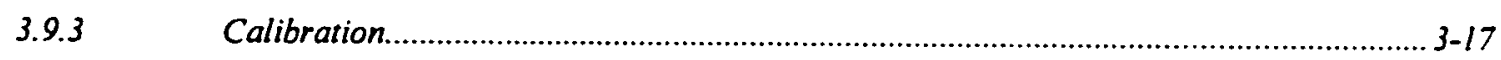

3.9.4 Measuring The Bending Energy ....................................................................... 3-18

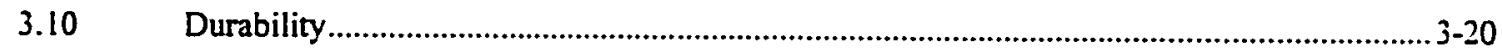

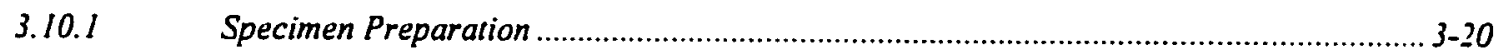

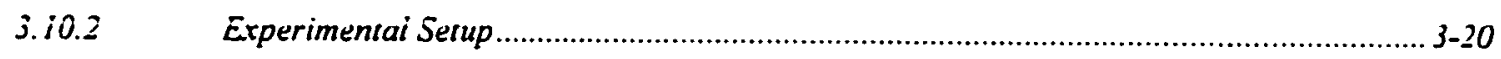

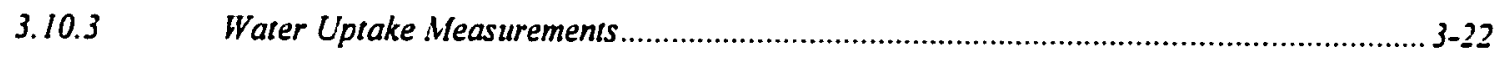

$4 \quad$ Results And Discussion ...........................................................................................................

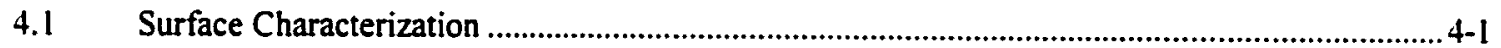

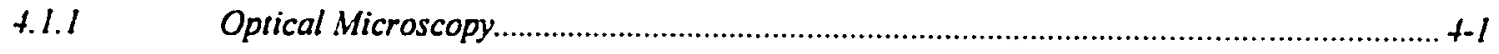

4.1.2 Scanning Electron Microscopy..............................................................................

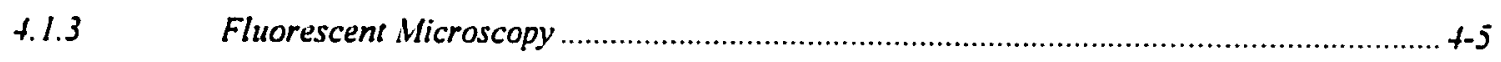

t.l.t Enhanced Contrast Image Analysis ......................................................................... t-7

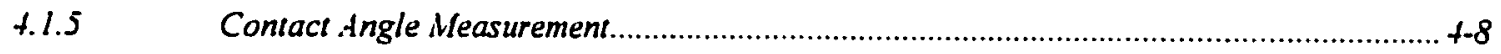

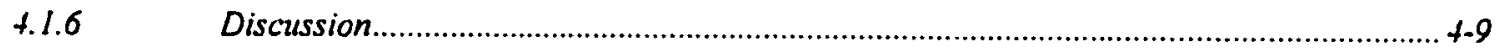

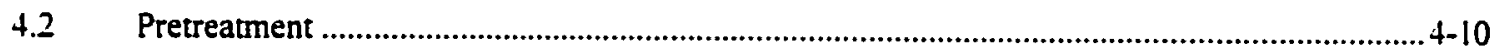

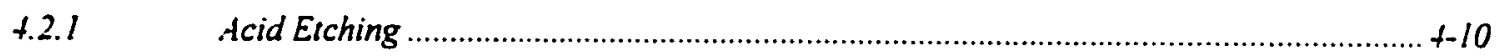

4.2.2 Mechanical Treatment .......................................................................................

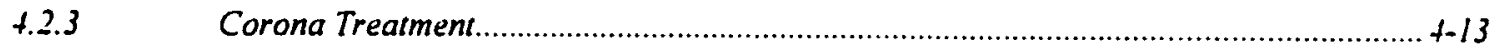

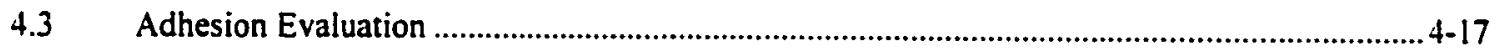

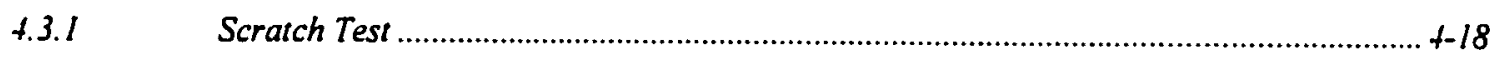

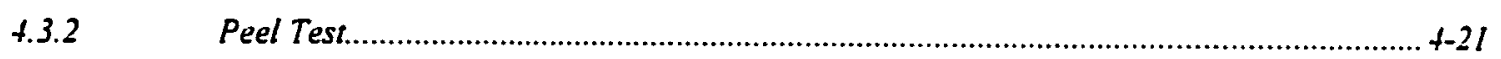

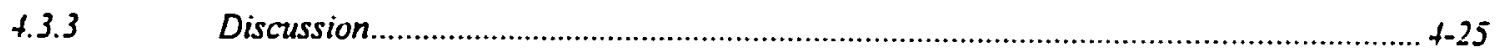

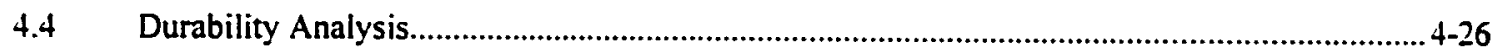

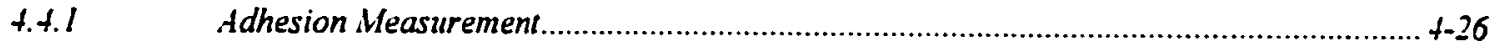

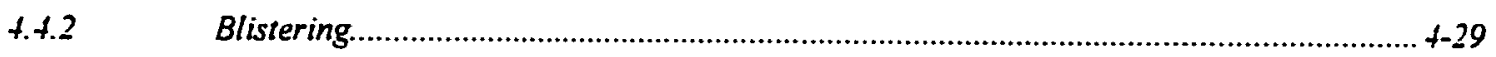

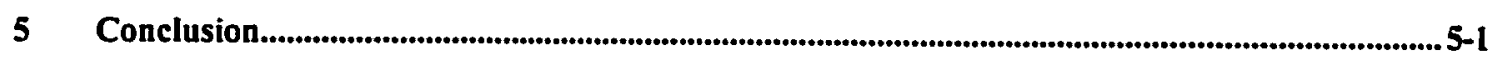

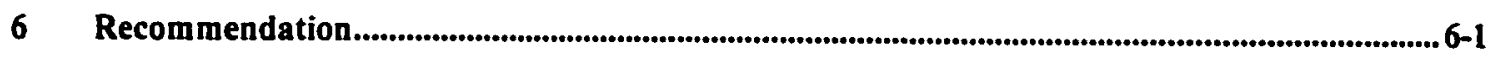

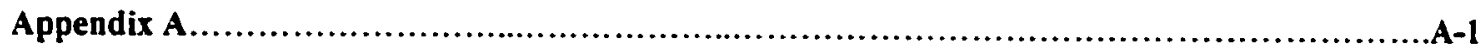

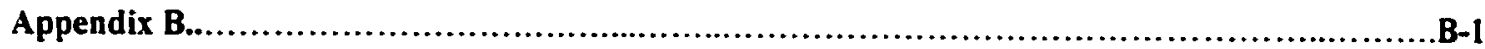




\section{List of Figures}

Figure 3-1 Light path in a fluorescent Olympus microscope type U-mnu.................... 3-5

Figure 3-2 Experimental setup for contact angle measurement. …………....................3-6

Figure 3-3 Threshold histogram of a) pure wood b) WFRP composite c) pure PE surface

Figure 3-4 Experimental setup for corona treater....................................................... 3-13

Figure 3-5 Scratch test blade and specimens .......................................................... 3-15

Figure 3-6 Peel test fixture and specimen.......................................................... 3-17

Figure 3-7 The measurement of the maximum bending radius.................................. 3-18

Figure 3-8 Peel test calibration experiment fixture ............................................... 3-19

Figure 3-9 The arrangement of specimens of water immersion test ........................... 3-21

Figure 4-1 Optical microscopy of cold molded (room temperature) WFRP .................. 4-2

Figure 4-2 Optical microscopy of hot molded $\left(160^{\circ} \mathrm{C}\right)$ WFRP ................................... 4-2

Figure 4-3 Optical microscopy of stained cold molded WFRP ....................................... 4-3

Figure 4-4 SEM micrograph of hot molded WFRP surface ............................................ 4-4

Figure 4-5 SEM micrograph of cold molded WFRP.................................................. 4-4

Figure 4-6 Fluorescent microscopy without any stain ...................................................... 4-6

Figure 4-7 Fluorescent microscopy after using stain................................................... 4-6

Figure 4-8 Exposed wood fiber area as a function of mold temperature. Error bars represent \pm standard deviation based on 2 specimens with 4 measurements per specimen.

Figure 4-9 WFRP surface sanded with emery cloth grit size $50 \ldots \ldots \ldots \ldots \ldots \ldots \ldots \ldots \ldots \ldots . . . .1-12$

Figure 4-10 WFRP surface, sanded with emery cloth grit size 50 and stained with $\mathrm{KMnO}_{4}$ 
Figure 4-11 Advancing water contact angle on HM/WFRP as a function of distance between electrode and surface for two types of elelctrodes. 4 samples with 8 measurement on each. Error bars represent \pm standard deviation based on $N=32$ 4-14

Figure 4-12 Advancing water contact angle on HM/WFRP as a function of duration of exposure. 4 samples with 8 measurement on each. Error bars represent \pm standard deviation based on $\mathrm{N}=32$ 4-15

Figure 4-13 Advancing water contact angle on HM/WFRP as a function of input current. 4 samples with 8 measurement on each. Error bars represent \pm standard deviation based on $\mathrm{N}=32$ 4-16

Figure 4-14advancing water contact angle on HM/WFRP as a function of aging (time). 4 samples with 8 measurement on each. Error bars represent \pm standard deviation based on $\mathrm{N}=32$ 4-17

Figure 4-15 Adhesion evaluation of sanded and blasted samples on different grit size and paint thickness. 4 samples and 5 measurements per sample. Error bars represent \pm standard deviation for $\mathrm{N}=\mathbf{2 0}$. 4-19

Figure 4-16 Adhesion evaluation of corona treated samples with duration of treatment. 4 samples with 5 measurements per sample. Error bars represent \pm standard deviation for $\mathrm{N}=20$. 4-20

Figure 4-17 Paint peel force of sanded HM specimens with different sandpaper grits. 3 samples with 2 measurements per sample. Error bars represent the \pm standard deviation for $\mathrm{N}=6$. 4-22

Figure 4-18 Sandpaper grit size 50: variation of peel force with peel length. (6 samples) 4-23

Figure 4-19 Sandpaper 150 grit size: Variation of peel force with peel length (6 samples)

Figure 4-20 Peel force as a function of treatment time. 3 samples, 2 measurements per sample. Error bars represent \pm standard deviation. .4-24

Figure 4-2I Peel force for painted samples as a function of immersion time. 4-27

Figure 4-22 The trend of change in peel force as a function of immersion time ...... 4-28

Figure 4-23 Blisters on HM surfaces after a) 20 days b) 30 days and c) 60 days of water immersion. 4-30

Figure 4-24 Blister size evaluation by means of blister number with immersion duration.. 
Figure 4-25 Water absorption of WFRP. Error bar represents \pm standard deviation for 4 measurements...................................................................................................... 4-33 


\section{List of Tables}

Table 4-1. Advancing water contact angles for different surfaces. Number of samples: 4; 8 measurement per sample. Errors represent \pm standard deviation based on 32

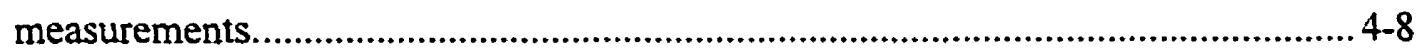

Table 4-2 Effect of chromic acid on water advancing contact angle. No of samples 2, 8 measurements per sample. Errors represent \pm standard deviation. 4-10

Table 4-3 Size number and frequency of the appeared blisters over a period of 180 days of water immersion $\left({ }^{*}\right.$ No result due to partial delamination) 4-29 


\section{Nomenclature}

b Adherend width

g Interfacial work of adhesion

Gc Fracture energy

P Steady state peel force

$\mathrm{R} \quad$ Bending radius

$T_{g} \quad$ Glass transition temperature of a polymer

$W_{t} \quad$ Total applied energy of delamination

$W_{p} \quad$ Expanded work in plastic deformation

$\mathrm{W}_{\mathrm{e}} \quad$ Elastic stored energy in metal strip

$\mathrm{W}_{\mathrm{T}} \quad$ Work of separation of bonded layers

$\beta \quad$ Stored strain energy

$\phi \quad$ Peel angle

$\gamma_{l v} \quad$ Liquid-vapor interfacial energy

$\gamma_{s l} \quad$ Solid-liquid interfacial energy

$\gamma_{s v} \quad$ Solid-vapor interfacial energy

$\theta \quad$ Contact angle 


\section{Introduction}

The use of wood fiber or flour as a reinforcing material in the plastics industry commenced in the early 1900 's, but for more than 50 years, wood fiber was used only for thermosets [1]. It was in the late 1970's that wood fiber attracted particular interest as a filler and/or reinforcing agent tor thermoplastic [2]. Wood fibers (WF) have many advantages over their inorganic counterparts, including low density, low volumetric cost, high specific modulus, and less abrasiveness. Moreover, being recyclable, renewable and biodegradable makes the WF more appealing to the environmentally sensitive manufacturer [3].

Wood fibers have been used in many thermoplastic resins including polyolefins, polyvinyl chloride, polystyrene, acrylic-butadiene-styrene, and ethyl-vinyl-acetate. Wood fiber reinforced polyethylene (WFRP) is a composite known for its lightweight, rigid structure and low cost. The most common manufacturing method for WFRP is melt blending in a thermo-kinetic mixer, and forming the product using conventional plastic processing methods such as extrusion, injection or compression molding [4].

Wood fiber composites have been used for many different purposes and in a variety of industries. In automotive production, WF composites are commonly used behind the vinyl and carpeting on the doors, trunk liners and seat backs. They are widely used as exterior construction including deck surface boards, landscape timbers, dock surfaces, picnic tables, and the like. Recently many window and door manufacturers are looking at WF composites as an alternative for solid wood. There are many other 
potential applications for WF composites that are not commercialized yet, but they are still under investigation [5].

For some of the WFRP applications mentioned above, the appearance of the final product is extremely important. The physical performance and the appearance of the compounded WFRP depend upon the degree of wood degradation and the original hue of the polyethylene. The temperature and the residence time of the melt blending process have to be adjusted to achieve the best performance [6]. For some of the applications, it is possible to obtain a wood-like finish, using virgin PE and maintaining the compounding temperature well below $200{ }^{\circ} \mathrm{C}$. In other applications, where the brown color is not preferred, adding color concentrates to the blend enhances the appearance of the composite. Although the cost for this method is relatively high, coverage is poor, and color matching is difficult. It is widely used only to achieve a variety of shades of WFRP.

Recent studies suggest that using recycled polyethylene (PE) has no dramatic effect on the mechanical properties of the composite, and many manufacturers welcome this opportunity to reduce their production costs. In spite of the acceptable mechanical performance of the composite, the dull and unpredictable color of recycled PE degrades the appearance of the final product. Adding color concentrates does not improve the appearance in this case except for very dark colors, and it is almost impossible to obtain pale and bright shades.

Coating the surface of the composite by a suitable paint is a simple and inexpensive way to enhance the appearance of WFRP, but the low surface energy of PE and the lack of functionality on its surface, create difficulties with conventional 
waterborne paints. Only solvent-based paints adhere well to the WFRP composites, but volatile organic compounds (VOC) have been identified as a significant problem for the environment. The fact that solvent-based paints are responsible for at least 15 percent of the total (VOC) emitted to the air, makes them less desirable [7].

Volatile organic compounds threaten to increase ozone where it is undesirable (in the lower atmosphere) and to destroy it where its existence is vital (in the upper atmosphere). Furthermore, some VOC's are known as probable or possible human carcinogens [8]. Most WFRP manufacturers are not willing to use a potential air pollutant to finish their environmentally friendly product, and are therefore looking for a better solution.

Applying waterborne paints with low VOC on WFRP offers many advantages in spite of their higher cost. They have less odor and can be cleaned up with soap and water rather than solvents. so workers formulating paints and people applying the paint or inhabiting freshly-painted areas are spared any risk of toxic solvents.

The adhesion of waterborne paints to the polyethylene surface is usually promoted through surface pretreatment. There are various effective techniques available to modify the PE surface including the use of flame, corona discharge, chromic acid and chlorine gas [9]. In the past 20 years, many treatments have been shown to greatly enhance adhesion to PE, such as low pressure plasma, $\gamma$-radiation, UV and organic peroxide. From a commercial viewpoint however flame and corona treatments are still by far the most widely used methods [10]. 
Theories proposed for the increase in the adhesion of corona treated PE surfaces include the elimination of a weak boundary layer, increased surface roughness due to pitting, and the introduction of polar groups due to oxidation and other chemical changes on the surface region. The most common theory is that corona discharge treatment causes an increase in surface energy by introducing polar groups to the surface. This improves wetting and adhesion [11].

In flame treatment, superficial oxidation is the major mechanism that describes the adhesion increase [12]. For a WFRP surface. flame treatment is able to modify the PE portion. but wood fiber degradation occurs. This might slightly deteriorate the mechanical properties, change the texture of the surface, and darken the color of WFRP.

Simply exposing the wood fibers on the surface is another possible remedy to improve paint adhesion. The major active group in wood $(70 \%$ cellulose and hemicellulose), is the hydroxyl group that ideally adheres well to waterborne paints. The amount of exposed WF is directly proportional to the percentage of WF in the initial compound, and varies with the method of production. In general, WF density is about $40 \%$ more than $\mathrm{PE}$, and occupies less volume in comparison, so the percentage of exposed WF is expected to be less than the percentage of exposed PE on the surface.

To improve paint adhesion on the WFRP surface, understanding the behavior of WF and PE in the blend and on the surface of the composite is necessary. For instance, the surface fraction of each portion should be measurable and predictable under known processing conditions. The relative quantity of the materials, the method of production and the molding temperature, are the main factors that would change the surface 
morphology. To achieve optimum paint adhesion, the surface fractions of PE and WF should be determined, and then the proper pretreatment technique can be selected. Pretreatment of WFRP surface should be immediately followed by painting and curing (if necessary) to achieve the desirable paint adhesion

In the painting industry, the scratch test is a common method to measure paint adhesion. Although this method is simple and applicable, the results are mostly qualitative rather than quantitative, and are difficult to reproduce. The scratch test was originally developed for metallic surfaces, and later it was defined as a standard test for plastics. In this method, it is critical to scratch only the paint and not the substrate, but thermoplastics, are relatively soft and are as flexible as the coating layer; therefore, it is difficult to prevent the scratching blade from penetrating into the surface. In this study the scratch test did not show paint performance clearly. In order to evaluate the pretreatment and paint. a method of measuring the adhesion more accurately had to be developed.

A durable coating protects the product from environmental damage and biodegradation, and would increase the life cycle. This necessitated an investigation of the long-term behavior of painted WFRP surfaces. 


\section{Objectives}

The objective of the present research was to study and improve the paintability of wood fiber reinforced polyethylene with waterborne paints. To achieve the main objective, four sub-objectives were defined.

The first objective was to quantify the amount of wood tiber and polyethylene on the surface by means of i) visual inspection ii) contact angle measurement iii) scanning electron microscopy iv) image analysis. In this part. the fraction of wood fiber is studied as a function of mold temperature.

The second was to study and select the best pretreatment method and conditions to modify the WFRP surface and increase the affinity with waterborne paints. Corona treatment, chromic acid etching, and mechanical treatment were examined

The third was to evaluate the pretreatment efficiency by measuring the paint adhesion to the modified surfaces. The strength of adhesion was investigated by means of the scratch test. To reduce the uncertainty of the results, a 45 -degree peel test was developed and used to measure the paint adhesion to the WFRP surfaces.

The fourth was to investigate the potential long-term performance of the pretreatment and paint. For this purpose, a water immersion test was conducted over a period of 6 months. The adhesion energy of the paint layer to the surface, and the degree of blistering were determined. Chemical analysis of blister liquid was done to describe the blistering effect. 


\section{$2 \quad$ Literature Review}

The use of agro-material as a filler and reinforcement in thermoplastics dates back almost 40 years. Wood fiber (flour) is the most common filler in this industry. The structure-process-properties relationships in wood fiber thermoplastics have been studied during the past three decades. Many studies were carried out to understand the effect of process factors on the mechanical behavior of the composite material including tensile strength and modulus. Although a few researchers studied the weatherability, water absorption and other environmental aspects of wood fiber thermoplastics, the relationship between surface properties and paintability has not been examined.

In the present chapter, the fundamental theory and relevant literature has been divided into five major categories. 1) wood fiber reinforced composites (general), 2) surface modification of polyolefins. 3) coating adhesion, 4) absorption properties of wood, 5) waterborne paints.

\subsection{Wood Fiber Thermoplastics}

Plastics are a very young class of materials in comparison to wood, and for the first time were defined by Staudinger as macromolecules in 1920 . However, the real development took place during the Second World War, leading to a dramatic advancement in the use of plastics starting in 1960 [13]. Fillers and additives were developed simultaneously to improve and achieve the desired properties. Therefore, natural fibers including agrofiber and wood were introduced to the industry and had a major role in development of a new generation of composites [14, 15]. In general, fillers 
increase flexural modulus and temperature capability. In many cases, however, fillers embrittle the thermoplastic and reduce its tensile strength [16]. Wood fiber composites combine the important characteristics of wood and thermoplastics, and result in a unique product that has many desirable properties.

Waste wood is one of the cheap resources for plastic fillers. The relationship between mechanical properties of composites and wood fiber specifications (including mesh size and wood species) has been studied and is still under investigation. The main concern is to combine the irregular, hygroscopic, thermo-sensitive and polar natural fiber with a hydrophobic non-polar plastic material that melts at high temperature [17]. The process should lead to desirable characteristics, but in principle, it is not expected that this combination will lead to a strong mutual intermolecular bonding.

In an attempt to increase the compatibility of the two components, several additives have been examined as modifiers or coupling agents [18]. Sometimes the components were modified through chemical derivation or surface treatment [19]. Although some of the wood modification methods have proven to be effective in improving the adhesion between two phases, and consequently leading to better mechanical properties, manufacturers prefer not to use them because they increase production costs [20].

Compounding and processing of wood fiber thermoplastic composites are challenging tasks. Two methods are commonly used by manufacturers: In the first method, fibers and polymer are mixed, melted and pelletized by means of buss kneaders or similar machines, then the pellet can be used in injection molding or extrusion. In the 
alternative method, a kinetic mixer is used to mix both components above the melting temperature of the polymer, then the molten material can be compression molded, or pelletized for injection molding and extrusion. The mechanical properties and dimensional stability of the final product are strongly dependent on fiber orientation and the percentage of fiber damage during processing. The relationship between fiber orientation and composite performance was studied by Woebken [21] for injection molding, and simulated for compression molding by Jackson et al. [22]. These studies show a high degree of anisotropy throughout the compression-molded part.

Since most of the wood fiber plastic composites are used outdoors, they are expected to be durable and resistant under environmental changes including ultraviolet radiation, moisture from rain and snow, freezing and fungal attack. Therefore, several studies have been carried out to determine the wood fiber composite environmental behavior. Simonsen [23] found that wood composites are not impervious to the effect of outdoor exposure and are degradable. English and Falk [24] reported that these composites absorb very little water, and increasing the fiber content substantially decreased the linear coefficient of thermal expansion. Johnson et al. [25], found that the water saturation levels increased and the saturation time decreased with increases in fiber loading. It was also reported that an increase in moisture content accelerated degradation.

Although nearly all thermoplastics, even mixed plastics, can be combined with wood fiber, typical plastic components include polyethylene, polypropylene, polyvinylchloride and polystyrene. The low cost, low density and relatively low melting point of polyethylene attracted a global interest in this polymer and its wood fiber composites. In 1992, the world market estimate of low density and linear low-density 
polyethylene was about 25.3 million tons. Environmental pressure for polyethylene recycling led to consumption of recycled polyethylene and wood fiber to achieve desirable mechanical properties. However, using polyethylene makes the final material difficult to paint, specifically with waterborne paints, and the polymer component needs to be modified.

\subsection{Surface Modification Of Polyethylene}

Prior to about 1950 , pretreatment for polymers was limited to the use of solvents and mechanical methods. In the mid 1940s, polyethylene was known as an excellent packaging material, but was very difficult to coat, which was a serious problem in many applications. To enhance adhesion to polyethylene. various methods were employed including corona discharge, flame treatment, chromic acid etching and chlorine gas. In 1977, the main concern was to understand the chemistry of the critical first few atomic layers of polymer surfaces. Greater knowledge about the chemistry of pretreatment in the last 20 years led to many new methods of surface modification for polyethylene, but corona and flame treatments continue to dominate the industry [9].

\subsubsection{Corona Treatment}

Since polyethylene (PE) and polypropylene (PP) are two of the three most widely used synthetic polymers [26], the majority of corona related research has been done on these two polymers. Most of the knowledge about corona treatment has been developed during past thirty years. The term "corona" is used to describe the condition of air (or other gases) between charged electrodes. Air can be broken down in a strong electrical 
field, and its ionized molecules conduct electricity. This usually can be seen by an arc or sparks between two electrodes. This soft bluish discharge of the air at atmospheric pressure is called a "corona".

Under a high voltage, electrons are accelerated toward the positive electrode, and they strike the gas molecule. The impacting electrons may drive an orbital electron out of the molecule. leaving the molecule with an electron and a positive ion. Otherwise the impacting electron shifts an orbiting electron to a higher energy level, and leaves the molecule excited. The excited molecules are unstable and decompose into radicals, ions and photons. After a short period, the gas will be full of electrons, positive ions. radicals. heat and light.

Introducing active components to the polymer surface leads to a higher surface free energy [27]. When the corona power increases. more ions are formed and the energy of the particles is elevated; therefore, more chemically active groups are introduced on the surface. The main cause of surface activation is believed to be the electrons [28]. Electrons cause chemical and physical changes, which might lead to changes in morphology of the surface, particularly in thin films.

The major chemical mechanism operating during corona treatment is air or photo oxidation. Oxidation leads to the formation of several functional groups including $\mathrm{ROOH}, \mathrm{RO} 2 \mathrm{R}, \mathrm{RO} 3 \mathrm{R},-\mathrm{O}-\mathrm{C}=\mathrm{O}$ and $>\mathrm{C}=\mathrm{O}[29]$. These polar groups are major adhesion sites for paint or inks, and can provide atomic oxygen, which can break a polymer molecule or cleave a hydrogen atom. The resulting free radicals have the potential to form new groups, and during the reactions (corona exposure), thousands of polymer 
chain transfers take place. Studying the corona mechanism in inert gases showed oxidation as the main mechanism, and the source of the oxygen can be impurities of the gas or superficial dissolved oxygen in the polymer, or dielectrics [30].

A physical change on the surface of polymers can also result in minor adhesion improvement. When high-energy particles bombard the surface, they dig tiny holes, termed micropits, which cause higher roughness on the surface. The roughness increases in the presence of oxygen. It was shown that corona treatment of polyolefins for long times leads to reduction in adhesion strength and surface free energy [31]. The size of the micropits on polyethylene surfaces increased with longer treatment times. but in the case of over-treatment the micropits changed to bumps. Overmey et al. [32] found that local surface melting or sublimation was a possible explanation. The molecules of the bumps were chemically different and had lower molecular weight; the diameter and size were found to increase proportionally with the applied corona dose. Hence. an optimum dose of corona should be applied which has to be defined according to the specification of the apparatus, specimen surface and the condition of the treatment.

\subsubsection{Evaluation of Corona Treatment}

To measure the corona treatment level, several techniques have been employed. Markgraft [33] used the "wetting tension test", which is based on using a mixture of formamide/cellulosic solutions. The solutions have a gradually increasing surface tension, and can spread completely to wet the surface in a critical surface tension, so that, by having the right mixture, the surface tension can be measured. This method involves solvents that can easily be contaminated or evaporated, and cannot give meaningful 
results on different substrates. Contact angle measurements are the most common and reliable method to indicate surface tension changes during corona treatment. Although, many liquids can be used to measure the surface tension, Blitshteyn [34] proposed the water contact angle measurement to estimate the surface tension, and to control quality of corona treated surfaces.

The contact angle $(\theta)$ of a non-wetting liquid on a solid surface is related to the solid-vapor $\left(\gamma_{s v}\right)$, solid- liquid $\left(\gamma_{s l}\right)$, and liquid-vapor $\left(\gamma_{1 v}\right)$ interfacial energies, as can be shown by Young's equation:

$$
\gamma_{\mathrm{lv}} \cos \theta=\gamma_{\mathrm{sv}}-\gamma_{\mathrm{sl}}
$$

$\gamma_{s v}$ is assumed to be $\gamma_{s}$ or the surface free energy due to negligible vapor absorption by solid surface. The measured surface energy varies depending on the liquid, and the model used to analyze the data [35].

Once a surface is corona treated to a desired level. the surface energy tends to decay with time [36]. The surfaces act dynamically after treatment. and migration of the additives and low molecular weight components changes the surface continuously. The amount of the energy decay depends on several factors, including time, treatment level, substrate type and components, handling and storage environment. Studies show that the higher the amount of initial treatment, the greater the relative treatment loss [37]. The aging effect is significant when the output power of the corona is small, but by reaching a certain level of power output, aging becomes slower. The measured surface energy also declines slightly with time, but retreatment can restore it. However, the retreated aged samples seem to have a higher level of surface oxidation. To decrease the effect of decay 
on final finishing process, many manufacturers have in line printing and coating immediately after the corona station.

A traditional corona, is an AC discharge apparatus, however, the use of short pulses of DC (impulse) discharge has been attracting interest as a means of corona treatment. Impulse corona discharge increases the power efficiency, and initiates chemical reactions more effectively. Advancing water contact angles decrease rapidly over a short period of time, which shows the formation of low molecular weight oxidized material as a result of the free radical oxidation process [38]. In this method the frequency is directly in proportion to contact angle and consequently, the lower the frequency, the higher the treatment level [39].

Recently other methods of treatment have become the subject of extensive research. Although over the next few years the flame and corona treatments are likely to continue to dominate the treatment of films, bottles, tubes and pots. low- pressure plasma will become more important as a commercial process.

\subsection{Absorption Properties of Wood}

Wood is a hygroscopic material by nature of its chemical composition. Chemically wood consists of two major components: cellulose and lignin. It also has two minor components: ash and extractives. These components are present in wood in the following approximate amounts: Cellulose $60-75 \%$, lignin $20-30 \%$, extractive $1-10 \%$, ash $0.1-0.5 \%$. 
In the cellulose fraction, the combination of carbon, hydrogen and oxygen are organized into $\beta$-cellulose with chemically reactive $-\mathrm{OH}$ groups. Hemicellulose is generally considered as part of the cellulose fraction and it ranges from a few percent to 25 percent. It influences the hygroscopic activity of wood because of its carbohydrate nature, and behaves more like an extractive, that is either soluble or easily degraded into soluble compounds.

The hydroxyl groups define the main characteristic of cellulose. During water absorption by cellulose, the hydrogen bonds between the cellulose molecules are broken and replaced by hydrogen bonds between cellulose and water molecules. Paint, varnish and adhesives can be absorbed by cellulose in a manner similar to the water absorption mechanism [40].

A complicated structure made of several carbon rings creates the lignin fraction. Although hydrogen atoms complete the structure, hydroxyls and oxygen are scarce. Subsequently, lignin can not be as reactive as cellulose and it is a rather brittle material. The primary functions of lignin are as an adhesive, bonding fibers together and as a stiffening agent $[41,43]$.

Although wood by nature is hygroscopic, changes in environment as well as processing method can change the wood surface properties. Well-established pretreatment methods for polymer surfaces, including plasma and corona discharge, have been recently employed on wood surfaces to increase water absorption [42].

Plasma treatment has been found effective to improve the wettability of wood surfaces and can decrease the advancing water contact angle from $65^{\circ}$ to $15^{\circ}$ after 10 
minutes of exposure. Corona treatment is less efficient than plasma [43]. In one study, a clear increase in surface free energy of wood due to oxygen plasma treatment was recorded, but this increase did not improve the adhesion between wood and polymeric surfaces [44].

\subsection{Coating Adhesion}

\subsubsection{Interfaces And Mechanism of Adhesion}

Functional and adhesion properties are the major factors that determine the performance of a coating system. Therefore, it is not surprising that the main cause of coating failure is inadequate adhesion. The adhesion mechanism can be divided into three categories: I) mechanical interlocking, II) physical bonding. III) chemical bonding. These mechanisms individually or together are responsible for adhesion, and usually one of them plays a dominant role.

The mechanical interlocking strength depends on the size and the geometry of the locking sites. These sites can vary from grooves and other macroscopic shapes to microroughness produced by grit blasting. There are three different improving possibilities, depending on the topography of the surface. The first one is increasing the surface area by which all other bonding mechanisms will be improved. To increase the friction between coating and surface is the second possibility. The third one is a true form of locking in which dove tail type grooves create adhesion between paint and substrates. 
Physical bonds including hydrogen and van der Waals bonds are generally weak, the higher population per unit area resulted in better adhesion. Chemical or primary bonds include metallic, atomic or ionic bonds and are stronger than physical bonds [45]. In order for the physical and chemical forces to be effective, the distance between coating and substrate should be less than $0.5 \mathrm{~nm}$. This can be achieved by using an appropriate coating technology for a specific substrate and coating.

Adhesion strength depends on the substrate/ coating interface system. There are five different types of interfaces created by technical processes: 1) monolayer interface, 2) diffusion interface, 3) intermediate phase interface, 4) physical bond interface, 5) interlocking interface [46]. The physical interfaces (e.g. wood fiber composite and waterborne paint) have comparatively low adhesion strength. and the strength has to be improved by an additional mechanism. Interlocking can be one of these mechanisms. To enhance the interlocking mechanism, sanding or blasting are common methods. The other method is to modify the surface, and enhance chemical bonding [47].

\subsubsection{Quantitative Assessment of The Adhesion Strength}

To assess the performance of a substrate/coating system, the determination of adhesion strength is the most important task [48]. The common measurement techniques can be divided into three groups: a) indirect techniques involving the application of a complex stress field, b) direct technique involving the application of relatively welldefined normal stress or shear stress, c) fracture mechanics tests which introduce a crack into the interface and measure the crack growth resistance. 
The first group of tests are indentation tests that include the micro hardness and scratch tests. These tests are used for hard coatings, and usually are done by inducing a complex ill-defined stress to the interface region which can lead to delamination of the coating [49]. The results depend on several limiting factors including coating and substrate properties, the stress applied, and the interpretation of the results. However, these semi-quantitative methods are useful to screen the coating systems and for quality control.

The second group of tests is based on application of a defined load to the surface. The first test of this group is the pull-off test, in which the loading bar is bonded to the coating with an adhesive. The adhesive should have higher bond strength than the coating. This test is standardized to measure the adhesion strength of powder coating. The second direct test. the shear test. is not limited by the adhesive strength since the coating is sheared off with a plate. The limiting factor is the thickness of the coating. This test is suitable for thermal spray powder coatings [50].

The crack growth resistance tests are the most promising group, since they measure the ability of the interface to resist the growth of a crack directly. The peel test and fracture mechanics tests are the main members of this group; however, they have to be developed further to yield accurate quantitative results.

The following general equation applies to an adhesion test.

$$
W_{T}=\gamma+W_{p}-\beta
$$

where $\mathrm{W}_{\mathrm{T}}$ is the work done for separation of adhesively bonded layer, $\gamma$ is the interfacial work of adhesion, $W_{p}$ is the work expended in plastic deformation and $\beta$ is the 
elastic energy due to the stored strain energy in the bonded adhesive layer [51]. When an adhesion measurement is carried out, the measured value is a combination of $\gamma$ and $W_{p}$. For most organic coatings which are viscoelastic, $\mathrm{W}_{\mathrm{p}}$ might be large. giving a wrong impression that the adhesion strength is also very high.

Many models have been developed to measure the dissipated energy in peel testing of adhesives. Moidu et al. [52], developed a model for the attached part of the flexible adherend adjacent to the root, and the model accounted for the compliance of both the flexible adherend and adhesive. Although this model, in principle, could be employed for paint adhesion measurement, the paint-adhesive-adherend system is more complicated than the adhesive-adherend system.

\subsubsection{Loss of Adhesion Due to Water Absorption}

All organic coatings are permeable to water; they differ only in the degree of permeability. The equilibrium concentration of water in a coating exposed to water is between $5-10 \%$. The flux of water through a free film with $100 \mu \mathrm{m}$ thickness is $1-10 \mathrm{~g} /$ $\mathrm{cm}^{2}$ day for many classes of coatings [53].

The major problem in studying wet adhesion is the difficulty in defining the degree of adherence when the paint is wet. Using a strong and sharp knife to check the loss of adhesion after a period of immersion is a common quantitative method. The scratch test or cross cut test is used with some degree of success with less than a $100 \mu \mathrm{m}$ thick coating. There are other indirect methods for estimating the loss of adhesion in the wet condition, but they are not as accurate as direct measurement [54]. 
The major unsolved problem related to wet adhesion is the mechanism by which water affects the adhesion. The behavior of the organic paint depends not only on the size, shape and chain structure of the individual units. Polymer coatings are exposed to the environment and thus are subject to degradation by environmental constituents. The major causes for the degradation includes temperature, mechanical and chemical factors and living organisms ( bacteria, fungi) [71]. The degradation is generally caused by chain scission, cross-linking, oxidation, and hydrolysis [50].

\subsubsection{Blistering}

Diffusion of water has negative effects on the appearance of paint. One of these effects is blistering, which is the first sign of breakdown in the protective nature of the coating. The blisters are local regions where paint/substrate adhesion has been lost and water may accumulate. The cause of blistering varies under different circumstances.

Swelling by water causes a shear (expansive internal) stress at paint/substrate interface. leading to blisters [55]. Air bubbles or volatile components of the coating may become encapsulated in the film during film formation and leave a void, which can then form a blister.

The osmotic mechanism is probably the most common mechanism by which blisters form. The driving force for osmotic blistering is the presence of a soluble salt or a solute leached from the paint or from the paint/substrate interface. As water penetrates to the interface, a concentrated solution is developed. The concentration gradient creates sufficient osmotic force to drive water from the coating surface to the interface, and a blister is formed. A special type of osmotic blistering can occur when the coating 
formulation has two solvents. If one of the solvents evaporates faster than the other, water can penetrate into the void left by the evaporated solvent and blisters are initiated [56].

\subsection{Waterborne Paints}

Synthetic polymer coatings traditionally were applied from organic solvents. Film properties, such as tensile strength, and toughness are proportional to molecular weight of polymer. To achieve acceptable viscosity with high molecular weight polymers, a greater amount of volatile organic compounds (VOC) have to be emitted to the atmosphere. In recent years, many industrial suppliers were actively engaged to decrease the VOC level. High solid ultra-violet cure and powder coating seemed to be the best solution for the problem; however. these methods have their own restrictions [57]. Ultra-violet curing of solvent- free formulations was only possible on a flat surface, with film thickness and pigmentation limitation. Powder coating is applied using electrostatic attraction and can not be applied to many surfaces [58].

During the Second World War, production of synthetic rubber led to the development of an emulsion polymerization process, which was the beginning of waterborne coatings.

A coating is a relatively thin liquid film containing a binder and perhaps pigments and various additives. The binder is used for pigment binding and film formation on the substrates. Usually water or other solvents are the media, in which the binder and the additives are dissolved or dispersed, and acts like a carrier. Before drying, paints are 
highly concentrated solutions of binders, and the high concentrations do not allow a regular formation of adsorbed layer of molecules. Molecules compete with each other for the bonding sites at the substrate surface. In order to permit an optimal yield of adsorption sites per macromolecule, binder concentration has to be reduced by applying paint as a monolayer [59].

In the drying process, the solvent evaporates and the binder makes a continuous film. In solvent systems, most of the drying occurs at a very fast rate due to low vapor pressure of the solvent. Water, however, has a much higher heat of vaporization, therefore it takes more heat to dry waterborne coatings. Water molecules can easily diffuse to the surface and can keep the surface wet even during evaporation. Thus, drying of waterborne coatings can be controlled by controlling time and substrate behavior. which is different from case to case [60].

By controlling the drying and film formation, the final properties of the paint can be improved through gradual cross-linking, which is desirable for a variety of reasons. The optimum cross-linking system should react via a condensation reaction as the polymer dries. Currently polymers with advanced cross-linking system have been developed which will undergo cross-linking reactions at room temperature. This reaction should not take place instantly but at the required time upon drying. Chemical resistance, weathering and optimal mechanical properties all improve as molecular weight of the binder increases by cross-linking. However, cross-linking should not occur to such an extent that the resulting film is brittle. In a system with rapid drying step, cross-linking rate is fast and sometimes incomplete. This leads to additional cross-linking during aging 
of the layers, increase in the glass transition of the binder $\left(T_{g}\right)$, and sometimes cracking and flaking of paint [7].

One of the most important functions of waterborne coatings is protection of the substrate against the destructive influences of the environment. To achieve the optimum protection, the organic coatings should resist the delaminating action of water. The adhesion of waterborne paints on exposure to water (wet adhesion) is a critical factor to define the level of environmental resistance of coating systems. In general. wet adhesion depends on substrate, paint, and the nature of the interfaces. To improve paint wet adhesion, a common method is to promote the cooperative bonding to the substrate by improving the conformation of the macromolecules from the binder [59]. 


\section{Experimental}

In this study, the experimental work was divided into 4 sections: The first section was designed to investigate the difference between the surface characteristic of wood fiber reinforced polyethylene (WFRP) under various mold temperatures. Several experiments were performed to determine the optimal molding conditions for further experiments. The second section was designed to examine mechanical and chemical techniques needed to enhance the paintability of the composite. In the third part, various methods were used to evaluate adhesion between paint and WFRP after surface modification. Once the optimal method of enhancing the surface was found, the durability and long-term performance of the paint under critical conditions were investigated.

\subsection{Material}

Recycled low density polyethylene provided by Royal Eco-Products was used as matrix material. The melt flow index was calculated as $2.5 \mathrm{~g} / 10 \mathrm{~min}$ according to ASTM D-1238 at $190{ }^{\circ} \mathrm{C}$ and $2.16 \mathrm{kgf}$. The material was supplied in the form of small chips in a cardboard container. Polyethylene was mixed thoroughly at the beginning to avoid any variance between different layers and stored at room temperature.

In typical manufacturing processes, wood fibers in the form of pellets are used as reinforcing fillers. In this study, wood fiber in the form of flour was used to promote homogeneous distribution. The wood fiber of mesh size 40-60 was provided by Northern Fibers in paper bags, and stored at room temperature. 
White water borne acrylic paint (Devflex 4208) was purchased from Glidden Paints (ICI) in 4.5-liter containers. The paint was mixed thoroughly before all painting operations and viscosity was measured according to ASTM Standard D-1200 using Ford Cup number \#4. Double-coated acrylic foam tape (VHB 4952) was purchased from 3M. The tape was used in peel tests to bond the paint to a steel strip. The specification of the tape is provided in Appendix A. Commercial grade spruce was purchased from Home Hardware to compare the results.

\subsection{Specimen Preparation}

\subsubsection{Kinetic Mixing}

All experiments were done on $50 \%$ by weight wood fiber reinforced polyethylene. A typical batch size of $135 \mathrm{gm}$ was mixed in a kinetic mixer (Werner and Pfleiferer, Gelimat) with a discharge temperature of $185^{\circ} \mathrm{C}$. The maximum tip speed was set at $22.8 \mathrm{~m} / \mathrm{s}(3300 \mathrm{rpm})$. Cycle time was measured from 50 to $55 \mathrm{~s}$.

\subsubsection{Compression Molding}

Test samples were compression molded under hot and cold conditions. For cold molded samples, material discharged from the kinetic mixer was immediately compression molded at 50 tons of pressure with $20^{\circ} \mathrm{C}$ platens in a 50 -ton press (Wabash 50). The mold was allowed to cool down for 5 minutes and then the pressure was released. Specimens were removed manually. For hot molded samples, the mold and discharged material were preheated to the desired temperature for 10 minutes in an oven. The heated material was compression molded under the same conditions as used for cold- 
molding. Water was circulated inside the platens to cool them. Specific details of individual specimen preparation are provided later where necessary.

\subsection{Painting}

The samples were painted according to ASTM Standard D-823 to provide a uniform thickness of paint. The viscosity was measured by Ford cup \# 4 and maintained constant by adding water during the painting processes. Before painting, the paint was mixed slowly and thoroughly to maintain uniform concentration and avoid the formation of air bubbles. An airless electric hand spray gun (Wagner AF-1) was used. The samples were placed horizontally on a platform and 3-6 layers of paint were sprayed from a distance of 2 feet. The wet thickness of the paint was measured with a wet thickness gauge purchased from Gardco using test method ASTM D-1212. The thickness was approximately $0.03-0.06 \mathrm{~mm}$. The painted samples were left at room temperature to dry for 48 hours before any testing. Preparation of test samples for scratch, peel and durability testing will be discussed in their respective sections

\subsection{Microscopy}

\subsubsection{Optical Microscopy}

To evaluate the effect of molding temperature on the surface of WFRP, three different microscopic techniques were used. Optical microscopy was used to inspect the surface. Hot molded (HM) specimens at $160^{\circ} \mathrm{C}$ and cold molded (CM) specimens at 23 ${ }^{\circ} \mathrm{C}$ were stained using red aniline dissolved in methyl alcohol for 5 minutes and then washed under running water to enhance the contrast of wood fiber on the surface. The 
specimens were then placed under the optical microscope (Nikon) and pictures were taken using Nikon camera at magnifications of $30 \mathrm{X}$ and $60 \mathrm{X}$.

\subsubsection{Scanning Electron Microscopy}

In optical microscopy the light can penetrate the semi-transparent polyethylene surface layer making it difficult to differentiate between the surface and the layers beneath it. Scanning electron microscopy was used to inspect the roughness and exposed wood fiber on the WFRP surface. Samples of cold and hot molded composite were mounted on specimen holders and gold coated. The specimens were scanned at $20 \mathrm{keV}$ with a magnification of $400 \mathrm{X}$.

\subsubsection{Fluorescent Microscopy}

A fluorescent microscope is similar to an optical microscope, with three additional filters. Figure 3-1 shows the path of light through a fluorescent microscope. The microscope was equipped with Olympus filters type U-mnu. The specimen reflects part of the florescent spectra while other visible light reflection is filtered. One cold molded and one hot molded specimen were prepared and stained with SYTO® Green Fluorescent Stain. The pictures were taken by digital color camera. 


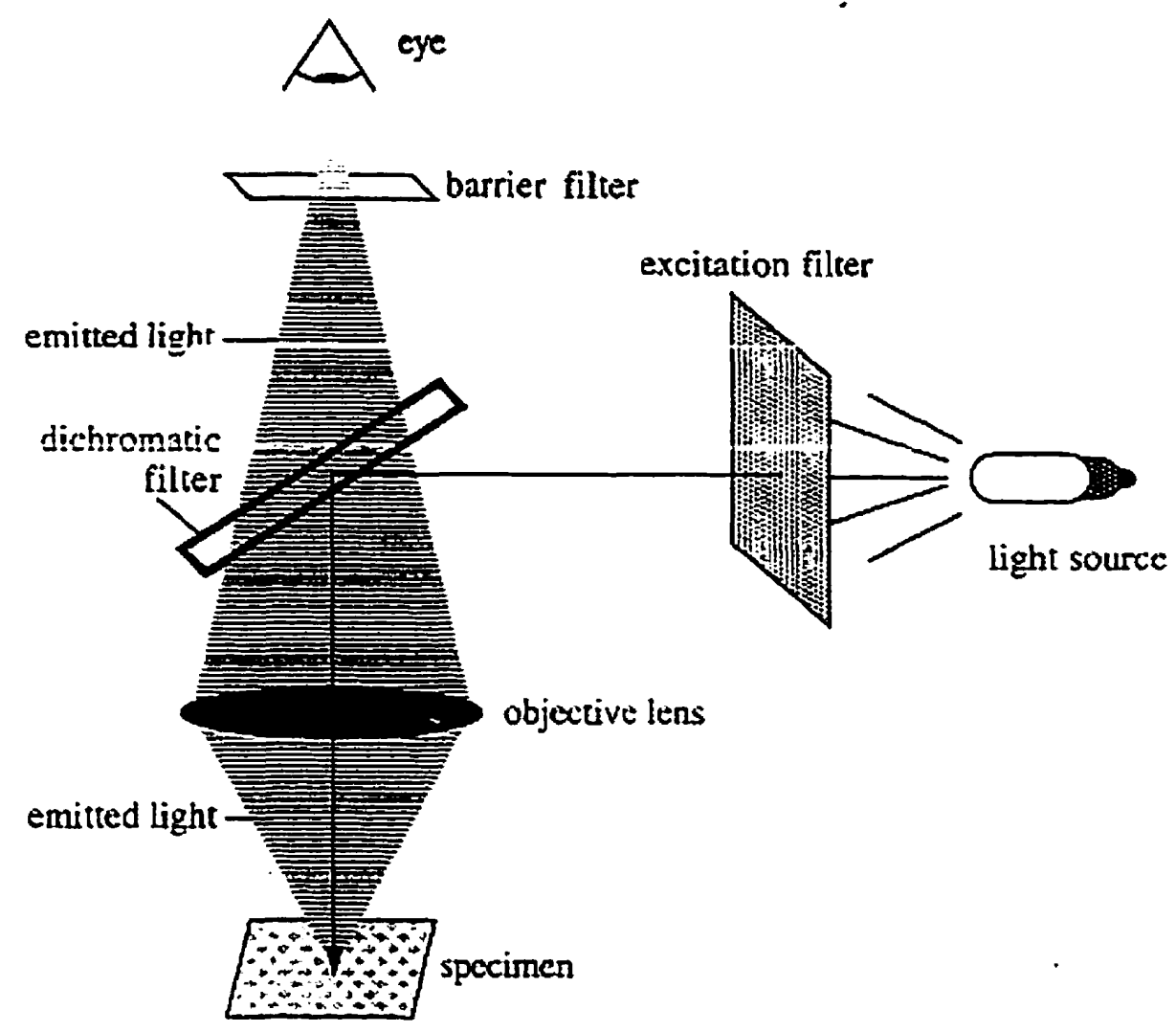

Figure 3-1 Light path in a fluorescent Olympus microscope type U-mnu.

\subsection{Contact Angle Measurement}

Contact angle measurements were used to evaluate the surface free energy on non-treated and treated samples. The experimental setup is shown in Figure 3-2. Specimens were placed on an adjustable height platform before a Kodak Megapixel monochrome CCD camera model 1.6i. The camera was equipped with Nikon 1:2.8 lens. The exposure size, resolution, speed and number of exposure per second were software controlled. OPTIMUS (VER 6.0) was used to capture 1200X1200 pixel images of water drops in profile. 


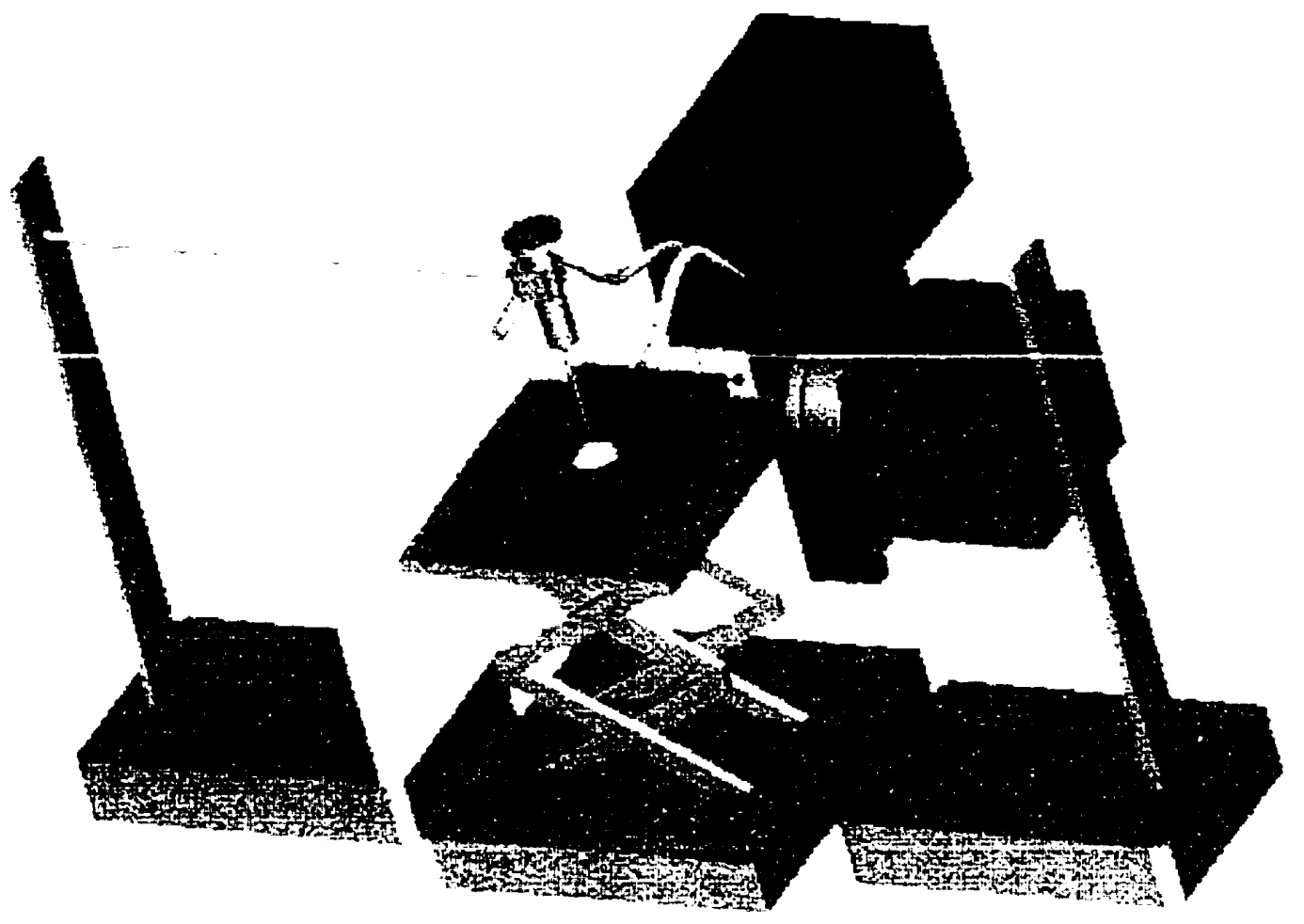

Figure 3-2 Experimental setup for contact angle measurement.

A drop of double distilled water was placed on the surface using a surgical syringe attached to $1 \mathrm{~mm}$ diameter plastic tube. A picture of the drop was taken by the CCD camera and stored in a TIF format. Two, four and eight drops were dropped from the same height on the first drop to measure the advancing contact angle and pictures were taken. The pictures were printed and contact angle was measured at both sides of the drop, by fitting the best tangent to the profile at the contact point with the surface. Then the angle of the tangent with the surface was measured by means of trigonometric relations. . The procedure for making contact angle setting is shown in Figure 3-2. 


\subsection{Surface Characterization}

The percentage of exposed wood fiber on the surface after molding at different temperature and mechanical treatment was measured to determine the effect of exposed wood fiber on pretreatment and paint performance.

\subsubsection{Specimen Preparation}

The contrast between transparent polyethylene and brownish wood fibers had to be enhanced. After compounding, the samples usually looked brown and it was impossible to distinguish the two phases. Adding a small amount of white pigment $\left(\mathrm{TiO}_{2}\right)$ enhanced the contrast. Using $10 \%, 5 \%$ and $1 \%$ of $\mathrm{TiO}_{2}$ revealed that the higher amounts resulted in a better contrast, but changed the molding properties of the component as well. Therefore, after several trials, $1.5 \%$ was found to be the optimum amount to enhance the contrast and retain the molding properties. Subsequently, $1.5 \% \mathrm{TiO}_{2}$ was mixed in $50 \%$ wood fiber reinforced polyethylene in the kinetic mixer. The compound was then maintained at $40,80,100,140$ and $160^{\circ} \mathrm{C}$ temperature along with the mold in an oven for 10 minutes. The composite was then compression molded as described previously in Section 3.2 into $120 \times 70 \times 10 \mathrm{~mm}$ specimens. One set of specimen was also molded immediately at room temperature and one at $10^{\circ} \mathrm{C}$. One specimen molded at room temperature and one at $160^{\circ} \mathrm{C}$ temperature were sanded with 220 grit size sand paper with random pattern for 5 minutes, to evaluate the volume fraction of wood fiber.

Although adding white pigment enhanced the contrast, measuring the amount of exposed wood fiber was still impossible. The specimens were then treated with $1 \%$ by weight $\mathrm{KMnO}_{4}$ solution for 15 minutes and then washed and rinsed under running tap 
water. $\mathrm{KMnO}_{4}$ was used to oxidize exposed wood fibers on the surface, turning it dark brown.

Calibration samples were also prepared to calibrate the measurement intensity threshold for image analysis. Samples prepared at $160^{\circ} \mathrm{C}$ showed no evidence of exposed wood fiber and were used to represent a $100 \%$ polyethylene surface while pure wood stained with $\mathrm{KMnO}_{4}$ was used to generate data for the $100 \%$ wood surface. Figure 3-3 shows the calibration and measurement histograms.

\subsubsection{Experimental Setup}

The surface scan was taken by Kodak Mega Pixel monochrome CCD digital camera as described in Section 3.5 mounted on an adjustable-height stand. Optimus software was used for image capture and analysis. Calibration was done by taking four monochrome images each of spruce as $100 \%$ wood and HM WFRP at $160^{\circ} \mathrm{C}$ as $100 \%$ polyethylene. The images were than analyzed for black and white histogram intensity to set the threshold. Once the image analysis system was calibrated, two samples at each temperature condition were scanned at four different spots. which covered the whole specimen. Area analyzing software determined the percentage of gray area, and hence the percentage of exposed wood fiber. 

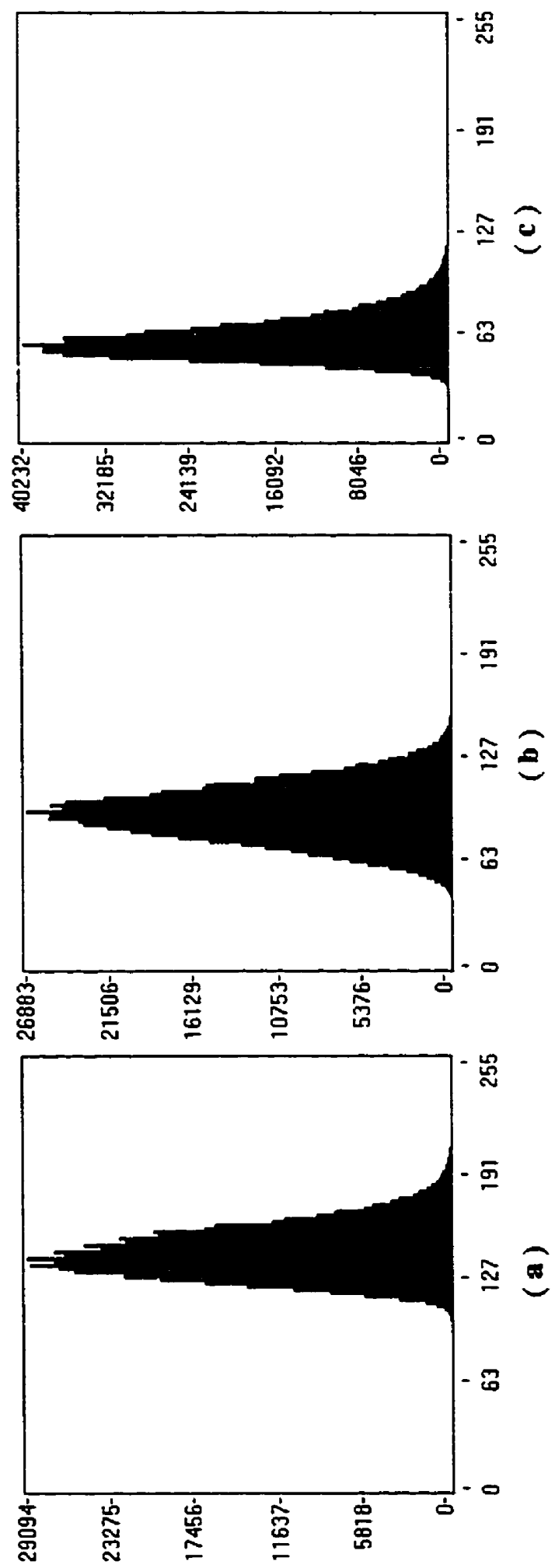

Figure 3-3 Threshold histogram of a) pure wood b) WFRP composite c) pure PE surface 


\subsection{Pretreatment}

To enhance the surface free energy of the WFRP surface, several methods were examined. In this section, the relevant experimental procedures are described.

\subsubsection{Acid Etching}

Specimens were prepared according to the method explained in Section 3.2. The recommended concentration of chromic acid was prepared by adding $\mathrm{K}_{2} \mathrm{Cr}_{2} \mathrm{O}_{7}(10 \% \mathrm{w})$ to concentrated $\mathrm{H}_{2} \mathrm{SO}_{4}$ (six molar) [66]. Then the acid was divided into two parts: the first part was placed in a warm bath to maintain the temperature at $60 \pm 1^{\circ} \mathrm{C}$ under a fume hood, and 2 specimens were immersed in it; the other part was placed under the fume hood at room temperature (approximately $23 \pm 1{ }^{\circ} \mathrm{C}$ ), and 4 specimens were immersed in it. After 60 minutes, the specimens in the warm bath, and two of the room temperature specimens were withdrawn. The 2 remaining specimens at room temperature were taken out of acid after 720 minutes (12 hours) of chromic acid immersion. To remove the residual of chromic acid, samples were washed under running tap water for 10 minutes, and dried at $40^{\circ} \mathrm{C}$ for 2 hours. Contact angle measurement was conducted to evaluate the etching efficiency as described in Section 3.5.

\subsubsection{Sanding}

Specimens prepared according to the method shown in Section 3.2 were cut into $120 \times 70 \times 15-\mathrm{mm}$ blocks. The specimens were mounted on a table and sanded using a Black and Decker orbital sander. Emery cloth with grit sizes 50, 80, 150 and 220 were used to create different surface finishes. The surfaces were sanded in a random pattern for 
5 minutes using constant pressure. The top surface of the composite was removed completely. The sanded samples were cleaned with a vacuum cleaner to remove loose particles.

Three blocks per sandpaper grit size were painted just after sanding according to the procedure in Section 3.3. The samples were left at room temperature for 48 hours to dry and then 2 hours in oven at $40^{\circ} \mathrm{C}$ to completely dry them. The samples were tested using the scratch and peel tests and described in Section 3.8.

\subsubsection{Blasting}

Wheat starch blasting was also used investigate its effect on enhancing the paintability of WFRP.

\section{Specimen Preparation}

The material was mixed in a kinetic mixter as described in Section 3.2. Two batches of material were mixed and kept in an oven at $160^{\circ} \mathrm{C}$ for 10 minutes along with molding plates. The specimens were compression molded into $300 \times 300 \times 5 \mathrm{~mm}$ samples at 50 ton pressure and $23^{\circ} \mathrm{C}$ platen temperature. Water was used to cool down the mold and WFRP.

\section{Experimental Setup}

The molded samples were mounted on a horizontal slider in front of a blasting nozzle. The movement of the table and velocity of wheat starch particles were controlled. The table speed was $90 \mathrm{~cm} / \mathrm{min}$, and the pressure was $30 \mathrm{psi}$, with a nozzle angle of 20 
degree. A mass flow of $9 \mathrm{~kg} / \mathrm{min}$ was initially used to roughen the surface. The surface removal was uneven and not appropriate for painting. The blasting rate was reduced and, the mass flow of $5.5 \mathrm{~kg} . / \mathrm{min}$ was used.

The blasted samples were cleaned using an air blast and painted according to the procedure described in Section 3.3. After the samples were dry, paint adhesion was measured using the scratch test as described in Section 3.8.

\subsubsection{Corona Treatment}

All experiments were done using a small lab-scale corona treater, BD-20 AC, from Electro Technic Products Inc. The corona treater was capable of generating a maximum of $10,000 \mathrm{~V}$ using a $120 \mathrm{~V}$ power supply. The specification and technical details for the corona treater are provided in Appendix B. The experiment was done in two steps: first the effect of corona intensity, treatment time, surface/ electrode distance and rate of decay of the surface free energy over time, were studied; these experiments were done on hot molded WFRP specimens. The specimens were compression molded as described in Section 3.2. Once the optimum conditions were established (see Section 4.2.3), corona treatment was performed on WFRP specimens for various short and long term adhesion tests. The specimens were prepared at $160^{\circ} \mathrm{C}$ and $23^{\circ} \mathrm{C}$ temperature in the size of $120 \times 70 \times 10 \mathrm{~mm}$ as described in section 3.2 . 


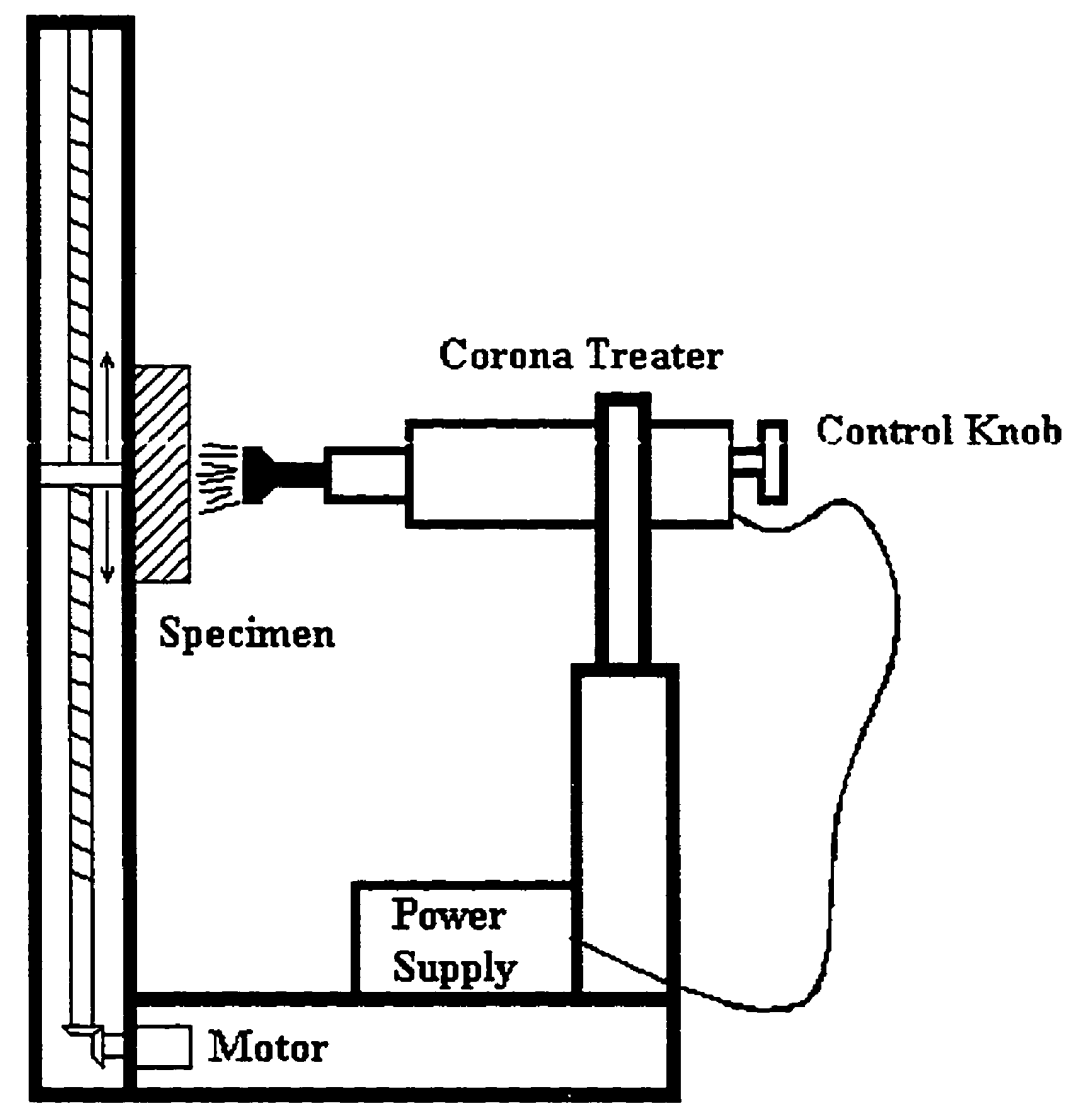

Instron Machine Modified for Corona Treatment

Figure 3-4 Experimental setup for corona treater

\section{Experimental Setup}

The experimental setup is shown in Figure 3-4. For the first part of the treatment, the specimens were mounted on a moveable cross head of an Instron load frame with the corona generator mounted on a fixed stand. The vertical speed of cross slide was controlled by an electric motor and gear arrangement. The speed was set at 50-250 $\mathrm{mm} / \mathrm{min}$ to achieve the best treatment time. The corona intensity was set at different levels using the intensity knob. Current was measured by ampere meter attached to the power supply as shown in Figure 3-4 to measure treatment power. Specimens were 
treated for 2.5-7.5 minutes and the distance between the sample surface and corona electrode was set at 3-60 mm. Cylindrical and bow shape electrodes were used to treat the composites.

The alteration of the surface free energy with corona intensity, distance between electrode and specimen, electrode shape, treatment time and elapsed time after treatment was studied using the contact angle measurement method described in Section 3.5.

The contact angle measurements were used to determine the optimal treatment conditions. Both hot and cold molded samples were treated using $50 \mathrm{~mm} / \mathrm{min}$ vertical speed, at on electrode distance of $5 \mathrm{~mm}$ and maximum treatment power was achieved while the input current was $375 \mathrm{~mA}$. Hot molded specimens were treated for $2.5,5$ and 7.5 minutes while the CM/WFRP specimens were treated for 2.5 and 5 minutes.

\subsection{Scratch Test}

Scratch tests were done according to ASTM D-3359. The scratch blade was 1 inch wide with 10 razor edges. Two sets of scratches were made perpendicular to each other on the painted specimens to create a grid of $10 \times 10$ small squares of paint as shown in Figure 3-5. Care was taken to avoid any penetration of the blade into the composite material.

Once the specimen was scratched, standard adhesive tape was cut into a length of $100 \mathrm{~mm}$, and bonded to the scratch grid by rubbing with an eraser to ensure complete adhesion to the paint surface. The tape was then peeled and the removed paint squares were examined and counted to yield a semi-quantitative measure of the paint adhesion. 


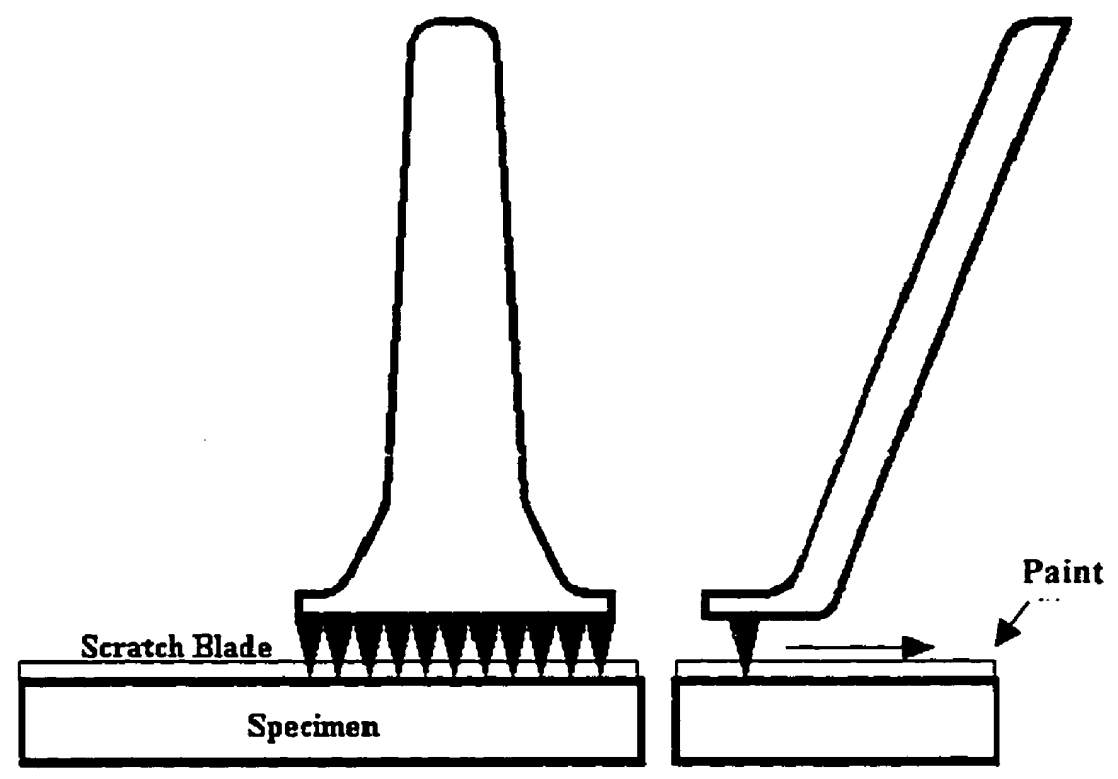

Figure 3-5 Scratch test blade and specimens

\subsection{Peel Test}

The scratch test could discriminate among poorly adhering specimens such as the blasted and sanded samples, but when corona treated samples were tested, and high adhesion was observed, no squares were removed. The scratch test was not a useful tool to differentiate between these high levels of adhesion. A new peel test was designed to measure the paint adhesion quantitatively. The basic mechanism was derived from adhesive testing where an adhesive is placed between two rigid materials and then peeled off to determine the bond strength. Here, the painted sample was bonded to a thin flexible steel strip by means of a double sided foam tape and peeled.

\subsubsection{Specimen Preparation}

Before conducting the peel test, painted samples were inspected and dried in oven for 2 hours at $40^{\circ} \mathrm{C}$. The specimens had dimensions of $120 \mathrm{~mm} \times 70 \mathrm{~mm} \times 10 \mathrm{~mm}$ and 
were each used for two peel tests. The painted surface was first marked gently with a pen for tape to define two $25 \mathrm{~mm}$ X120 mm long strips. Double-sided foam tape (VHB 4592), purchased from $3 \mathrm{M}$, was cut into $140 \mathrm{~mm} \times 25 \mathrm{~mm}$ strips and stuck to the surface of the specimen between the marks. Steel strips with dimensions of $150 \mathrm{~mm}$ X25 mm were cut with scissors, and were ground by hand to remove sharp edges. Then the strip was sanded with sand paper (grit 220) to enhance its adhesion to the tape. The steel strip was then bonded to the foam tape and pressed with 2 psi for 72 hours.

\subsubsection{Experimental Design}

Peel testing was done at room temperature on a computer-controlled screw driven Sintech 20 tensile testing machine using Testworks 2.1 software running under DOS 6.22 on a 486 microprocessor based computer. The experimental setup is shown in Figure 3-6. The base of $45^{\circ}$ fixture was attached to the base of Sintech machine. Specimens were clamped to the $45^{\circ}$ arm of the fixture using two C-Clamps. The steel strip attached with foam tape was sandwiched between two steel plates using 4 screws. The plates were attached to cross head using a $200 \mathrm{~mm}$ steel wire rope. The rope was used to reduce the change in peel angle during the peel test. A cross-head speed of $20 \mathrm{~mm} / \mathrm{min}$ was used to peel the strip. The load was measured using load cell (Sintech 3132-149, 1000lb) attached to the cross-head. Testworks 2.1 calculated the maximum force, average force 
and force per unit length. For all experiments six samples were tested.

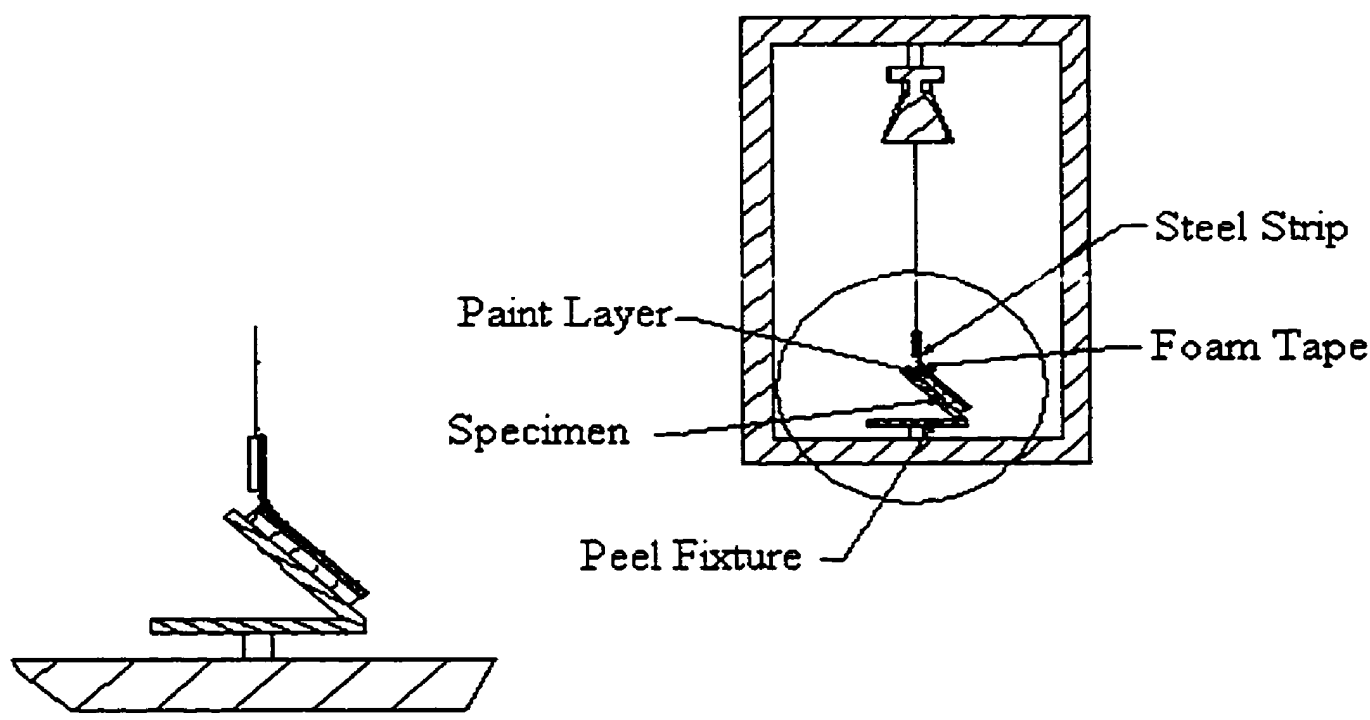

Figure 3-6 Peel test fixture and specimen

\subsubsection{Calibration}

The steady state peel force reflects the peel strength: however, plastic deformation in the strip due to bending, introduces uncertainty in comparing results if the local detachment conditions change. Previous investigation showed that $45^{\circ}$ is the optimal peel angle [52]. The proportion of the peel energy consumed in the deformation of the strip, depends on the adherend, paint and peel strength itself. This suggests that when measured peel strength increases, the plastic dissipation portion of the peel force enlarges proportionally. In a peel test under steady state conditions, the energy balance may be formulated as follows [61]

$$
\mathrm{W}_{\mathrm{t}}=\mathrm{P} / \mathrm{b}(1-\cos \phi)=\mathrm{G}_{\mathrm{c}}+\mathrm{W}_{\mathrm{p}}+\mathrm{W}_{\mathrm{e}}
$$


where $\mathrm{W}_{\mathrm{t}}$ is the total applied energy, $\mathrm{P}$ is steady state peel force, $\mathrm{b}$ is adherend width, $\phi$ is the peel angle, $G_{c}$ is the fracture energy, $W_{e}$ is the elastic stored energy which is negligibly small and $W_{p}$ is adherend dissipation energy.

Since it can be the dominant term. $\mathrm{W}_{\mathrm{p}}$ was measured directly as described below.

\subsubsection{Measuring the Bending Energy}

Using the Equation 3-1 as a model, $W_{p}$ can be calculated by means of a Matlab program that was developed by Moidu et al. [52] Using this program. $W_{p}$ would be too large.

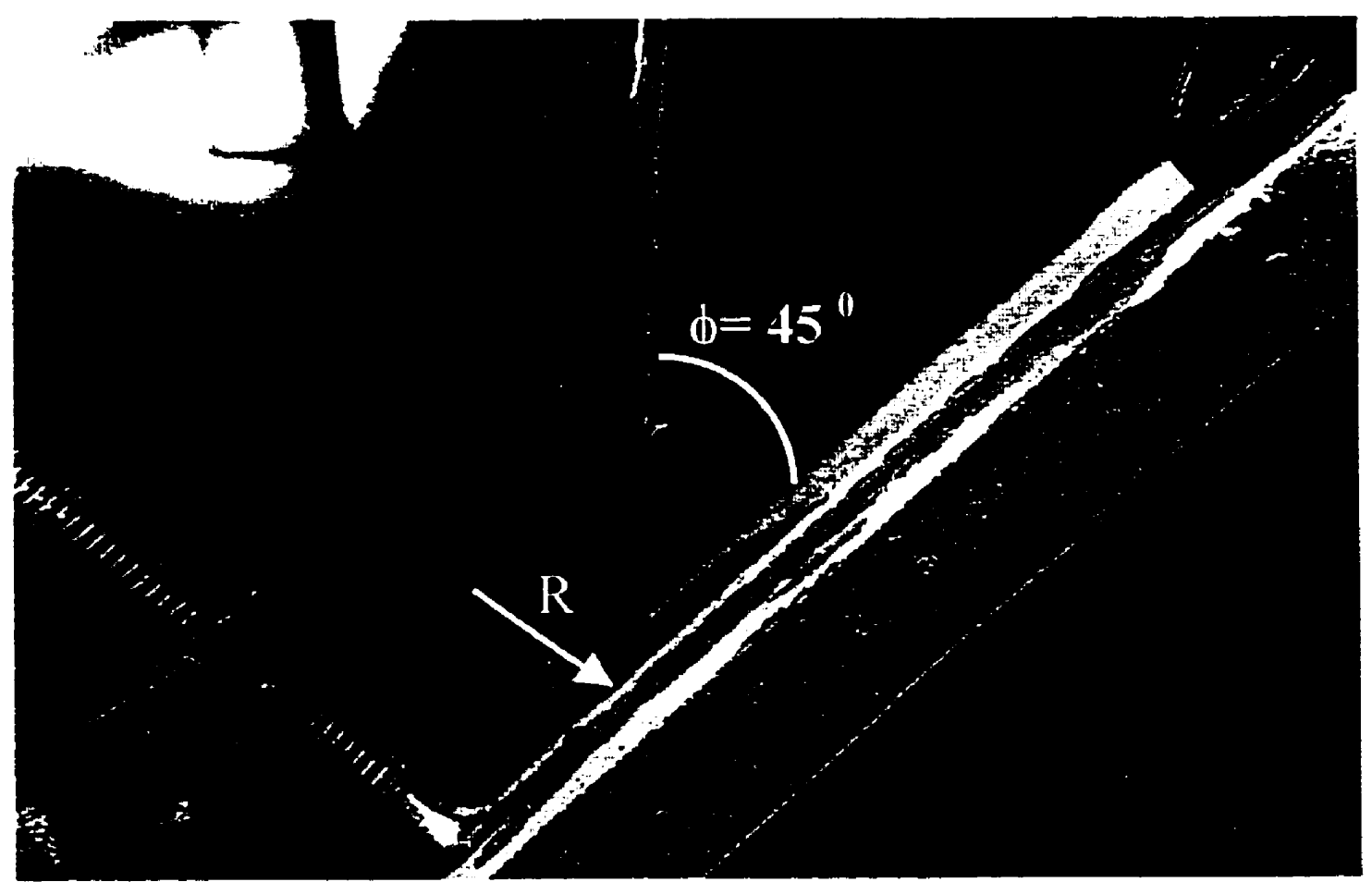

Figure 3-7 The measurement of the maximum bending radius

To measure the bending energy, an experimental method was employed. In this procedure, the major parameter was the root rotation (bending) angle, which determined 
the strip deformation level. Figure 3-7 shows the maximum bending angle and subsequent bending radius that occurred. The measured radius of the relevant bending angle is $2.5 \pm 0.1 \mathrm{~cm}$. To get an approximate measure of the energy dissipated due to bending, a fixture was designed which simulates the same bending condition e.g. load (1000 lb) and angle. In this experiment, the strip and the flexible tape were bent around a drum, that had a radius similar to the bending radius observed in adhesion test.

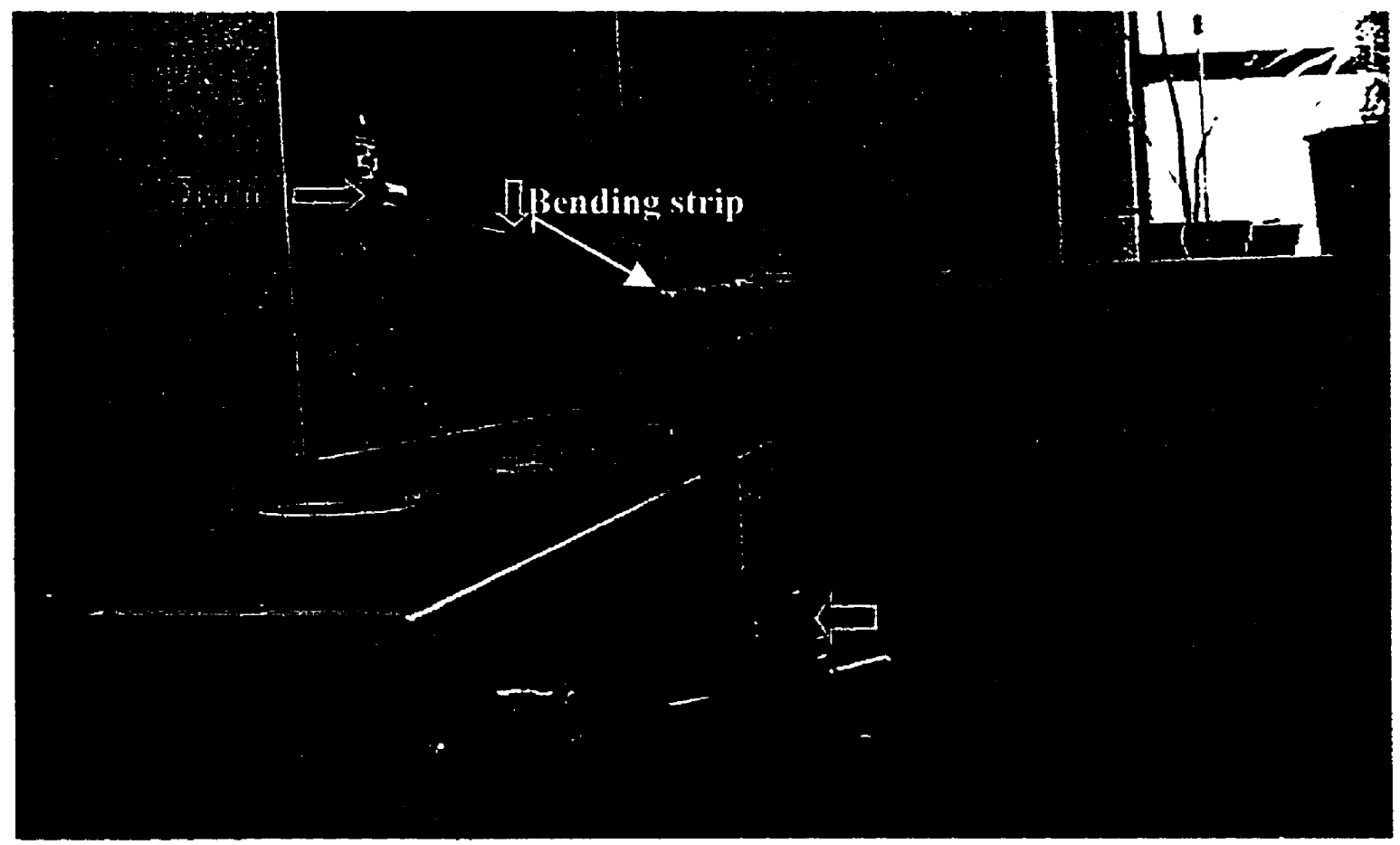

Figure 3-8 Peel test calibration experiment fixture

A dead weight equal to the measured peel force was applied while the friction was minimized (Figure 3-8). The results showed that the maximum dissipated energy per unit strip area was less than $0.4 \mathrm{~J} / \mathrm{mm}^{2}$. This suggests that the dissipated plastic deformation energy was negligible in comparison to the peel energies measured for paint film, and $W_{p}$ was subsequently ignored. 


\subsection{Durability}

A long term durability test was designed to determine the effect of weather on the painted surface and its adhesion strength. As opposed to most of the common experiments where the samples were tested below $40^{\circ} \mathrm{C}$ and $50 \%$ relative humidity, a more conservative approach was used to study long term adhesion performance. Full water immersion tests were designed to study both hot and cold molded corona treated painted samples. This experiment was set up based on the standard test ASTM D-357.

\subsubsection{Specimen Preparation}

Specimens were prepared at $23^{\circ} \mathrm{C}(\mathrm{CM})$ and $160^{\circ} \mathrm{C}(\mathrm{HM})$ as described in Section 3.2., and corona treated as described in Section 3.7.4. The distance between the electrode and specimens was maintained at $5 \mathrm{~mm}$ with a treatment speed of $50 \mathrm{~mm} / \mathrm{min}$. The cylindrical shaped electrode was used to treat $\mathrm{CM}$ specimens for 2.5 minutes and HM specimens for 5 minutes. The specimens were painted as described in Section 3.3, and dried at $40^{\circ} \mathrm{C}$ in an oven for 24 hours.

\subsubsection{Experimental Setup}

To accommodate a large number of samples in water at $40^{\circ} \mathrm{C}$ a special container was prepared. The experimental setup is shown in Figure 3-9. A $30 \mathrm{~cm}$ diameter and 60 cm long cylindrical polyethylene container was used to place all samples in warm water. Three wooden bars supported a five tier cylindrical steel cage. 


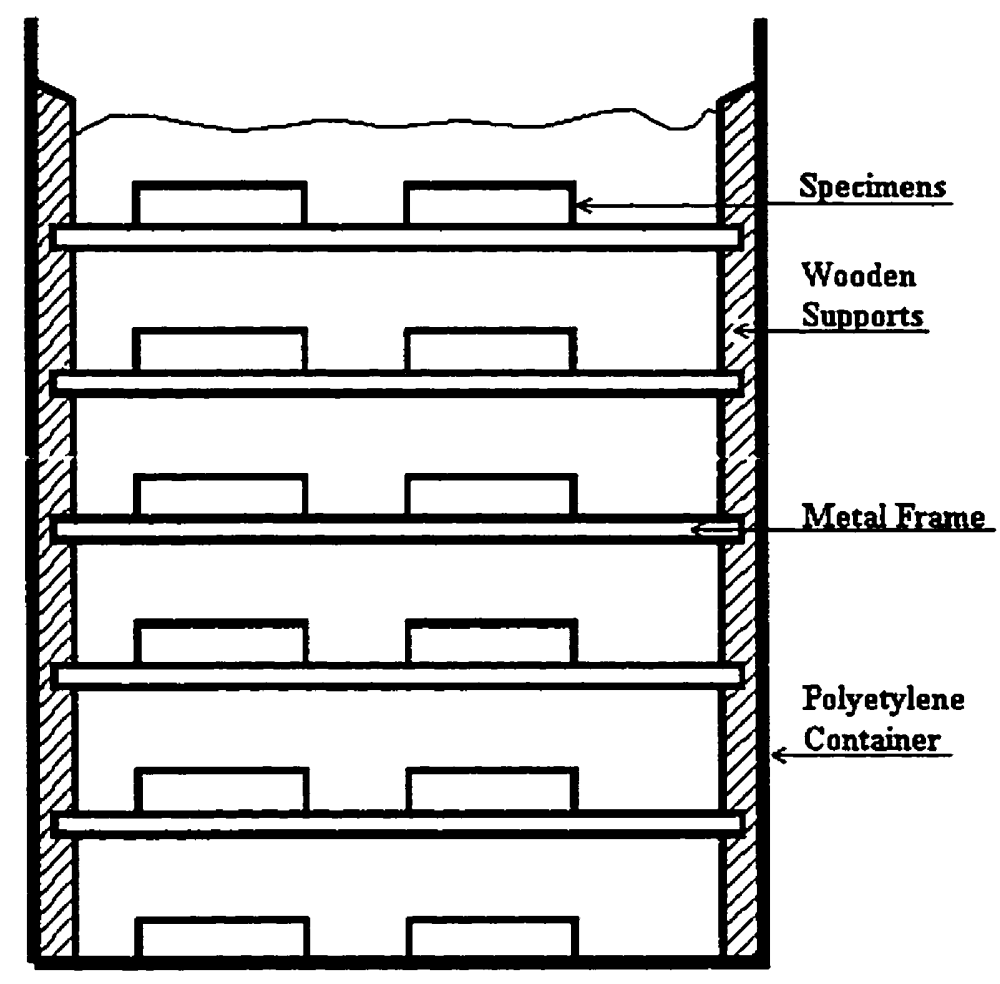

Figure 3-9 The arrangement of specimens of water immersion test

The container was filled with water and placed in a convection oven at $40 \pm 1^{\circ} \mathrm{C}$. The painted specimens were placed on the steel supports and put inside the container 2 hours after the water achieved $40^{\circ} \mathrm{C}$ temperature.

The samples were taken out after $10,20,30,60,120,150$ and 180 days. Pictures were taken immediately to record any swelling, blistering and damage to the paint surface. The specimens were then dried in an oven at $40^{\circ} \mathrm{C}$ for one hour to measure the wet adhesion on CM surfaces, and for 24 hours to remove any trace of moisture. Dried samples were then prepared for peel tests as described in Section 3.9. 


\subsection{Water Uptake Measurements}

For measuring the water absorption by the $\mathrm{CM}$ and $\mathrm{HM}$ surfaces, samples were prepared as described in Section 3.10.2. The specimens were $3 \mathrm{~mm}$ thick and the edges were sealed with a silicone sealant to prevent water absorption through the edges. Then the specimens were conditioned in an oven at $40^{\circ} \mathrm{C}$ for 24 hours to remove all the moisture, and subsequently weighed. The experiment was conducted under the same conditions used for durability testing. Four specimens of each type (HM and CM) were immersed in water and after 1, 2, 3,7.14 days the specimens were towel dried thoroughly. The amount of water uptake was measured afterward, using a balance with an accuracy of $\pm 0.0001 \mathrm{~g}$. 


\section{Results And Discussion}

\subsection{Surface Characterization}

The surface properties, including roughness, and free energy, and their changes were studied for various molding temperatures. Microscopic methods including optical. scanning electron microscopy (SEM) and fluorescent microscopy were employed to study the surface structure. The surface free energy of the composite surface, and its variation with molding temperature were determined by means of contact angle measurements. Image analysis was performed to determine the amounts of WF and LDPE on the surface. The results were used to understand the effect of surface structure on further processes including pretreatment, painting and aging.

\subsubsection{Optical Microscopy}

Figure 4-1 and 4-2 show that cold molded (CM) and hot molded (HM) surfaces reflect light in different ways. The greater level of light scattering on $\mathrm{CM}$ surfaces suggests non-homogeneity and roughness, associated with exposed wood fiber. In Figure 4-2, wood fibers are visible on the HM surface, but they were buried under a layer of PE.

In Figure 4-3, a selective dye for wood was applied to the composite to confirm the presence of wood fiber on the surface. The darker (red) areas are exposed wood fiber that absorbed the dye and are in contrast with the PE. There are wood fibers just below the surface that are visible but didn't absorb the dye. 


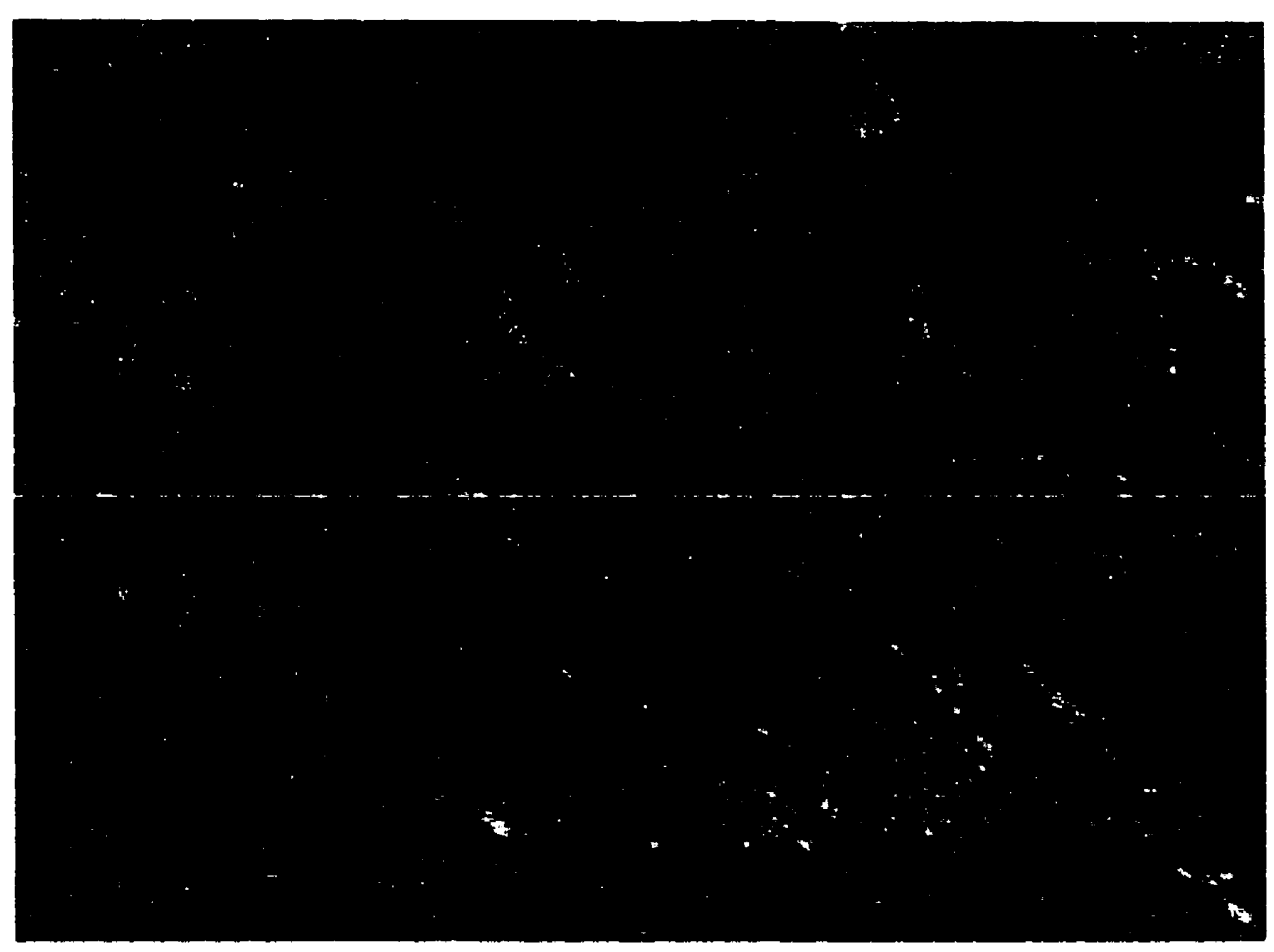

Figure 4-1 Optical microscopy of cold molded (room temperature) WFRP

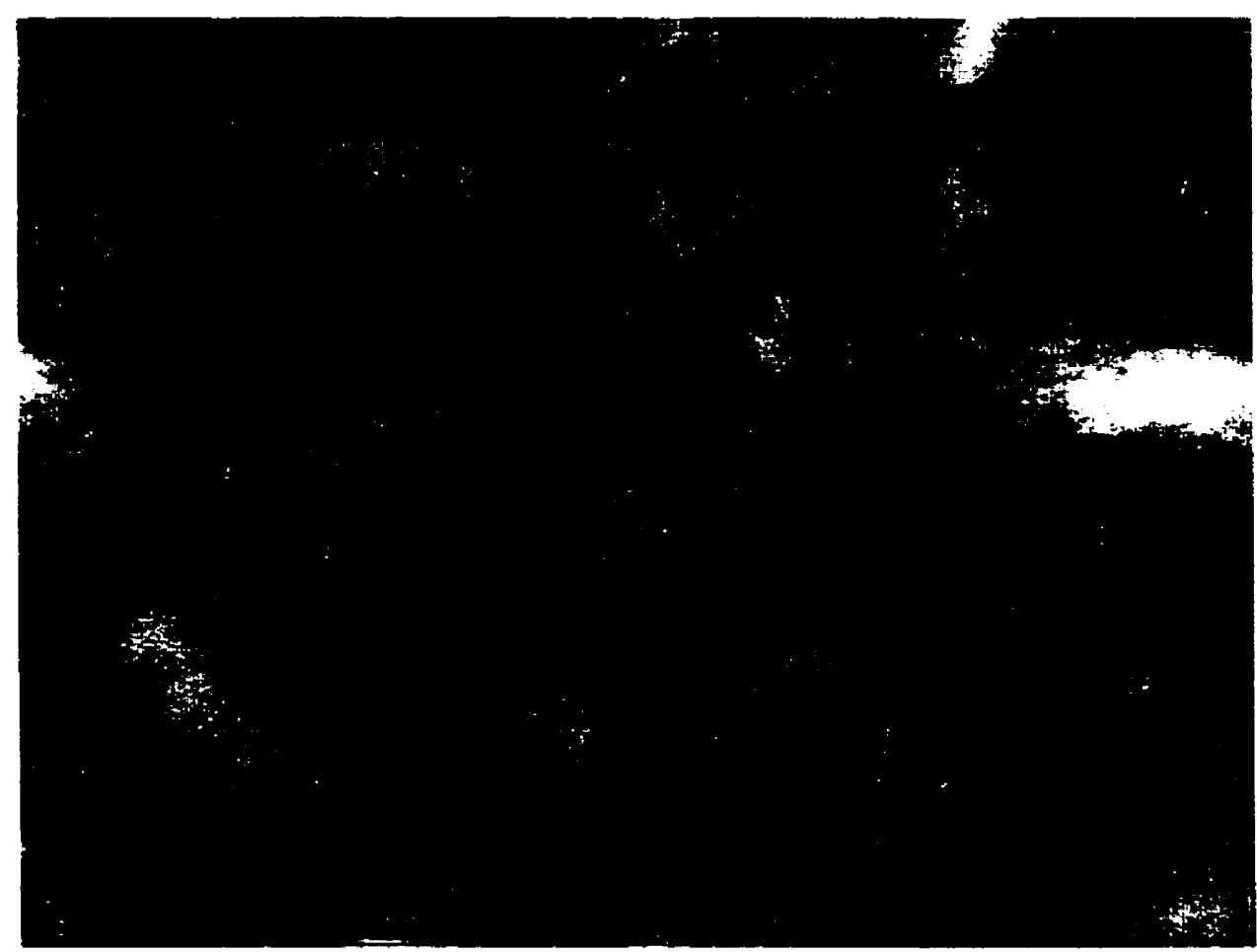

Figure 4-2 Optical microscopy of hot molded $\left(160^{\circ} \mathrm{C}\right)$ WFRP 


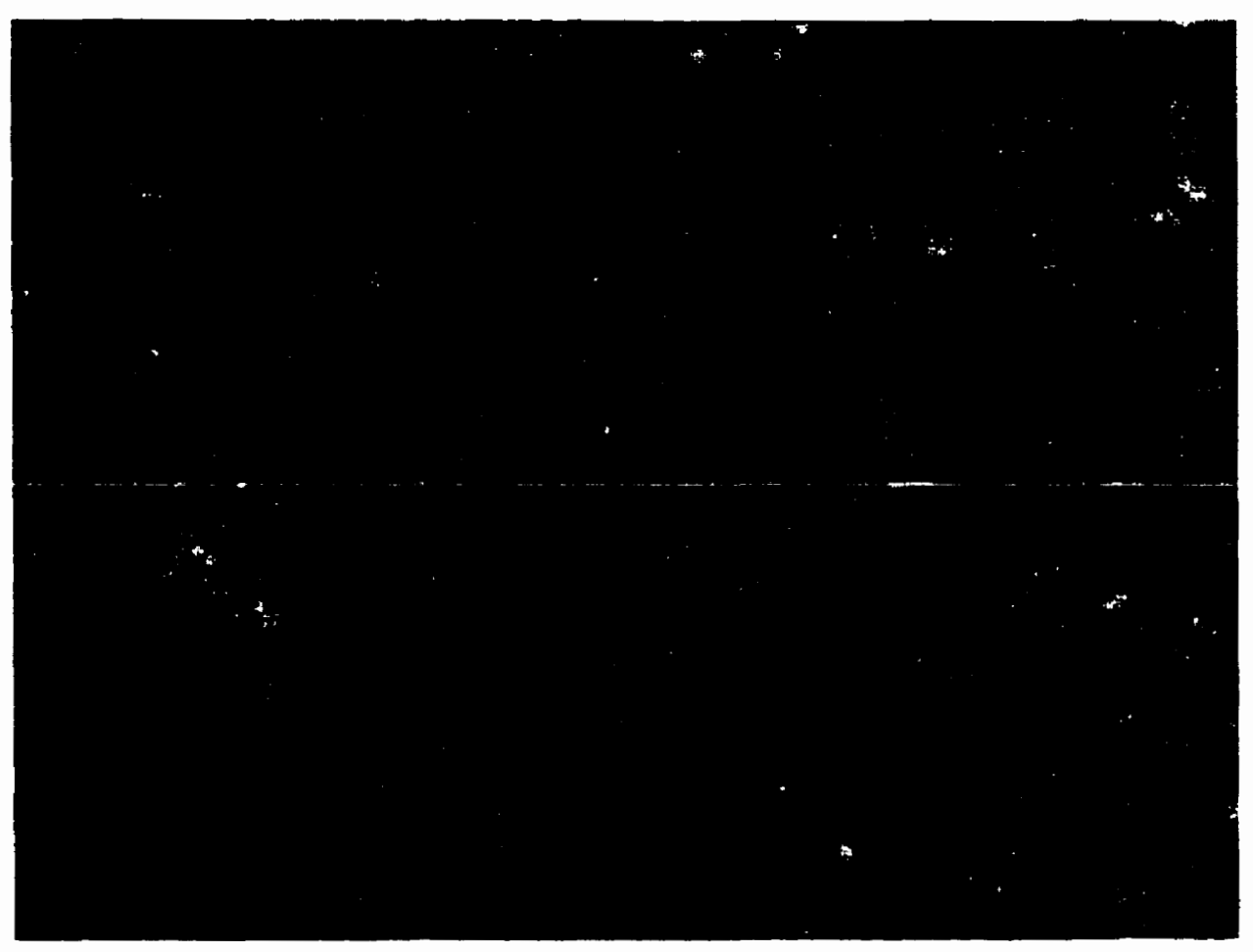

Figure 4-3 Optical microscopy of stained cold molded WFRP

\subsubsection{Scanning Electron Microscopy}

Scanning electron microscopy (SEM) produces an image of the surface topography. In Figure $4-4$, no fibers are visible on the extremely smooth HM surface, confirming that a thin layer of PE was present on the composite. On the other hand, roughness was visible on the cold molded specimen depicted in Figure 4-5 due to exposed wood fibers. 


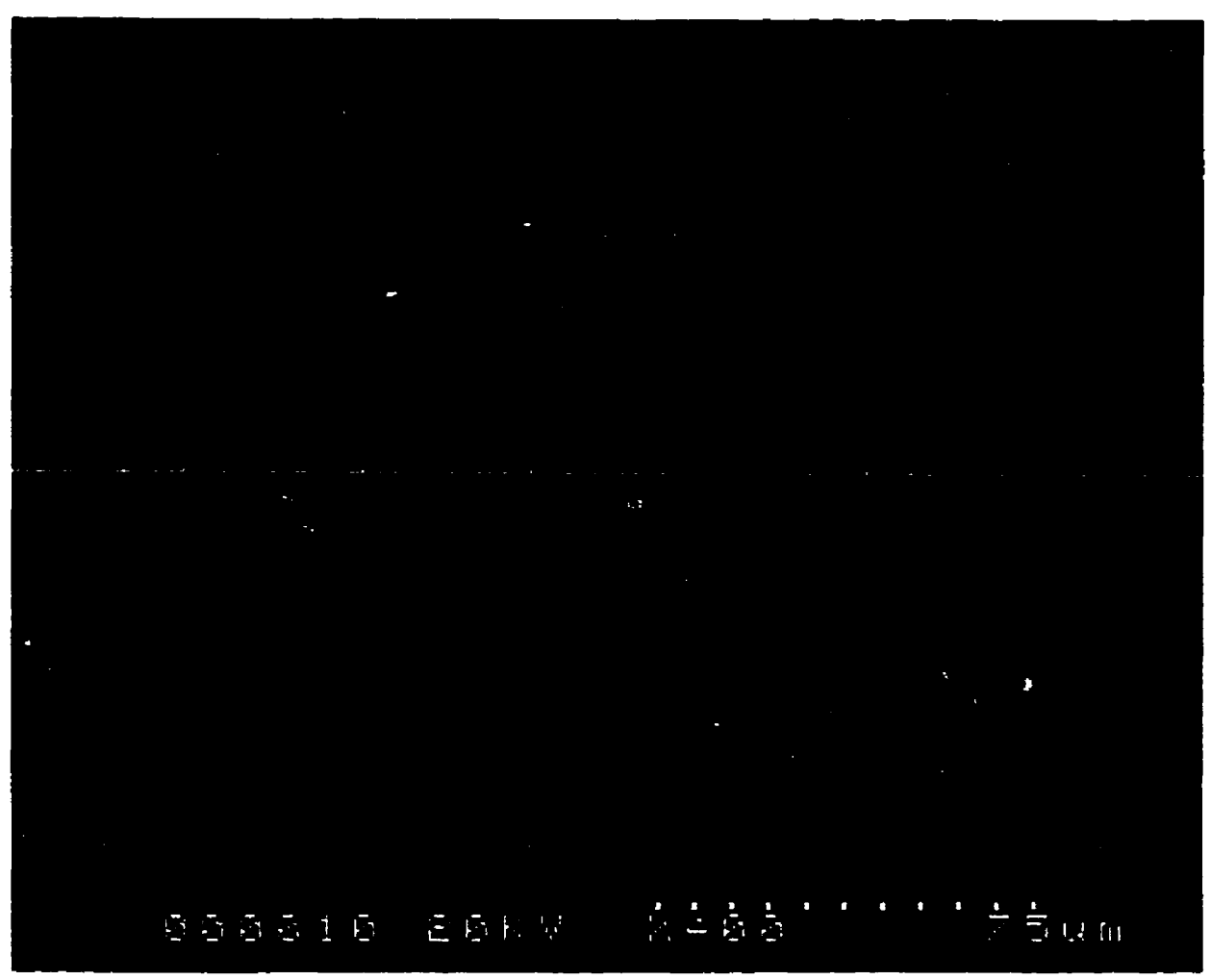

Figure 4-4 SEM micrograph of hot molded WFRP surface

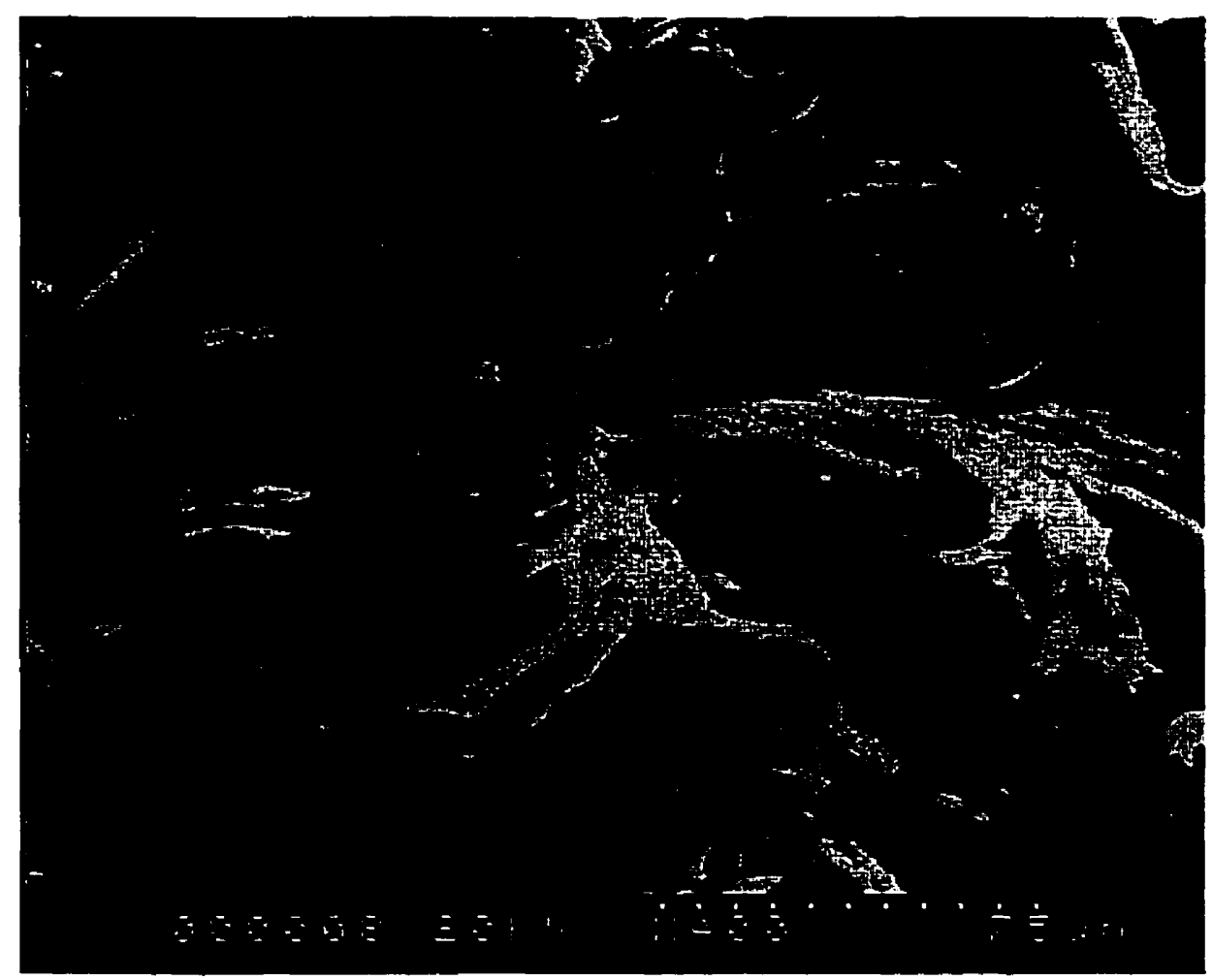

Figure 4-5 SEM micrograph of cold molded WFRP 
Scanning electron microscopy, along with optical microscopy confirmed the increased presence of wood fiber on the surface of CM/WFRP, but these methods could not be used to quantify the amount of exposed wood fibers.

\subsubsection{Fluorescent Microscopy}

An attempt was made to use fluorescent microscopy in conjunction with image analysis to measure the area fraction of exposed wood fibers. Figure 4-6 shows the surface of CM/WFRP without any staining. The observed red color is the natural fluorescence of lignin [62]. After staining with a high-affinity dye for cellulose (Syto green fluorescent), the green color in Figure 4-7 shows the presence of cellulose on the surface.

The intensity of the red color in both pictures was consistently more than what would have been expected from the amount of exposed lignin. Observing the same results in many trials suggested that this extra intensity of red was associated with the lignin in wood fibers that are covered by a very thin layer of PE. These fibers are not exposed. but the PE layer is transparent and does not block the red fluorescence. This subsurface fluorescence was a barrier to the measurement of the quantity of wood fibers on the surface. Although confocal laser microscopy could be a solution to this problem, due to its shallow depth of light penetration, its limited sampling size was not suitable for our investigation.

The superficial cellulose was dyed green by the selective dye, so the amount of exposed cellulose, in principle, should be measurable. The value obtained does not reflect the total amount of exposed wood fiber, however, because wood fiber is composed of other components including lignin and hemicellulose. 
Figure 4-6 Fluorescent microscopy without any stain

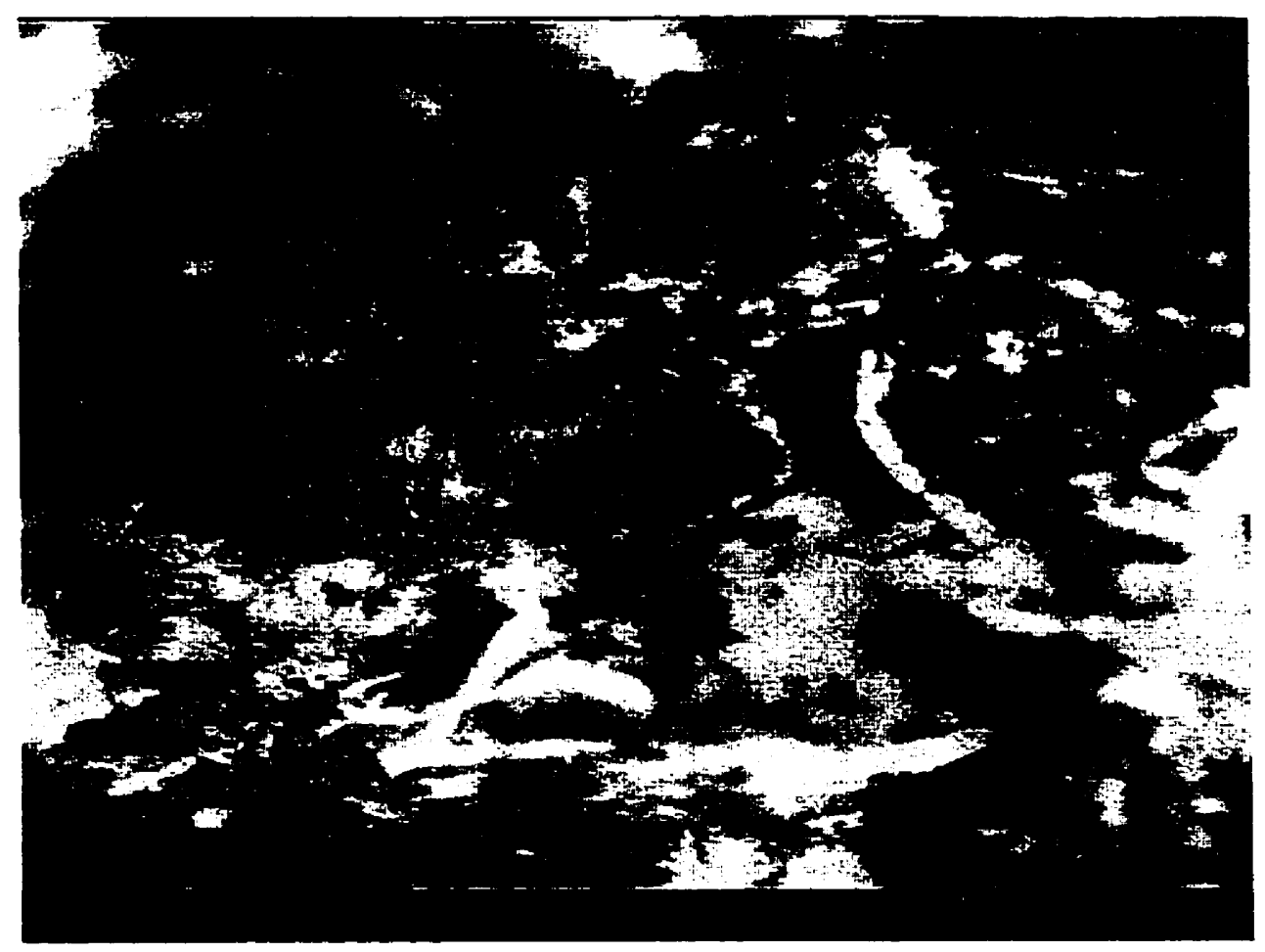

Figure 4-7 Fluorescent microscopy after using stain 


\subsubsection{Enhanced Contrast Image Analysis}

Optimus image analysis software was used to obtain a quantitative result for the surface composition under various molding temperatures. In order to use this method, a high level of contrast between the fiber and PE is required. The desired contrast was achieved by adding $1.5 \%$ of $\mathrm{TiO}_{2}$ to the compound, and using an oxidizing agent (e.g. $\mathrm{KMnO}_{4}$ ) to stain the exposed wood fibers. Thus, the percentage area that was covered by wood fibers could be measured, and plotted versus molding temperature as illustrated in Figure 4-8.

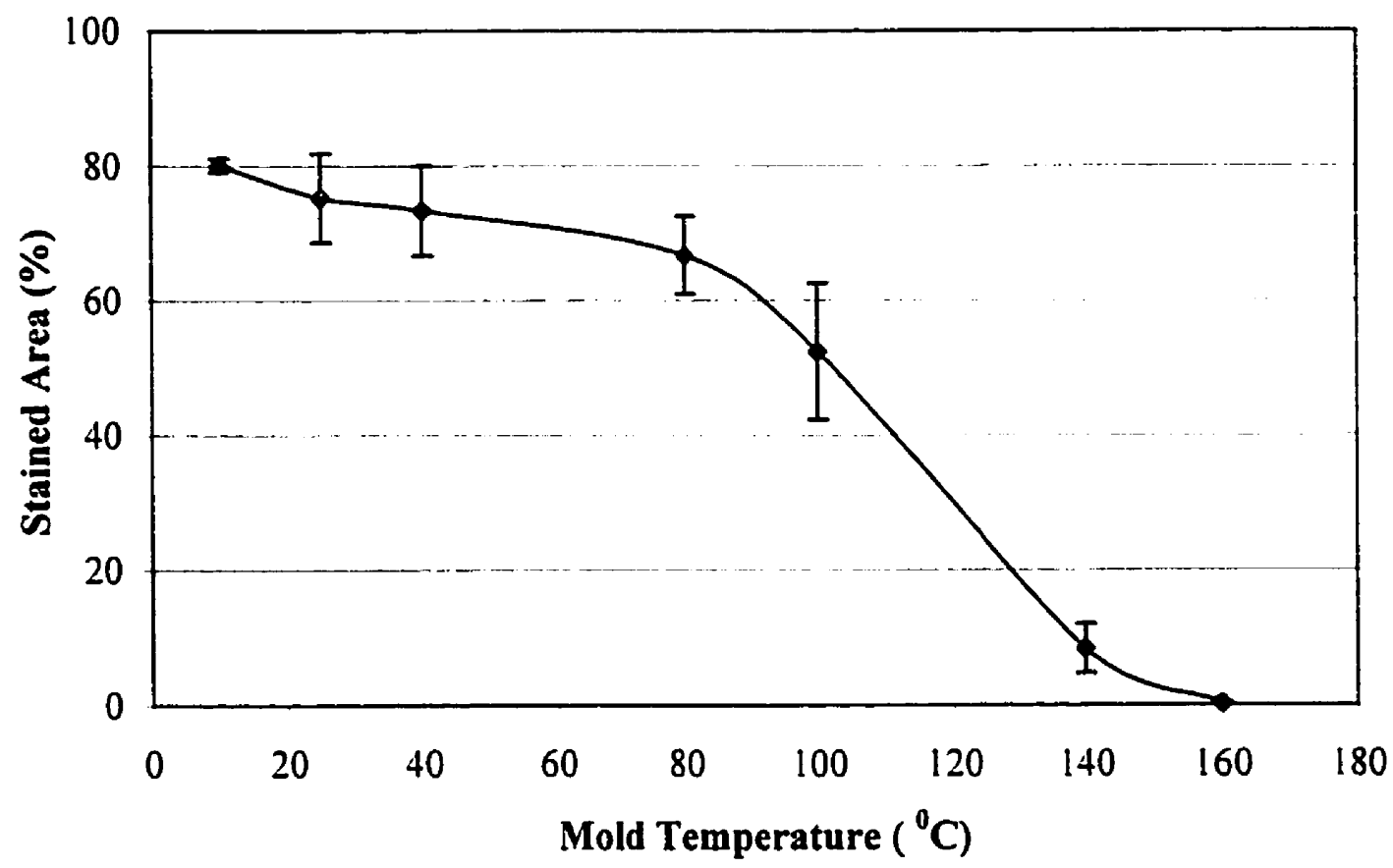

Figure 4-8 Exposed wood fiber area as a function of mold temperature. Error bars represent \pm standard deviation based on 2 specimens with 4 measurements per specimen.

In this study, the weight fraction of wood fiber in WFRP was 50\%. Therefore, observations of $80 \%$ exposed wood fiber on the $\mathrm{CM}$ surfaces were not expected. To confirm the accuracy of the method, we used the same technique to measure the 
percentage of wood fiber volume in the composite core by carefully sectioning and

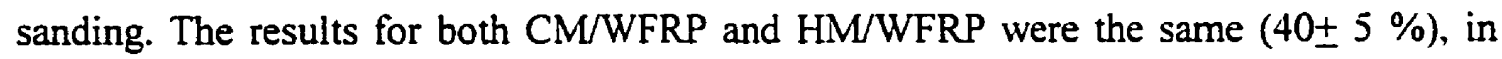
agreement with volume fraction as expected. This suggests that the measured value of $80 \%$ for the CM surface is accurate, and hence that fibers appear on the surface under these molding conditions.

\subsubsection{Contact Angle Measurement}

Water advancing contact angles were measured and interpreted in terms of the composite surface tension. Surface tension is proportional to the cosine of the contact angle, and has been extracted from a conversion table based on the surface tension of distilled water [63].

Table 4-1 shows the advancing water contact angles for wood, polyethylene, CM and HM wood fiber reinforced polyethylene (WFRP).

\begin{tabular}{lcc}
\hline & Contact angle (degrees) & Surface free energy $\left(\mathrm{mJ} / \mathrm{m}^{2}\right)$ \\
\hline Wood & $69 \pm 5.3$ & $41.8 \pm 2.9$ \\
Polyethylene & $88 \pm 2.2$ & $30.1 \pm 1.8$ \\
Cold molded WFRP & $74 \pm 7.6$ & $38.8 \pm 5.4$ \\
Hot molded WFRP & $86 \pm 3.5$ & $31.3 \pm 2.2$ \\
\hline
\end{tabular}

Table 4-1 Advancing water contact angles for different surfaces. Number of samples: $4 ; 8$ measurement per sample. Errors represent \pm standard deviation based on 32 measurements. 
The result for pure polyethylene is in agreement with results that have been reported in reference [64]. Although the HM surface result is not significantly different from the pure PE with $95 \%$ confidence level, it showsa higher standard deviation (SD). The higher SD results from a non-uniform surface, which is associated with the existence of the two non-miscible components (matrix and fiber) in WFRP. On the other hand, CM surfaces has a contact angle, significantly greater than wood surfaces, with the highest standard deviation among all, suggesting that the surface had the greatest amount of nonuniformity.

Of course, the CM surface also had a lower contact angle, because of the high percent of exposed WF. This is similar to the observation in reference [65]. In fact the contact angle is part way between that of PE and that of wood, as expected.

\subsubsection{Discussion}

In general, changing the mold temperature affects the morphology and topography of the surface through changing the amount of exposed wood fiber. The reason for this is not entirely clear. It is known that when molding temperature is above the melting temperature of the $\operatorname{PE}\left(110^{\circ} \mathrm{C}\right)$, polymer can easily flow in the mold, and is expected to wet the mold surface. When the mold surface is completely covered by PE, no wood fiber will be visible on the surface. On the other hand, when the mold temperature is lower than the melting point of $\mathrm{PE}$, the polymer cannot wet the mold surface completely and on the non-wetted area, wood fiber is exposed. When the mold temperature is well below the melting point of $\mathrm{PE}$, the absence of shear at mold surfaces exposes more wood fibers and retards the appearance of PE on the surface. This explains 
why the amount of exposed wood fiber on cold molded surface is more than the volume fraction of wood fiber in the compound.

\subsection{Pretreatment}

Polymer surfaces are often modified, or treated prior to painting. In this study a number of pretreatment techniques were used including acid etching, sanding, blasting and corona treatment.

\subsubsection{Acid Etching}

Acid etching is a widely used and convenient method to improve the surface tension of a polymer. In this study, chromic acid $\left(\mathrm{H}_{2} \mathrm{SO}_{4}, \mathrm{~K}_{2} \mathrm{Cr}_{2} \mathrm{O}_{7}\right)$ immersion was used. The results are shown in Table 4-2.

\begin{tabular}{ccccc}
\hline & $\begin{array}{c}\text { Temperature } \\
\left({ }^{\circ} \mathrm{C}\right)\end{array}$ & $\begin{array}{c}\text { Immersion time } \\
\text { (Minute) }\end{array}$ & $\begin{array}{c}\text { Contact angle } \\
(\text { Degree })\end{array}$ & $\begin{array}{c}\text { Surface tension } \\
\left(\mathrm{mJ} / \mathrm{m}^{2}\right)\end{array}$ \\
\hline Control (HM) & $23 \pm 1$ & 0 & $86.0 \pm 3.5$ & $31.3 \pm 2.2$ \\
1 & $23 \pm 1$ & 60 & $81.1 \pm 2.1$ & $34.4 \pm 0.9$ \\
$2^{*}$ & $23 \pm 1$ & 720 & $64.5 \pm 2.3$ & $44.4 \pm 1.6$ \\
$3^{*}$ & $60 \pm 1$ & 60 & $63.2 \pm 2.9$ & $44.6 \pm 2.0$ \\
\hline
\end{tabular}

Table 4-2 Effect of chromic acid on water advancing contact angle. Number of samples 2, 8 measurements per sample. Errors represent \pm standard deviation.

* Drastically changed appearance

According to a single factor Anova analysis, chromic acid did not significantly modify the surface tension after one hour at the $95 \%$ confidence level. After 12 hours of 
cold immersion, although the contact angle decreased, the general appearance of the composite deteriorated. The change in the surface was also observed after one hour of warm immersion, but with less damage intensity.

Sulfuric acid can degrade the cellulose in wood, and this oxidation process changed the appearance of the composite. It has been shown that acid etching decreases the shear and tensile strength of PE [66], and in WFRP, oxidation of the cellulose portion also occurs, making this method less desirable.

\subsubsection{Mechanical Treatment}

Mechanical surface treatment is commonly used to improve the surface topography and enhance the mechanical interlocking adhesion of paints. In this study, mechanical treatment was used to achieve the same goal as well as to expose wood fiber on the surface. The latter increased the potential for physical bonding between paint and substrate through wood fiber $-\mathrm{OH}$ sites.

\section{Sanding}

The first mechanical treatment used was sanding with emery cloth. Contact angle measurement was not a valid method of evaluation in this case due to the roughness of the surface; however, it was observed that changing the paper grit did not change the contact angle results significantly. Scratch and $45^{\circ}$ peel tests were employed to distinguish and understand the effect of various grits on exposing wood fiber, and the results are given in Section 4.3. Figure 4-9 shows the appearance of the sanded sample and Figure 4-10 shows the same sample, after it was stained with $\mathrm{KMnO}_{4}$ (dark spots 
represent the exposed wood fiber). The method of staining was the same as for the image analysis experiments in Section 4.1.4.

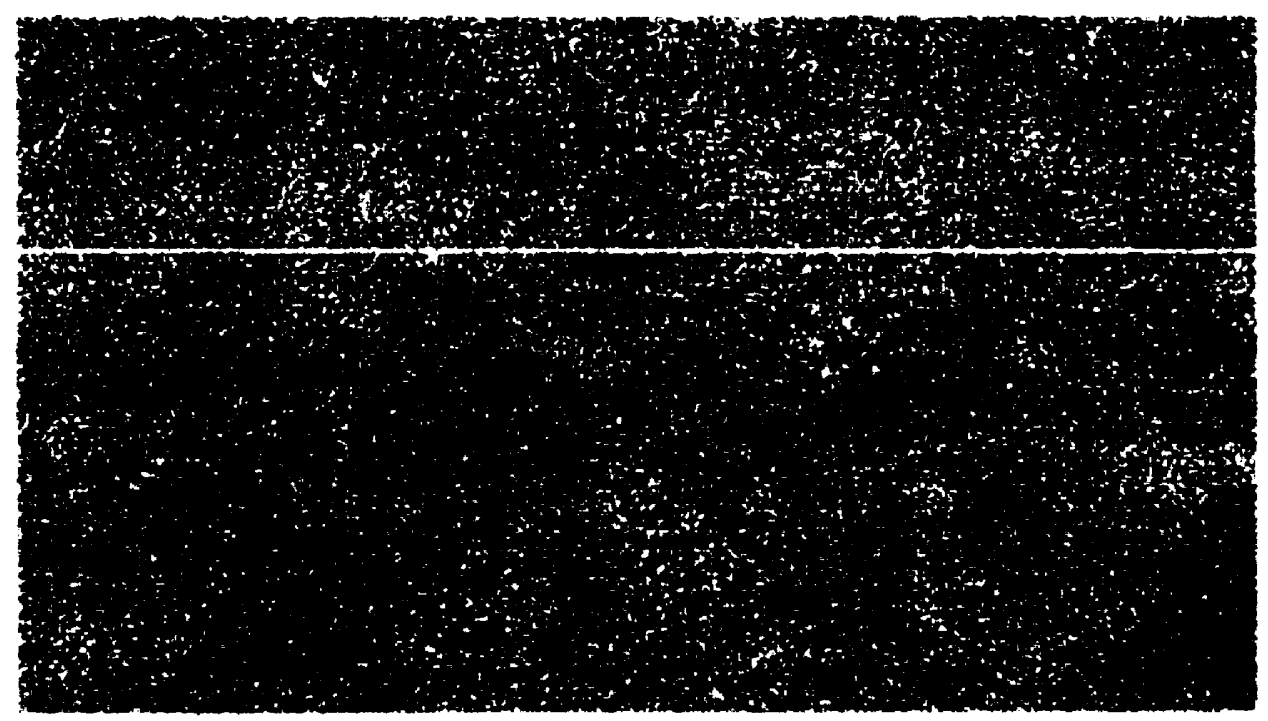

Figure 4-9 WFRP surface sanded with emery cloth grit size 50

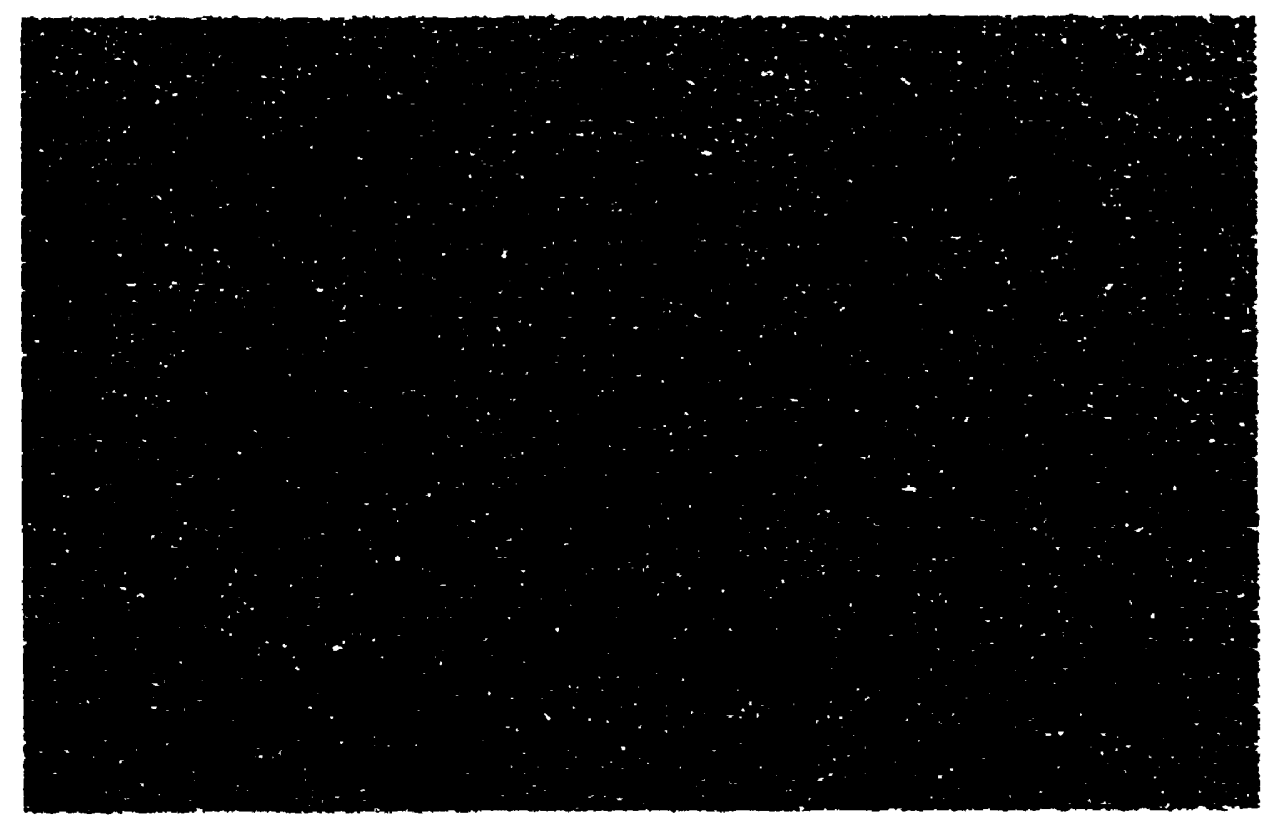

Figure 4-10 WFRP surface, sanded with emery cloth grit size 50 and stained with $\mathrm{KMnO}_{4}$

\section{Blasting}


The appearance of the blasted samples was almost the same as those that were sanded. Blasting with wheat starch media modified the surface more significantly than the sanding treatment. The final evaluation of this treatment was done by means of scratch and $45^{\circ}$ peel tests, and the results are given in Section 4.3.

\subsubsection{Corona Treatment}

A corona treatment was used to modify the WFRP surfaces. This method enhances the chemical structure of the surface and increases the potential for the chemical and physical bonding of the paint. Contact angle measurement was used to evaluate the efficiency of the treatment as a function of application conditions including time, input, power and distance between electrode and substrate.

\section{Distance between electrode and surface}

As described in the experimental section, the laboratory corona treater had two types of electrodes. Figure 4-11 shows the results of contact angle measurement after exposure for both of the electrodes. The contact angle was seen to depend on the electrode/ WFRP-surface distance, which proves that the active part of corona is close to the tip of electrode [67]. Tsutsui et al. [68] showed that by increasing the distance, the peel strength of the paint decreased on pure polyethylene surface. The results of the present work are in agreement with the previous results and show that the smaller the distance from the electrode tip, the better the surface treatment. Decreasing contact angle is indicative of greater surface tension and better paint adhesion. 


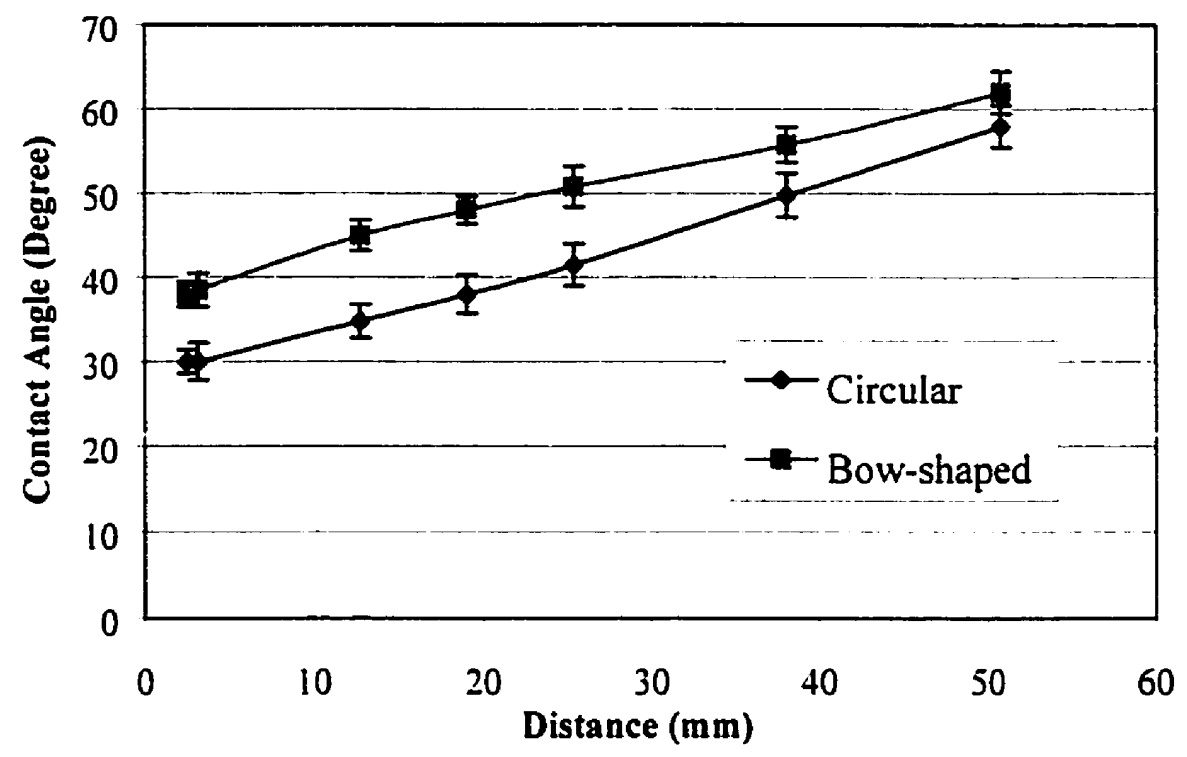

Figure 4-11 Advancing water contact angle on HM/WFRP as a function of distance between electrode and surface for two types of electrodes. 4 samples with 8 measurements on each. Error bars represent \pm standard deviation based on $\mathrm{N}=32$

It was observed that the circular electrode performed better than the bow-shaped electrode, so the circular electrode was used in subsequent experiments. The results suggest that the maximum surface tension achieved was $64 \mathrm{~mJ} / \mathrm{m}^{2}$, for an electrode/WFRP-surface distance of $6 \mathrm{~mm}$.

\section{Duration of treatment}

Figure 4-12 shows the effect of corona exposure time on the advancing water contact angle at a distance of $6 \mathrm{~mm}$. These results are similar to the results of Tsutsui et al. [68], which showed that the peel strength increases in proportion to the duration of exposure. 


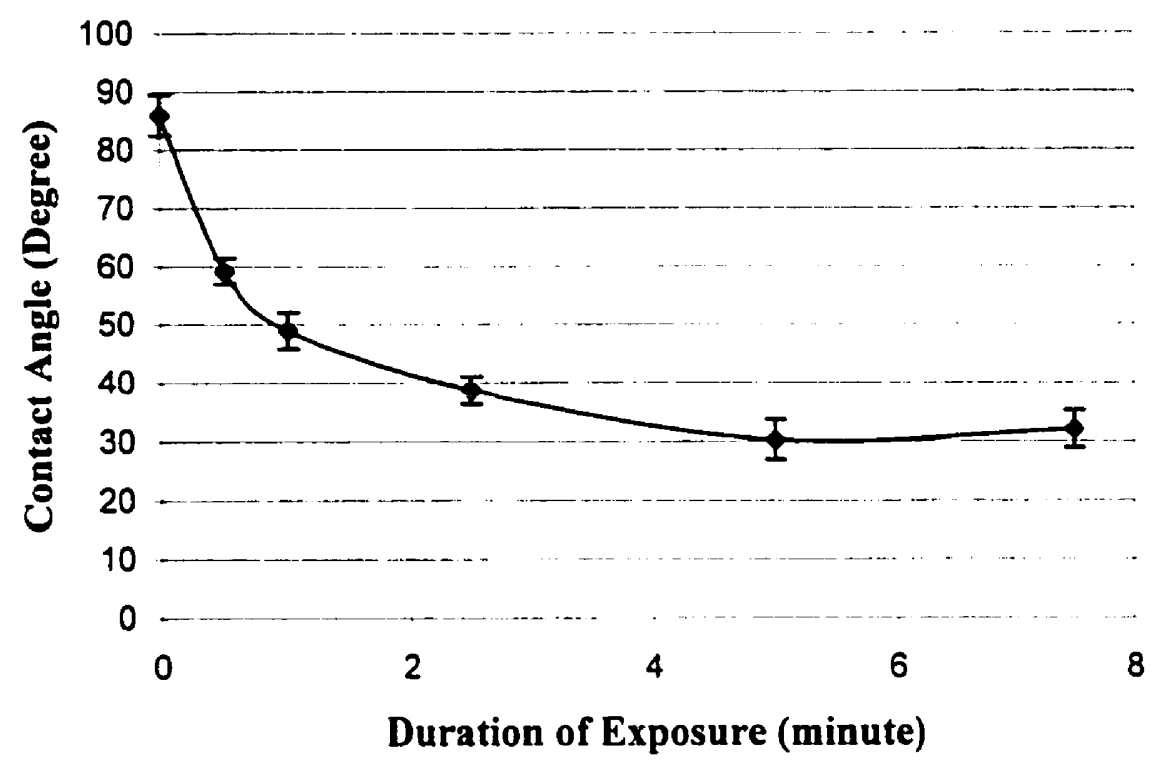

Figure 4-12 Advancing water contact angle on HM/WFRP as a function of duration of exposure. 4 samples with 8 measurements on each. Error bars represent \pm standard deviation based on $\mathrm{N}=32$

These data suggested that the optimum duration for pretreatment with corona discharge was about 5 minutes and that, there was no further improvement in surface tension with longer times. Therefore, 5 minutes exposure was used in all subsequent experiments.

\section{Output power}

The output power of the corona was another factor that could change the effect of the corona treatment. Measuring the output power was not possible, and therefore the input current, which should be roughly proportional to the output power, was measured. Figure 4-13 shows the changes in advancing water contact angle with the input current of the corona treater. Apparently, both insufficient treatment and over-treatment decreased the wettability. The term over-treatment is used when corona treatment of polyolefin 
surfaces leads to reduction in bond strength and surface free energy [31]. A long duration or high energy level of corona exposure can cause over-treatment.

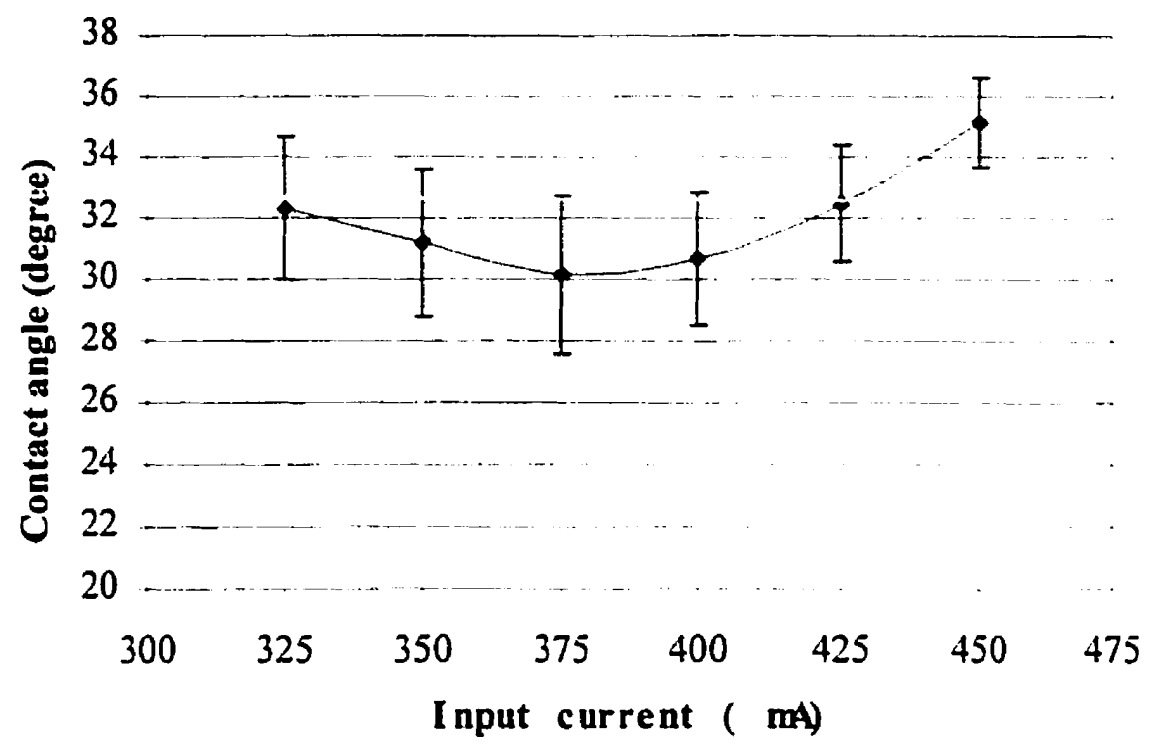

Figure 4-13 Advancing water contact angle on HM/WFRP as a function of input current. 4 samples with 8 measurement on each. Error bars represent \pm standard deviation based on $\mathrm{N}=32$

Figure 4-13 shows that the contact angle decreased with increasing current (increasing power) to $375 \mathrm{~mA}$ beyond which samples were over-treated. Single factor anova analysis shows that points between $350-425 \mathrm{~mA}$ are not statistically significant, Consequently, treatment at $350-400 \mathrm{~mA}$ was adopted as the input current for other tests.

\section{Rate of decay}

In the corona treatment of plastic film and sheets, it is well known that the elevated surface tension decreases with time. This effect is normally referred to as an aging effect. Figure 4-14 shows this effect for the present HM/WFRP material. 
In a similar investigation on $\mathrm{PE}$, Kim et al. [31] obtained results showed bonding strength reduced by $50 \%$ in a period of 10 days. The possibility of decreasing the rate of decay by increasing the treatment time was discussed in the same study.

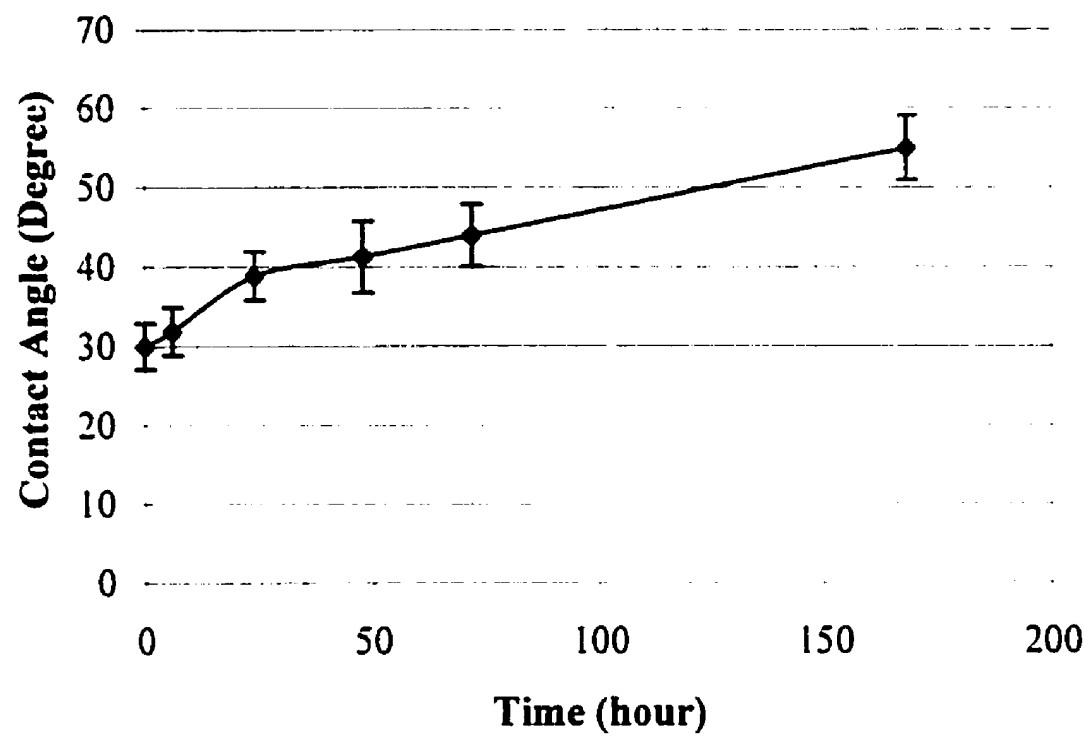

Figure 4-14 advancing water contact angle on HM/WFRP as a function of aging (time). 4 samples with 8 measurements on each. Error bars represent \pm standard deviation based on $\mathrm{N}=32$

Sutherland et al. [69] showed that aging has a negative effect on the work of adhesion for corona treated PE samples. Our results show a $20 \%$ reduction in surface tension over a 7-day period. Although in most previous investigations, experiments were run over a period of 30 days, the results obtained here have shown the same trend.

These results suggest that painting the samples immediately after treatment is desirable.

\subsection{Adhesion Evaluation}

Contact angle measurement was performed on HM surfaces to evaluate the pretreatment efficiency, but it was not possible to measure the corresponding differences 
in advancing water contact angles on CM surfaces, because of the rough surface of these specimens. In order to characterize the surface of both $\mathrm{HM}$ and $\mathrm{CM}$ specimens, we painted the modified surface, and measured the peel strength. A scratch test was performed according to ASTM D-3359. In addition, a $45^{\circ}$ peel test was performed. The results are reported in the following sections.

\subsubsection{Scratch Test}

Figure 4-15 shows the results of scratch tests on the sanded samples described in Section 4.2.2. The results suggested that the scratch test was sensitive to paint thickness on WFRP surfaces. The penetration depth of the scratching blade on plastic surfaces also affects the result; when it passes through the paint and penetrates the plastic surface, the peel strength is lower than when it just scratches the paint. This explains the higher peel strength for thicker paint.

Blasted samples had higher peel strength, but the modification process was destructive. The blasting process is actually designed for removing paint, and therefore the depth of particle penetration is higher than for sanding. In general, both methods give similar results, but sanding is convenient and relatively non-destructive.

The scratch test showed that the peel strength decreased with increasing sandpaper grit number (finer grit). As has been discussed in Section 4.2.2, enhanced contrast image analysis showed that the amount of exposed fibers was the same regardless of grit number. On the other hand, the standard deviation was lower with higher grit number. It is known that by increasing the grit number, the surface uniformity increases. By decreasing the grit number, the roughness increased, and improved the 
adhesion level. This can be attributed to better mechanical interlocking of paint and substrate.

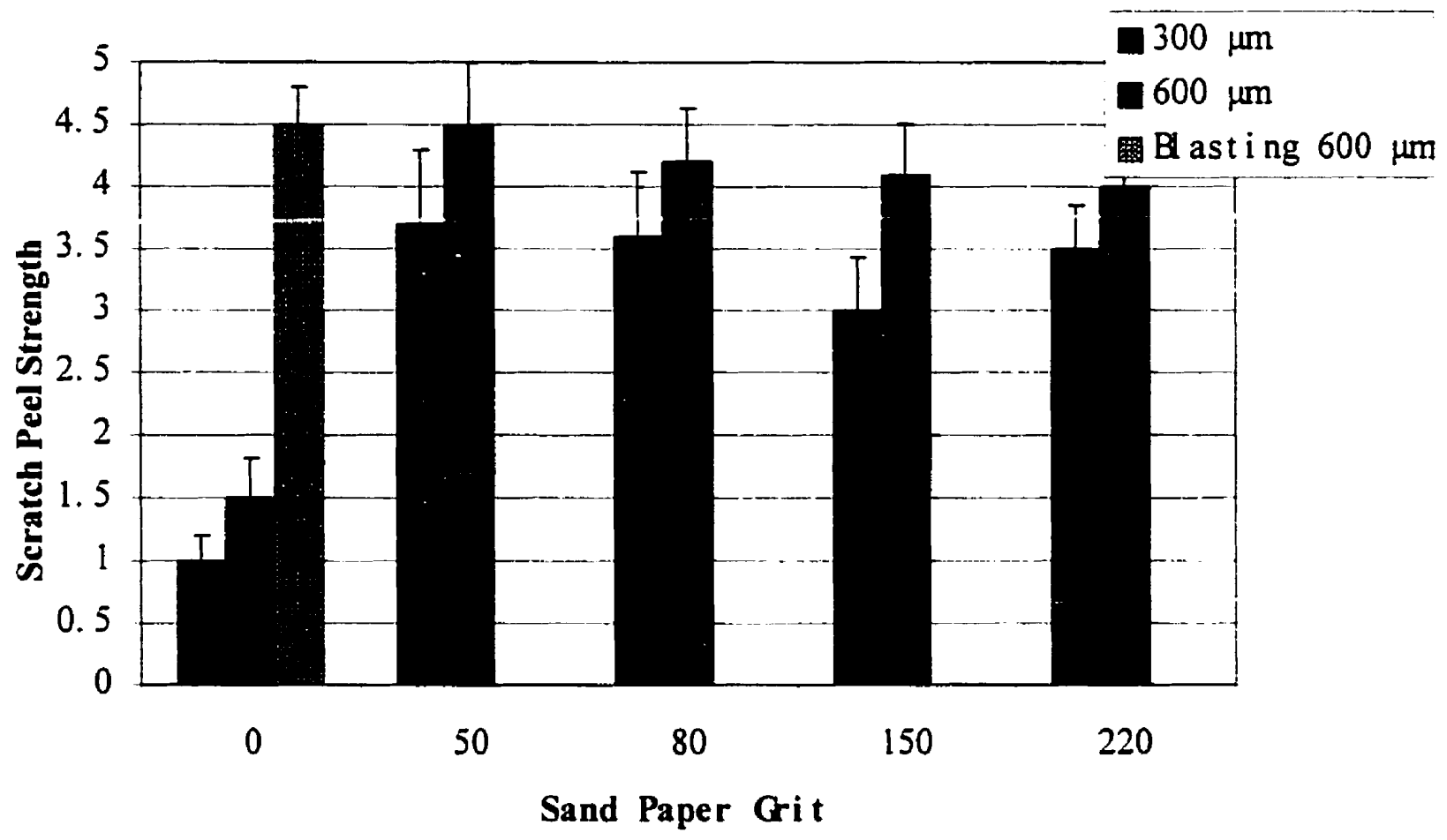

Figure 4-15 Adhesion evaluation of sanded and blasted samples on different grit size and paint thickness $(\mu \mathrm{m})$ on HM surfaces. 4 samples and 5 measurements per sample. Error bars represent \pm standard deviation for $\mathrm{N}=20$.

In order to compare sanding and corona treatment techniques, the scratch test was used to evaluate the corona treated samples. As shown in Figure 4-16, the corona treatment is more effective and the adhesive strength is generally higher than that produced by sanding. The scratch test results of the corona treated samples reached the maximum possible (5), which was not achieved with sanding and blasting methods. These corresponding variability was lower with corona treatment, especially after 5 and 7.5 minutes of treatment. 


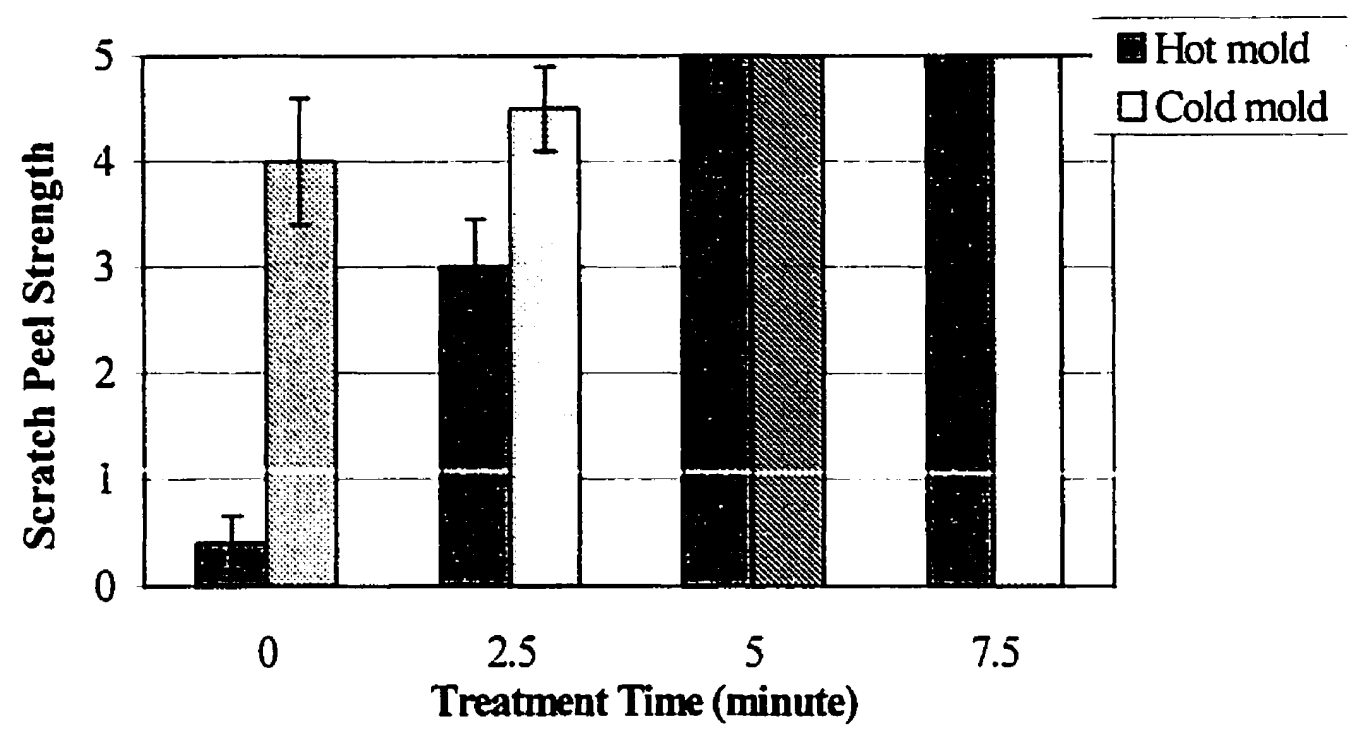

Figure 4-16 Adhesion evaluation of corona treated samples with duration of treatment. 4 samples with 5 measurements per sample. Error bars represent \pm standard deviation for $\mathrm{N}=\mathbf{2} 0$.

Based on the results of the scratch test, CM and HM surfaces had the same adhesive strength after 5 and 7.5 minutes of corona treatment. However, the higher adhesive strength for untreated CM samples. and the higher level of exposed wood fiber on the $\mathrm{CM}$ surface, suggests that the $\mathrm{CM}$ surfaces should have a higher strength than that formed on the HM surface.

Kleive [70] used the scratch test to measure the adhesion of paint on weathered wood. He increased the 5 scratch adhesion levels to 10 , and designed a mechanical device to measure the adhesion and quantify the results. He reported that with the highest level of adhesive strength (10), the adhesion force varied between $3-5.5 \mathrm{~N} / \mathrm{mm}$. In the present study, the adhesion level of 5 was obtained for several samples, and the scratch test could not discriminate between these samples. 
In addition, statistical analysis (single factor Anova) of the results showed no significant difference between the results of the scratch test for differing paint thickness for either mechanical or corona treated surfaces.

Although the scratch test reflects the quality of adhesion, if the adhesion is too high or too low, this method cannot be used to evaluate it. Another test method must be employed to measure the actual peel strength.

\subsubsection{Peel Test}

One of the most promising methods of adhesion measurement is the peel test. In this method, painted samples were bonded to an aggressive double-sided tape. and then a steel strip was laminated to the tape. A crack was initiated at the paint /substrate interface, then the paint layer was peeled from the surface while the peel force was measured continuously by means of a load frame. Therefore. the interface strength could be directly determined.

\section{Peel test for sanded surfaces}

The $45^{\circ}$ peel test was used to evaluate the paint adhesion to the sanded and blasted surfaces. Figure 4-17 shows the results of these experiments.

In general, the peel strength shows the same trend as the scratch test results. The higher peel force for the lower grit number was expected and can be explained by the corresponding higher roughness of the treated surface. Cold molded samples were also tested, and showed a higher peel force due to the greater amount of exposed wood fiber on the surface, when compared with sanded and blasted samples. 


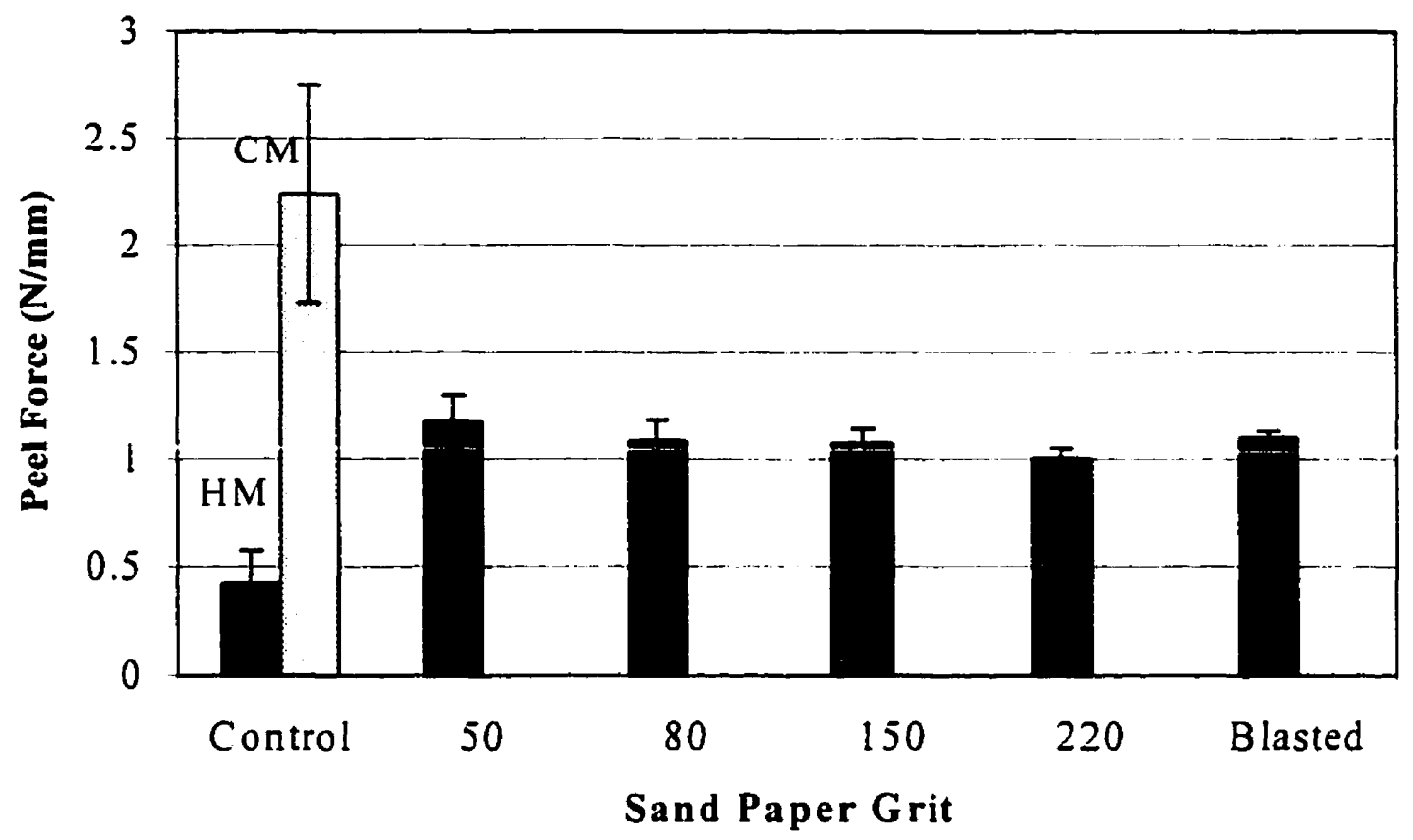

Figure 4-17 Paint peel force $\left(W_{\Gamma} G_{C}\right)$ of sanded $H M$ specimens with different sandpaper grits. 3 samples with 2 measurements per sample. Error bars represent the \pm standard deviation for $\mathrm{N}=6$.

Single factor Anova analysis showed that the measured peel forces are statistically significant with more than $90 \%$ confidence level. To understand the source of variation in the standard deviation, the measured load and its variation with peel length for 50 and 150 grit sandpaper was studied. Figure 4-18 and 4-19 show the results.

With higher grit number of sandpaper, both the maximum peel force and standard deviation were lower. As illustrated in Figure 4-19, with grit size 150, the minimum load was around $60 \%$ of the maximum load. By decreasing the grit number, the difference between maximum and minimum load noticeably increased, and with 50 grit size the minimum load was $40 \%$ of maximum load and the variation coefficient is obviously higher than for grit size 150. 


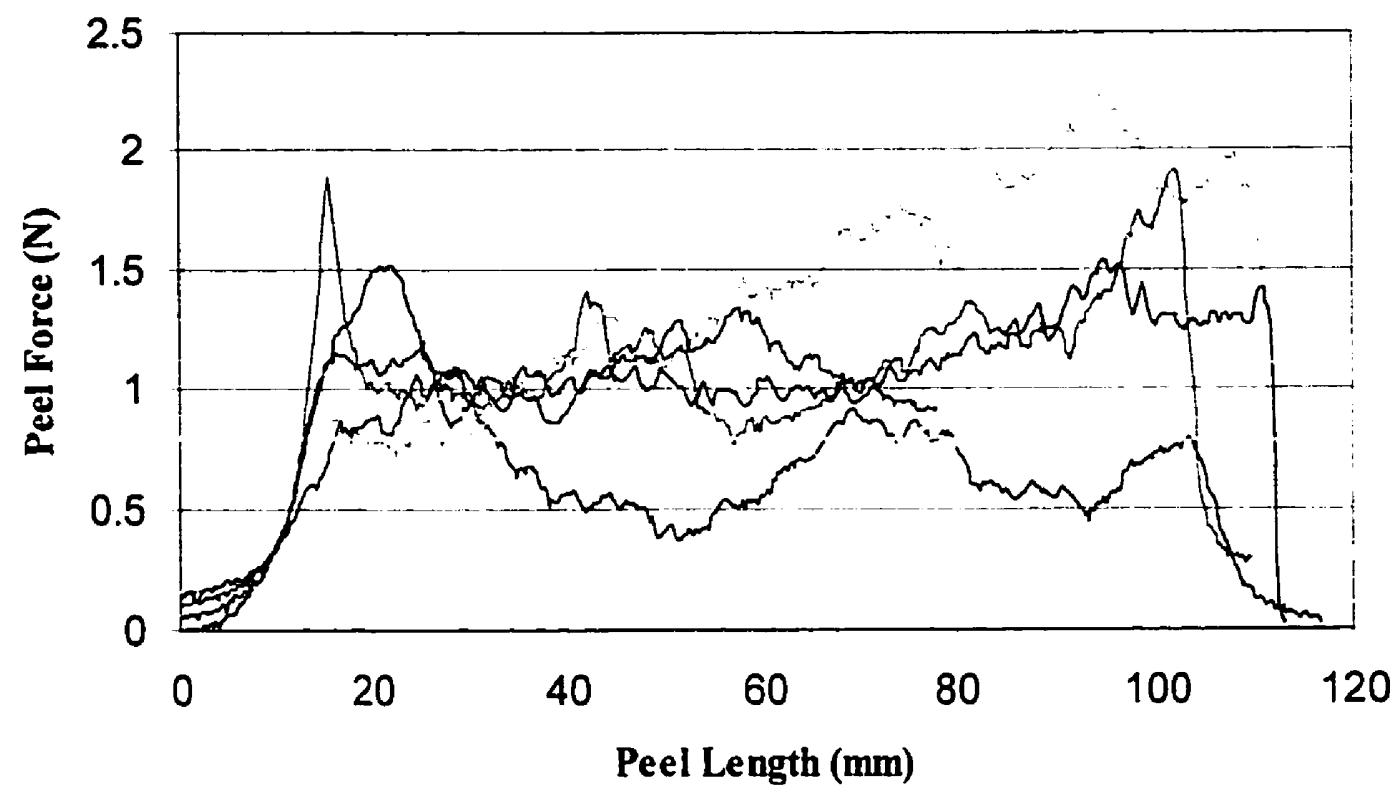

Figure 4-18 Sandpaper grit size 50: variation of peel force with peel length. (6 samples)

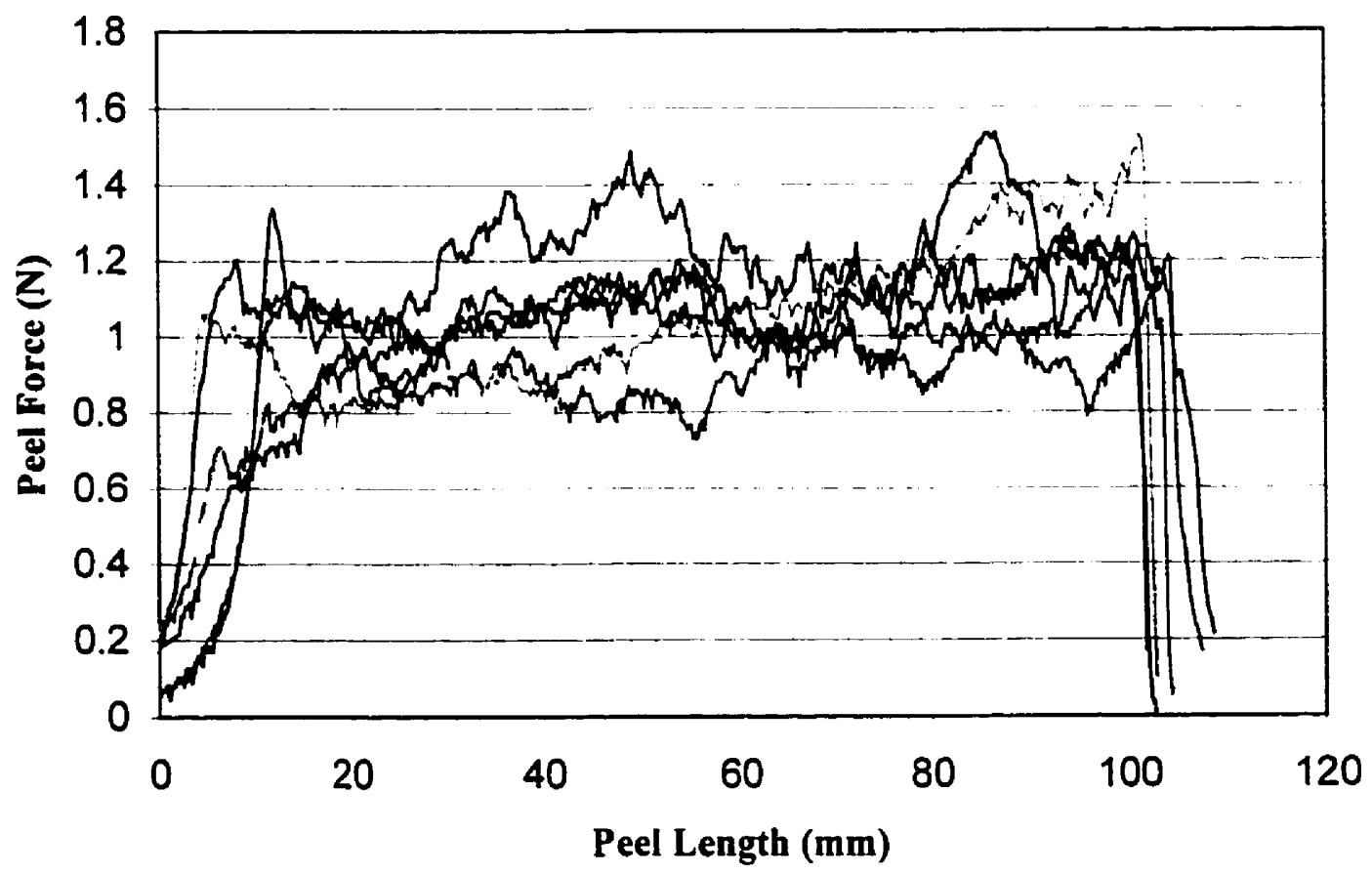

Figure 4-19 Sandpaper 150 grit size: Variation of peel force with peel length (6 samples) 
The peel test for blasted samples also showed trends similar to those found with the scratch test. The lower standard deviation suggests more uniformity in treatment compared to sanded surfaces.

\section{Peel test on corona treated samples}

Figure 4-20 shows the resuil of $45^{\circ}$ peel test on corona treated sampie. The difference between peel force on HM and CM surfaces is greater than what was expected from the scratch test. Although the 5 to $7.5 \mathrm{~min}$ treated specimens had identical scratch test results, the peel test suggests that the $\mathrm{CM}$ interfaces are much stronger, as expected.

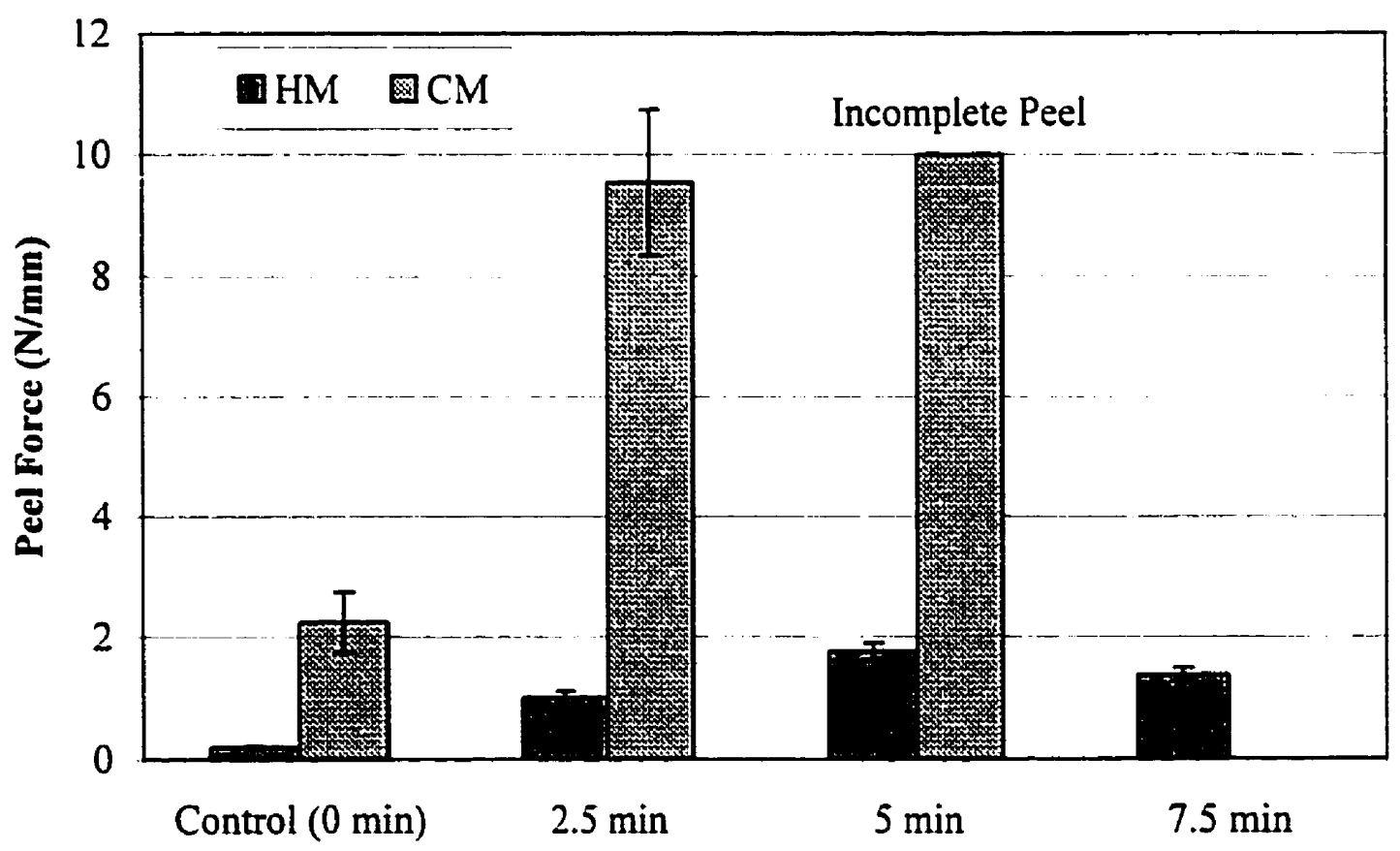

Figure 4-20 Peel force $\left(W_{T} \sim G_{C}\right)$ as a function of treatment time. 3 samples, 2 measurements per sample. Error bars represent \pm standard deviation.

The results show that after 2.5 minutes of corona treatment, the measured peel force increased to $500 \%$ of the initial value (control sample) for both $\mathrm{HM}$ and $\mathrm{CM}$ surfaces. The values for $\mathrm{CM}$ are noticeably higher than $\mathrm{HM}$ surfaces at all treatment 
times. Enhanced contrast image analysis results showed that there was $20 \% \mathrm{PE}$ on $\mathrm{CM}$ and $100 \%$ on $\mathrm{HM}$ surfaces. Therefore, if corona treatment only improved the PE surfaces, the HM surfaces would have a greater benefit from corona. The results obtained suggest that corona had a positive effect on wood fiber as well, and improved the paint adhesion on both components. Corona treatment in fact, introduces polar groups to the surface and increases the possibility of physical bonding as well as chemical bonding between paint and substrate.

The previous research shows [43] corona treatment modifies the wettability of the wood surfaces, but using a different test method (pull test), no improvement in adhesion was observed. In this study, using the $45^{\circ}$ peel test. a significant increase in adhesion was observed on CM/WFRP surfaces. This increase in adhesion is mainly attributed to a modification of the exposed WF.

\subsubsection{Discussion}

In general, corona treatment greatly improves paint adhesion on both the $\mathrm{CM}$ and HM surfaces. Although the level of adhesion is extremely high on $\mathrm{CM}$ surfaces, treatment on HM surfaces yields a lower standard deviation of peel force.

Results of the $45^{\circ}$ peel test for sanded and untreated CM surfaces (Figure 4-17) reveals a significant difference. The higher peel force for the CM surface is caused by the higher amount of exposed wood fiber $(-80 \%)$ on the surface in comparison with the sanded surfaces $(-45 \%)$. As mentioned in Section 4.1.4., however, the value of peel force for the untreated CM surface was $150 \%$ greater than the value for sanded surfaces. Therefore, it is hypothesized that on a sanded surface, some fibers are crushed, or partly 
cut. Either the crushed cells have collapsed lumens or lumens are plugged with sander dust. Both of these effects retard paint penetration into the wood fiber and reduce the paint adhesion [41].

The exposed wood fibers had three major effects on paint adhesion:

1) By increasing the roughness, thev improved the mechanical interlocking of paint

2) By increasing of the number of $-\mathrm{OH}$ groups on the surface, they improved the paint/ substrate chemical bonding

3) By accepting active groups, they improved the paint/ substrate chemical bonds.

Having no exposed wood fiber. HM surfaces are only capable of having PE modified to accept polar groups. Consequently, the level of adhesion force was generally lower on HM surfaces.

\subsection{Durability Analysis}

The long-term performance of the painted surface is one of the major factors for coating success. In this study, the durability of the painted surfaces (HM and $\mathrm{CM}$ ) under water immersion was investigated according to test method ASTM D-357. The change in adhesion force and appearance of the specimens was measured over a period of 6 months.

\subsubsection{Adhesion Measurement}

The $45^{\circ}$ peel test was employed to measure the level of adhesion on both HM and CM surfaces. Specimens were examined after one hour and after 24 hours of drying, to study the level of recovered adhesion with drying. 
Figure 4-21 shows the result of the adhesion test as a function of time. As illustrated, paint adhesion to the HM samples decreased rapidly over a period of one month and the adhesion loss was more than $95 \%$. Whereas, after 30 days, the loss of paint adhesion to the $\mathrm{CM}$ surfaces, was about $20 \%$ of the original value. However, the rate of adhesion loss (the slope of the curve) was similar for both CM and HM surfaces.

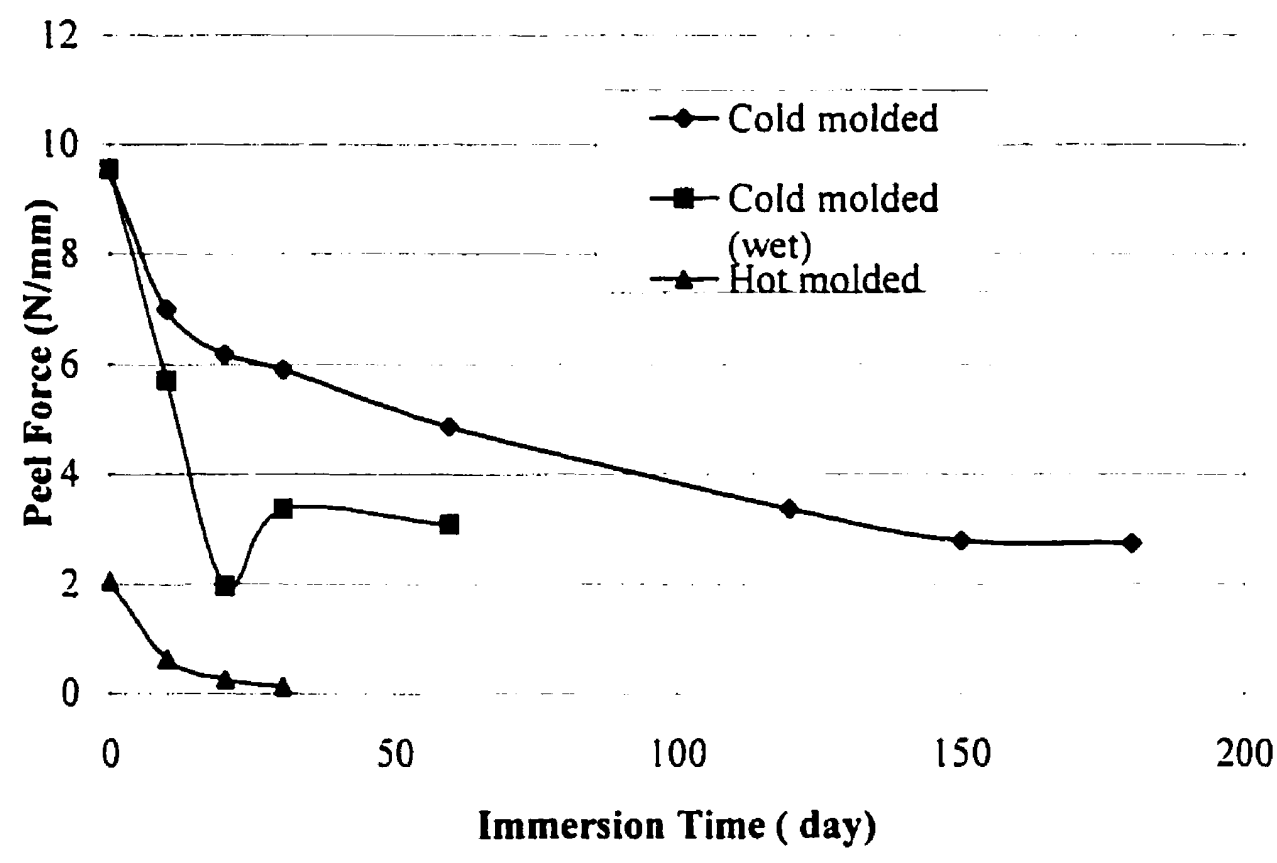

Figure 4-2I Peel force $\left(W_{T} G_{C}\right)$ for painted samples as a function of immersion time.

The trend of adhesion decreasing with time on CM surfaces was studied. The trend was clearly an exponential relation, so the best fit for the data was found and illustrated in Figure 4-22. Extrapolating the data suggests that after a period of 4 years, the adhesion force would approach zero. Considering the severe conditions that were used in this experiment (i.e. water immersion) it seems likely that the loss of adhesion would be much slower under normal service conditions and environmental attack ( e.g. raining). 


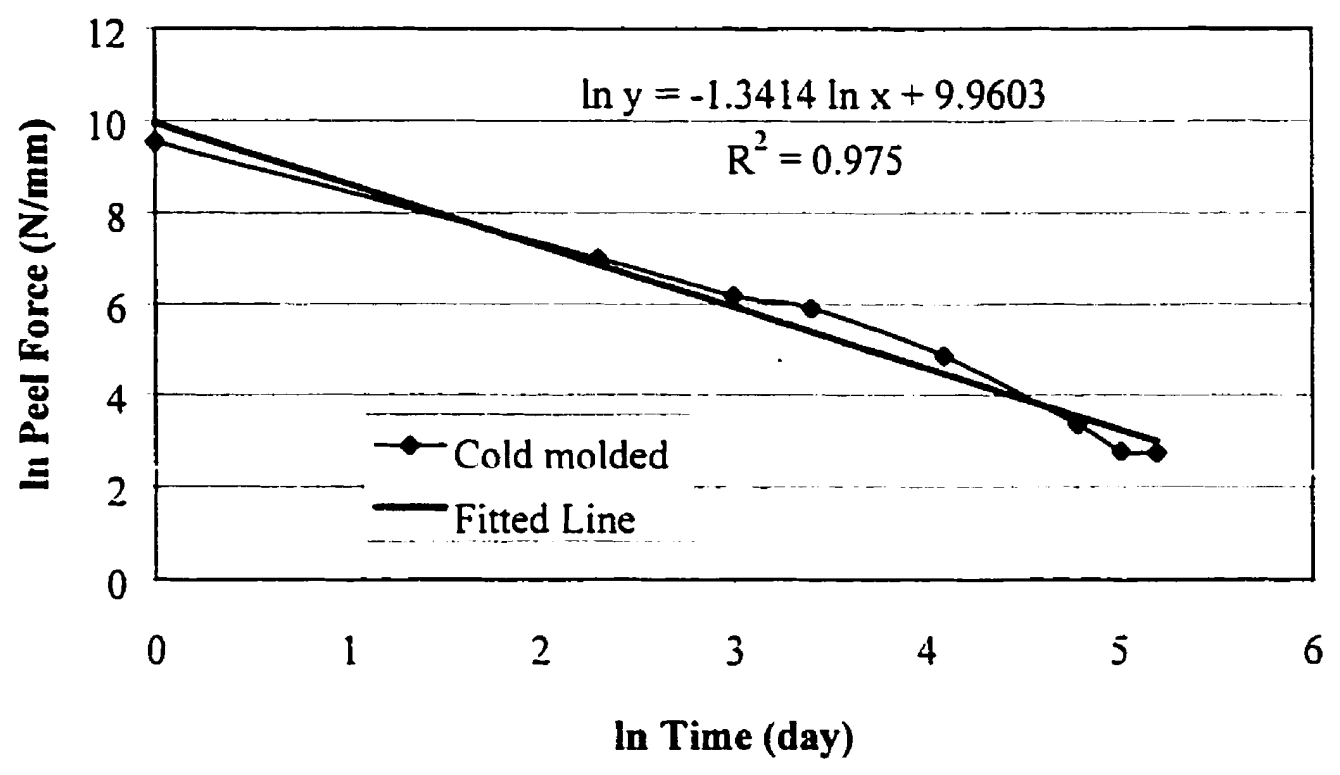

Figure 4-22 The trend of change in peel force as a function of immersion time

The adhesion force was measured after 1 hour of drying the wet samples. so water molecules existed at the paint substrate interface. Beyond 60 days of water immersion, the paint surface remained soft and wet after one hour of drying, and the double-sided tape did not adhere to the paint surface properly. Consequently it was not possible to conduct the $45^{\circ}$ peel test on wet specimens for longer immersion times.

The sudden drop in adhesion of the CM wet surface after 20 days was an unexpected result that might be due to an experimental error. The level of adhesion was obviously lower but water did not delaminate the paint. This can be explained by assuming an intermediate adhesion state [50]. In this condition, some of the bonding sites of the substrate are occupied by water molecules, and after drying, they can recover and adhere to the paint again. This is referred to as a reversible adhesion loss. In contrast, a permanent loss in adhesion is due to hydrolysis and degradation of both paint and substrate. 
The main mechanisms for the loss of adhesion are not well understood. It is partially associated with formation of the thin oxide layer at the interface between the paint and substrate [71]. Hydrolysis of the interfacial bonds is another mechanism purported to accelerate the degradation of paint film [59]. A common sign of adhesion loss is blistering, and this will be discussed in Section 4.4.2.

\subsubsection{Blistering}

The effect of water immersion on the appearance of the painted surface was studied as the second part of the durability analysis. Flaking and blistering are the major signs of water damage. Blisters have two major effects on the surface: 1) they reduce adhesion and, in the long run they accelerate the delamination of the paint 2) they deteriorate the appearance .

The sizes and the frequency of appearance of the blisters were examined, in accordance with ASTM D-714; the results are shown in the Table 4-3.

\begin{tabular}{cclcl}
\hline Immersion time & \multicolumn{2}{c}{ Cold molded } & \multicolumn{2}{c}{ Hot molded } \\
(Day) & Size (No) & Frequency & Size(No) & Frequency \\
\hline 0 & 10 & None & 10 & None \\
10 & 10 & None & 8 & Few \\
20 & 8 & Few & 6 & Mid dense \\
30 & 8 & Few & 4 & Mid dense \\
60 & 8 & Mid dense & 2 & Dense \\
90 & 6 & Mid dense & $*$ & \\
180 & 4 & Mid dense & $*$ & \\
\hline
\end{tabular}

Table 4-3 Size number and frequency of the blisters over a period of 180 days of water immersion (* No result due to partial delamination) 

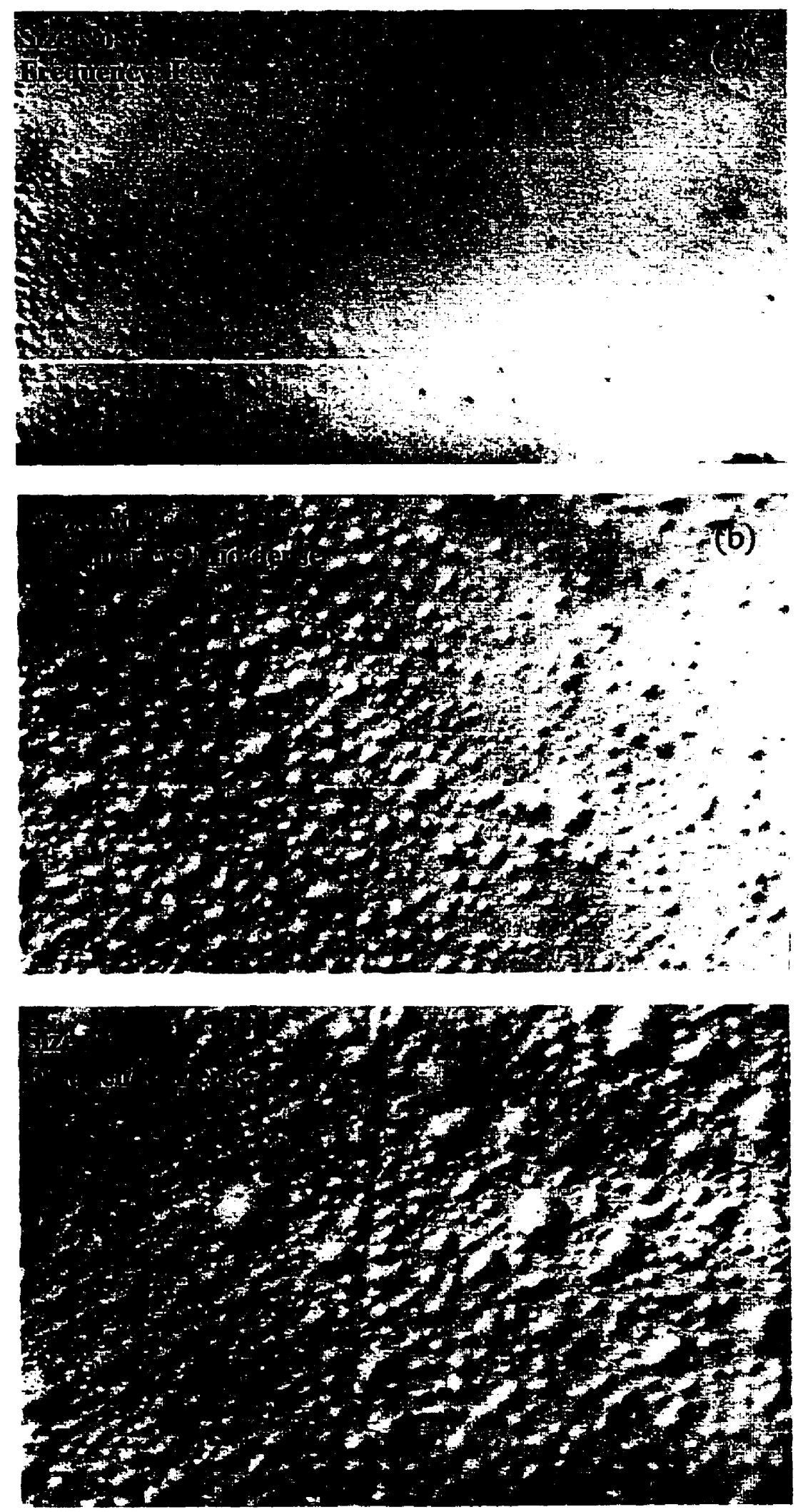

Figure 4-23 Blisters on HM surfaces after a) 20 days b) 30 days and c) 60 days of water immersion. 
In this test, the reported size number was 10 when the size of blisters was zero, and when blisters enlarged, the reported size number decreased. Blister frequency was another important parameter. In general, the frequency of blisters increased over time. Figure 4-23 shows three samples of blisters on HM surface a, b and $c$ after 10,30 and 60 days of immersion, respectively. The frequency and size of the blisters rapidly increased with time on the HM surfaces, whereas on the $\mathrm{CM}$ surfaces blister formation was slow. Figure 4-24 shows the rate of size increase for the blisters with time for $\mathrm{CM}$ and $\mathrm{HM}$ surfaces.

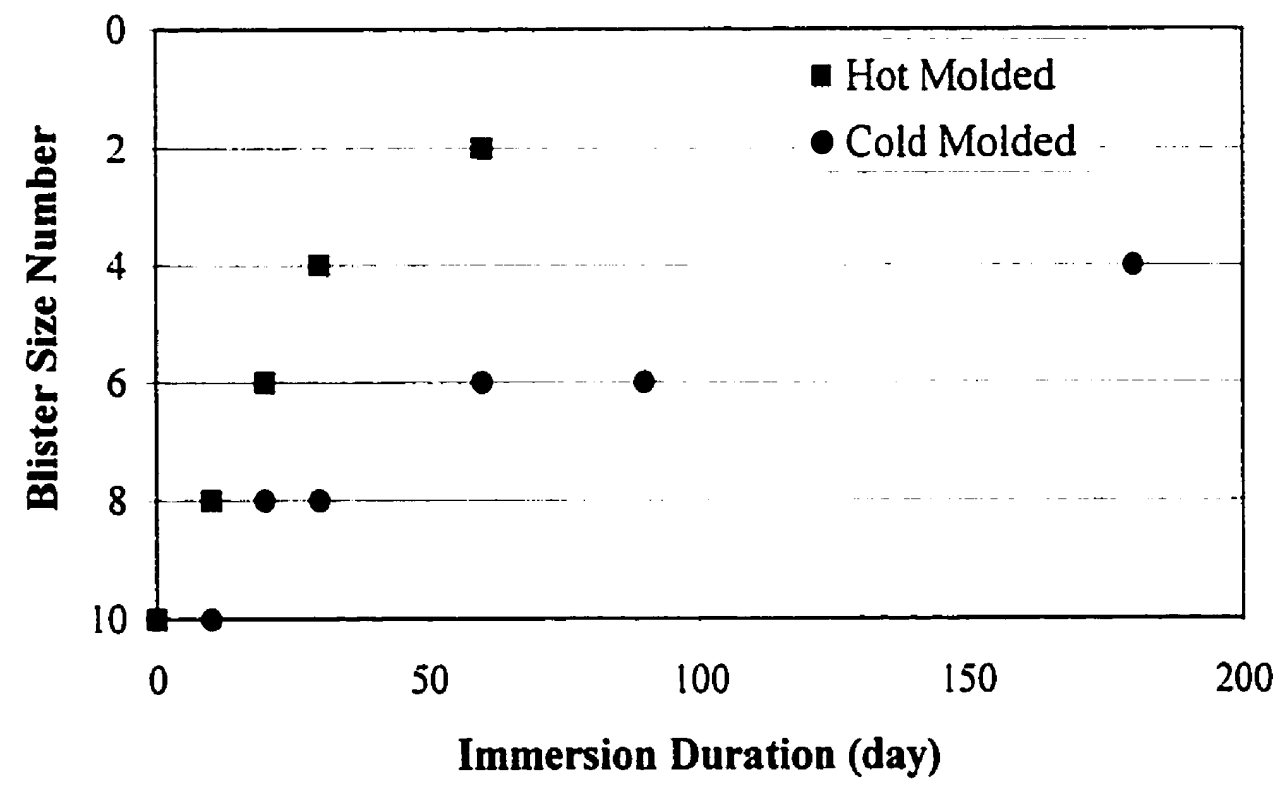

Figure 4-24 Blister size evaluation by means of blister number with immersion duration.

To understand the effect of time and heat on blistering, specimens were also examined after immersion in boiling water for 4 hours. The frequency of blisters on the HM surface was dense but their size remained small (number 8). The results revealed that long exposure enlarged the size of the blisters. Using the severe condition, i.e. boiling 
water, the rate of water diffusion accelerated, and subsequently the density of the blisters on the HM surface increased. Blisters did not appear on CM surfaces after four hours of boiling water immersion.

Osmotic blistering would be a possible explanation for WFRP blistering. Osmotic pressure blistering is due to the presence of soluble salts at the paint/substrate interface [56]. In this case, the concentrated solution of the salt drives the water from the coating surface to the interface. In this system, the lower the percentage of impurity in the water, the higher the rate of blistering should be. In this study, the use of distilled water to grow blisters showed the opposite effect; after two months of immersion for HM specimens, the size number of blisters was 6 and frequency of appearance was medium. In this experiment, the rate of blistering was slower with distilled water than using tap water. The results suggested that the osmotic blistering mechanism was not responsible for blister formation in this system.

It is obvious that the exposed wood fiber on the surface of the CM specimens retarded the rate of blistering. The reason can be associated with the higher capacity of water absorption of wood fiber. When water diffuses to the paint/ substrate interface, wood fibers can absorb part of that water, and prevent blisters from forming. This hypothesis was examined by measuring WFRP water absorption. This measurement was designed to measure the water absorbed per unit area. Specimens were specifically thin (thickness $<3 \mathrm{~mm}$ ) and the edges were sealed to prevent the influence of specimen thickness.

Figure 4-25 shows the results. 


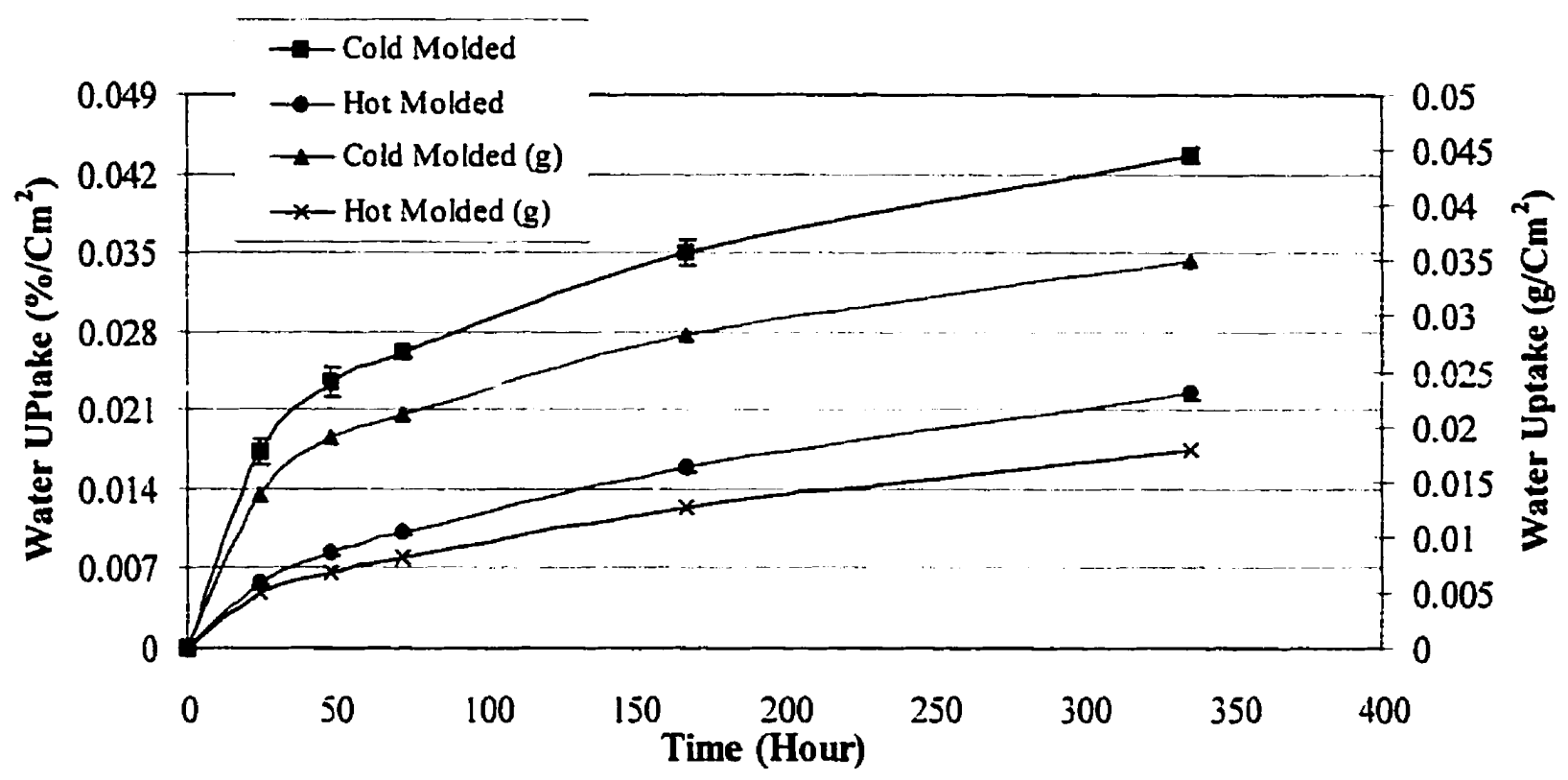

Figure 4-25 Water absorption of WFRP. Error bar represents \pm standard deviation for 4 measurements.

The water absorption experiment revealed that water was absorbed at a higher rate by the CM surfaces. After two weeks of immersion, HM surface absorbed only $50 \%$ of the water that was absorbed by $\mathrm{CM}$ surfaces.

The rate of blistering depends on the water absorption by the coating system. Waterborne paints usually can absorb water and swell. Swelling by water causes an expansive internal stress [72], and subsequently volume expansion in paint layers. This expansion usually appears in the form of blisters. In this case, the adhesion force in the paint/ substrate interface is an important factor that influences the rate of blistering. If the adhesion force is higher than paint expansive stress, no blister will appear. Otherwise, by decreasing the adhesion force, the expanded paint blisters, and gradually the size and the frequency of blisters will increase. 
In general, higher water absorption and higher adhesion force on CM surfaces reduced the rate of blistering. 


\section{Conclusions}

Changing the mold temperature affects the composition and topography of the WFRP surfaces. This change is due to variation in the amount of exposed wood fiber, which has an indirect relation with mold temperature. In other words, increasing the mold temperature decreases the amount of exposed wood fiber, and after the meiting point of the PE, no wood fiber appears on the surface. This is significant because exposed wood fibers improve the final paint adhesion.

Corona treatment is able to modify the WFRP surfaces to a higher level than other examined methods including acid etching, sanding, and blasting. Treatment parameters including duration, output power, and electrode distance to the surface play a critical role in determining the level of surface energy, and have to be adjusted for individual situations. The painting station should be installed immediately after corona treatment to prevent treatment decay with time.

Although corona treatment modifies the cold molded surfaces more than it does the hot molded surfaces, treatment on hot molded surfaces yields a lower standard deviation and is thus more uniform and consistent

The hot molded samples show a lower durability in water immersion and after two months, the adhesion level dropped to zero. Cold molded samples can be immersed in water for 4 months before the paint delaminates.

The rate of water absorption on hot molded surfaces was almost half of that on cold molded surfaces, consequently, blisters appear on hot molded surfaces faster and 
with higher frequency and larger size than on cold molded surfaces. In summary, exposed wood fiber increased the paint adhesion, improved the water durability and decreased the blistering rate. 


\section{Recommendations for further research}

It is recommended that future studies examine:

1- Various wood fiber/ PE weight ratios and their effect on surface properties and paintability.

2- Other molding methods and their effect on paintability.

3- The rheology of the composite in the mold and the relation between polymer flow and temperature.

4- Other methods to quantify the amount of exposed wood fiber.

5- The effect of corona treater type and model on final adhesion.

6- Other techniques of surface modification for PE and wood.

7- The possibility of developing other adhesion measurement methods.

8- The durability under real environmental conditions and over longer period.

9- The effect of blistering rate on paint adhesion.

10- The possibility of using a new method to measure the wet paints adhesion.

11- The application of other types of paint. 
1. R.T.Woodhams, G.Thomas and D.K.Rodgers, Polymer Engineering and Science, 1984, Vol. 24, No. 15, pp. 1166.

2. J. A. Youngquist, Forest Produce Journal, Vol. 45, No.10, 1995, pp. 25.

3. N. M. Stark, M.J. Berger, The Fourth International Conference on WoodfiberPlastic Compositess, 1997, pp. 134.

4. B. English, The Fourth International Conference on Woodfiber-Plastic Compositess, 1997, pp. 79.

5. M. P. Wolcot, The Fifth International Conference on Woodfiber-Plastic Compositess, 1999, pp. 289.

6. T.G.Stropoli. The Fourth International Conference on Woodfiber-Plastic Compositess, 1997, pp. 50.

7. D.R.Karsa and W. D. Davies." Waterborne Coatings and Additives". Royal Society Of Chemistry, 1995, pp.105.73-75.

8. J. Edward Glass, "Technology for Waterborne Coatings", American Chemical Society, 1997. pp. 35.

9. D. M. Brewis, J. of Adhesion Science and Technology, 1996, Vol.11, pp 81.

10. M.Strobel, M.C.Branch, M.Ulsh, R.S.Kapaun, S.Kirk and C.S.Lyons, J of Adhesion Science and Technology, 1996, Vol. 10, pp. 515.

11. Q.C.Sun D.D.Zhang and L.C.Wadsworth, Tappi Journal, 1998, Vol. 81, No. 8, pp. 177.

12. I. Sutherland, E.Sheng, D.M.Brewis and R.J.Heath, J. Adhesion, 1994,Vol. 44,pp 18. 
13. A.K.Blezki and V. E. Sperber, Fifth International Conference on WoodfiberPlastic Composites, 1999,.pp. 187.

14. A.K.Blezki and J. Gassan., Natürliche Verstar-Kungsfasem Fur Kunstoffe. In: Spektrum Der Wissenschaft, 1996. pp 258.

15. R. Kohler and R.W. Kessler, Fifth International Conference on Woodfiber-Plastic Composites.1999,.pp. 29-30.

16. C.H.Eckert, Fifth International Conference on Woodfiber-Plastic Composites, 1999.pp. 19-22.

17. A.K.Beldzki. Fifth International Conference on Woodfiber-Plastic Composites, 1999, pp. 187-192.

18. Conner Et Al.. Wood Adhesives, Forest Product Research Society.. 1990. pp. 163-189.

19. Narayan, R. Amer. Chem. Soc., Washington, D.C, 1992. pp. 57-75.

20. M. Kazayawoka, The Fourth International Conference on Woodfiber-Plastic Composites, 1997, pp.81-93.

21. W. Woebken,, Kunststoffe, 1961, Vol. 51, pp. 547.

22. W.C. Jackson, S.L. Avandi and C.L. Tucker, J. Composites Material, 1986, Vol. 20, pp.539. 
23. J. Simonsen, The Third Conference on Woodfiber-Plastic Compositess, 1996, pp. 47-55.

24. B.W. English and R.H. Falk, The Third Conference on Woodfiber-Plastic Compositess, 1996, pp. 189-194.

25. D. A. Johnson, D. A. Johnson, J. L. Urich, R. M. Rowel, R. Jacobson and D D. F. Caufield, The Fifth International Conference on Woodfiber-Plastic Compositess, 1999, pp. 207.

26. L. Gerenser, J. M. Polymer, 1985, Vol. 26. pp 1162.

27. R.M. Podhanjy, J. Plastic Film and Sheeting. 1987. Vol .4. pp.7.

28. H. Steinhauser and G.Elinghorst,. Angew. Makromol. Chem.. 1984, Vol. 120, pp.177.

29. W.C. Harris. G.E Earler, and S.B. Samuels. Tappi J.. 1990, Vol. 73, No.1. pp. 145.

30. D.K. Owens . J . Appl. Polym.Sci., 1975, Vol. 19. pp. 265.

31. C. Kim, J.Evans, and D.A.I.Goring, 1971, J. Polymer Science, Vol. 15 ,pp. 1357.

32. C.J. Overmy, J. Appl. Phys., 1994, Vol. 75. pp. 1401.

33. D.A. Markgraft, Coextrusion Seminar Proceeding; Tappi Press, 1986, pp. 85.

34. M. Blitsteyn, Tappi J., 1995, Vol. 78, No. 3, pp.138. 
35. A.W. Neumann and Jan K. Spelt, "Applied Surface Thermodynamics",Marcel Dekker, 1996, pp. 189.

36. H.L. Spell, Paper Conference Proceedings, 1978, Tappi Press, pp. 173.

37. D. Markgrag, Tappi J., 1985, Vol. 68: No. 2, pp. 65.

38. M. Strobel, C. Dunatov, J.M. Strobel, C.S. Lyons, S.J. Perron, and M.C. Morgen. J. Adhes. Sci. Technol., 1989, Vol. 3, No. 5, pp.321.

39. S.W. Kim., J Of Korean Chem. Eng. 1995, Vol. 13, No.1. pp. 97-100.

40. M. Lewin, I. S.Goldstein, "Wood Surface and Composition", Marcel Dekker, 1991, pp. 3-4.

41. A. A. Marra, "Technology of Wood Bonding". Van Nostrand Reinhold. 1992. pp. 161,179 .

42. D.N.-S. Hon, "Chemical Modification of Lingocellulosic Materials". Marcell Decker Inc., 1996. pp 45-48.

43. L. Podogorski, B. Chevet, L. Onic, and A. Merlin, International J. of Adhesion and Adhesives, 2000, Vol. 20, pp.103-111.

44. R. Mahlberg, H..E. M. Neimi, F. Dense and R.M. Rowell, 1998, International J. of Adhesion and Adhesives, Vol. 18, pp. 283-297.

45. C.Bischof, W. Possart, Adhasion, Akademie-Verlag, Berlin, 1983, pp.123. 
46. H.K. Pulker, A.J. Perry, and R Berger, Oberflache Surf, 1982, Vol. 23, pp. 118.

47. B. Lowerie and J.R. Sargent, ALSE Trans., 1977, Vol. 21, pp. 285.

48. T. Arai, H. Fujita and M. Watanabe, Thin Solid Films, 1987, Vol. 154, pp. 387.

49. P.C. Jindal, D.T Quinto and G.J. Wolf, Thin Solid Films, 1987, Vol. 154, pp. 361.

50. H. Grutzner and H. Weiss, Surface Coating Technol. . 1991, Vol. 45, pp. 317.

51. R. J. Farris, M.A. Maden and J. Goldfrab. Proc. $14^{\text {th }}$ Annual Meeting The Adhesion Society, 1991, pp. 138.

52. A. K. Moidu. A.N. Sinclair and J. K. Spelt., Journal of Testing and Evaluation. JTEVA, 1998, Vol. 26, No. 3, pp.247-254.

53. A. J. Kinloch, 1979. In "Adhesion 3" (K. W. Allen, Ed.), Applied Science, London, pp. 1-12.

54. W. Funke. "In Corrosion Control By Coatings". National Association of Corrosion Engineers, 1981, pp. 70.

55. O. Negele and W. Funke, Progress in Organic Coatings, 1996, Vol. 28, pp. 285289.

56. W. Funke, Progress in Organic Coatings, 1981, Vol. 9, pp.29-46.

57. J. E. Glass, "Technology For Waterborne Coatings", American Chemical Society Press, 1997, pp59. 
58. A. Bouvy and G.R. John, Polymer Paint Colour, 1993, Vol. 183, pp.284.

59. T. Provder, M. A. Winnik, M. W. Urban, "Film Formation in Waterborne Coatings", American Chemical Society, 1996. pp.3-5.

60. T. Imoto, Progress in Organic Coatings, 1973, vol.4, No. 2, pp.193.

61. J. G. Williams, J. Adhesion, 1993, Vol. 41. pp.225-239.

62. A. G.Zink and E. Katunova, Forest Product J. 1998, Vol. 48, No.4. pp. 71.

63. A.W. Neuman, D.R. Bsolom, D.W. Francis and C.J. Van Oss, "Conversion Tables Of Contact Angles to Surface Tension", Marcel Dekker. 1980.

64. R. Raff and V. August. Polyethylene. 1956. New York: Interscience Publishers, pp. 178.

65. R. Mahlberg, H.E.M Niemi, F. Dense, R.M. Rowell, Intemational J of Adhesion and Adhesives. 1998. Vol. 18, pp. 283-297.

66. C. Fonseca. J.M. Perena, J. B. Fatou, and A. Bello. J. Material Science., 1985, Vol. 20, No. 9, pp. 3283-3288.

67. C.Sun, D.Zhang, and L.C. Wadsworth, Advanced in Polymer Technology, 1999, Vol. 18, No. 2. pp.174-176.

68. K. Tsutsui,, A. Iwata and S. Ikeda, J. Coatings Technol., 1989, Vol. 61, No. 776, pp. 65 .

69. I.Sutherland, R.P. Popat, and D.M. Brewis, J. Adhesion, 1994, Vol. 46, pp. 85.

70. K. Kleive, J. Coatings Technology, 1986, Vol. 58, No. 740, pp. 39-43.

71. F. Mansfeld," Corrosion Mechanisms", Marcel Dekker, 1986, pp.190-194. 
72. D.Y. Perera, Progress in Organic Coatings, 1996, Vol. 28, pp. $21-23$. 


\section{A. Appendix A}

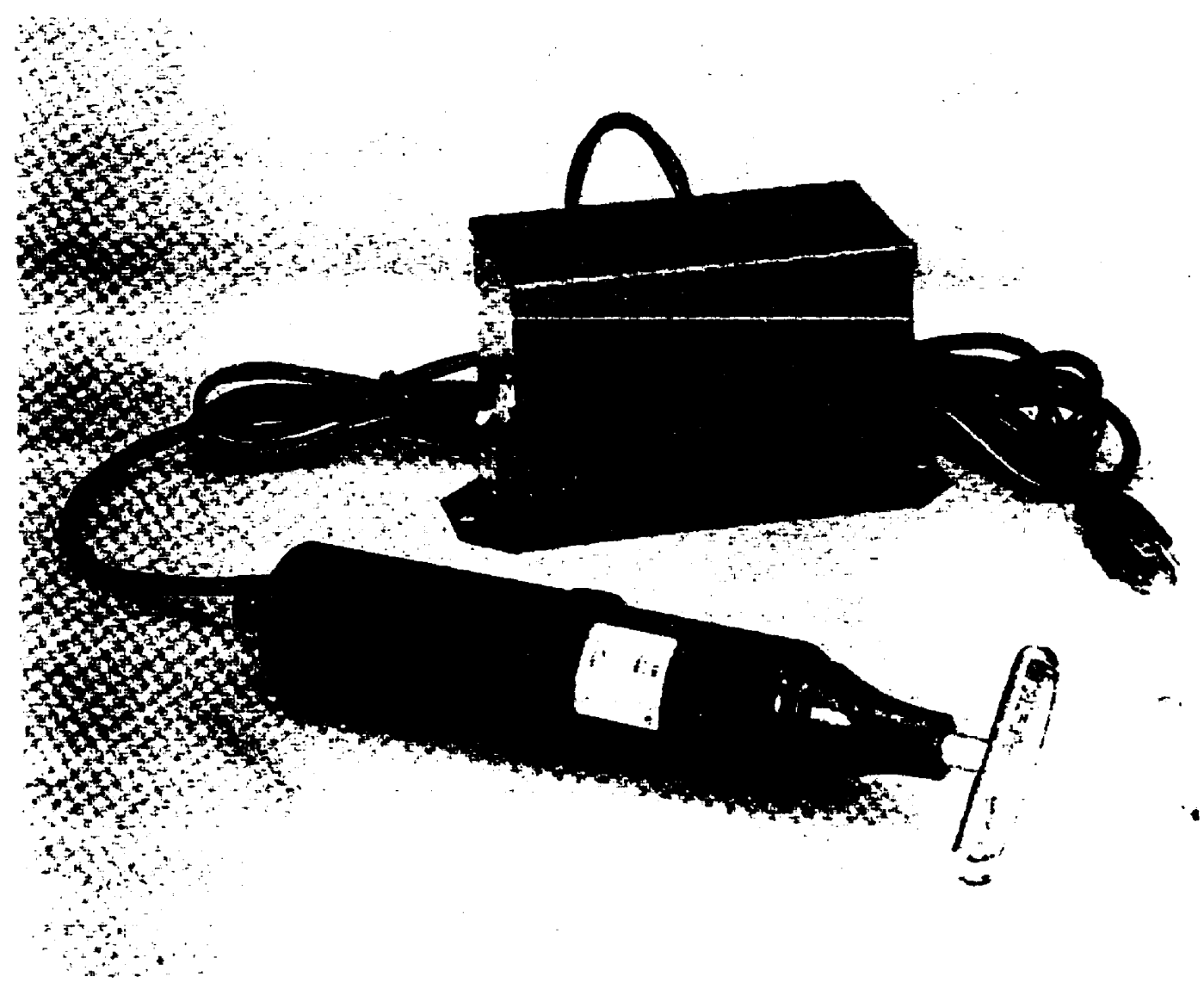

Figure A-1. Corona Treater BD-20AC

Speciffcations

\begin{tabular}{|l|l|}
\hline Output Voltage & 10,000 to 48,000 volts \\
\hline Frequency & 4 to $5 \mathrm{MHz}$ \\
\hline Operating Duration & Continuous \\
\hline Input Voltage & $115 \mathrm{~V}, 50 / 60 \mathrm{~Hz}(\mathrm{BD}-20 \mathrm{~A})$ \\
& $220 \mathrm{~V}, 50 / 60 \mathrm{~Hz}(\mathrm{BD}-20 \mathrm{AV})$ \\
\hline Generator (1xd) & $11 \times 2-1 / 2 \mathrm{in} .(28 \times 6.4 \mathrm{~cm})$ \\
\hline $\begin{array}{l}\text { Power Supply } \\
\text { (h } \times \text { w } \times \text { d) }\end{array}$ & $4-1 / 8 \times 7-3 / 4 \times 3-1 / 8 \mathrm{in}$. \\
\hline Shipping Weight & $(10.5 \times 19.7 \times 8 \mathrm{~cm})$ \\
\hline & BD-20AC: $6 \mathrm{lbs}(2.7 \mathrm{~kg})$ \\
& BD-20ACV: $7 \mathrm{lbs}(3.2 \mathrm{~kg})$ \\
\hline
\end{tabular}




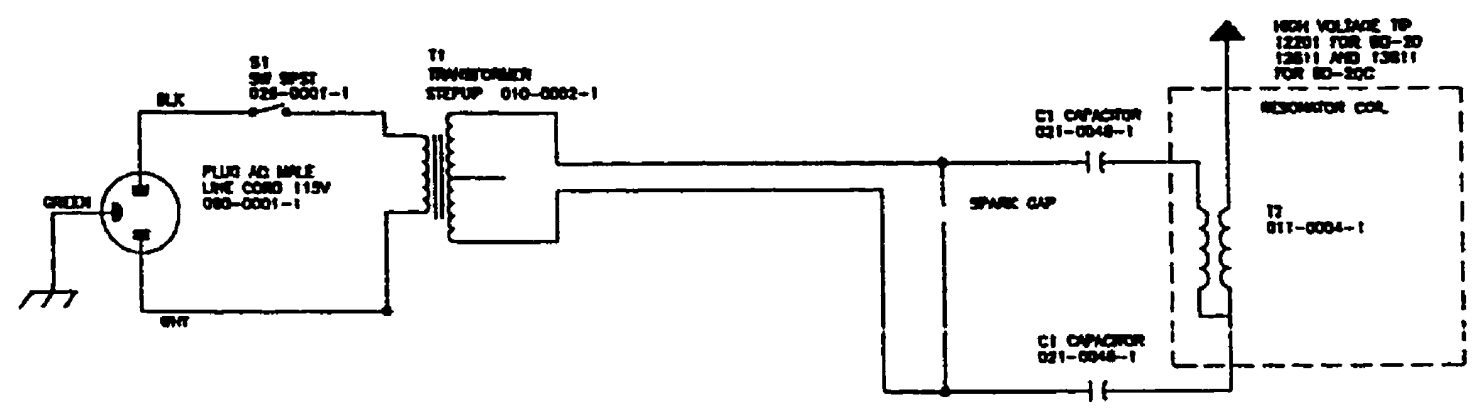

Model BD-20AC, $115 \mathrm{~V}$

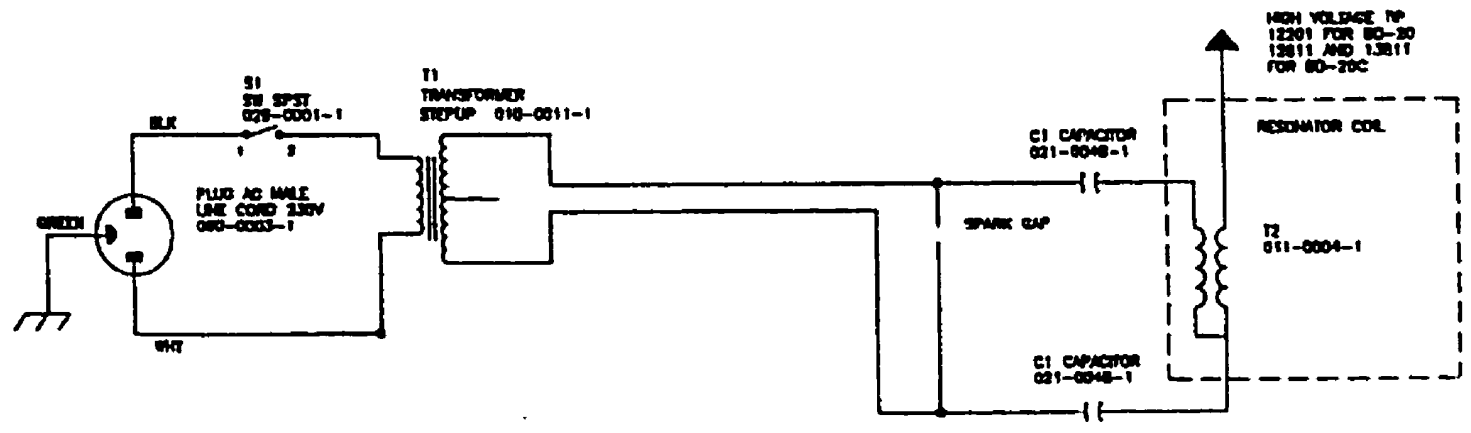

Model BD-20ACV, $230 \mathrm{~V}$

Electrical Schematic Diagram 
Appendix B

VHBTMI Double Coated Acrylic Foam Tapes and Adhesive Transfer Tapes. Technical Specification 


\section{VHB $^{\text {mi }}$ Double Coated Acrylic Foam Tapes and Adhesive Transfer Tapes}

Technical Data

March, 1948

Supersedes August, 1994
$3 \mathrm{M}^{\mathrm{TM}}$ VHBB ${ }^{\mathrm{TM}}$ Tapes utilize high performance adhesives which have excellent longterm holding power. The peel adhesion and tensile holding power of tapes in the VHB family are significantly higher than typical pressure sensitive tapes.

Product Description

VHB tapes are ideal for use in many interior and exterior industrial applications. In many situations they can replace rivets, spot welds, liquid adhesives, and other permanent fasteners.

Each tape in the VHB tape family has specific features. These can include high tensile, shear and peel adhesion, resistance to solvents, moisture and plasticizer migration, U.L. recognition, low outgassing, film liners, conformability and adhesive which can be applied at temperatures as low as $32^{\circ} \mathrm{F}\left(0^{\circ} \mathrm{C}\right)$.

VHB tapes are ideal for bonding a variety of substrates. including most metal, sealed wood and glass, as well as many plastics. composites and painted surfaces.

Note: All VHB tapes should be thoroughly evaluated by the user under actual use conditions with intended substrates to determine whether a specific VHB tape is fit for a particular purpose and suitable for user's method of application, especially if expected use involves extreme environmental conditions.

\begin{tabular}{|c|c|c|c|c|c|c|}
\hline \multirow[t]{2}{*}{ Products } & \multicolumn{3}{|c|}{ Double Coated Acrylic Foam Tapes } & \multicolumn{3}{|c|}{ Adhesive Transfer Tapes } \\
\hline & $\begin{array}{l}4905 \\
4910 \\
4920 \\
4925 \\
4926 \\
4929 \\
4930 \\
4932 \\
4936^{\circ} \\
4940^{\circ} \\
4941^{\circ} \\
4943 \mathrm{~F} \\
4945 \\
4946 \mathrm{~F} \\
4949 \\
4950 \\
4951 \\
4952 \\
4955 \\
4956^{\circ} \\
4957 \mathrm{~F} \\
4959 \\
4979 \mathrm{~F}\end{array}$ & $\begin{array}{l}0.020 \text { in. } \\
0.040 \text { in. } \\
0.015 \text { in. } \\
0.025 \text { in. } \\
0.015 \text { in. } \\
0.025 \text { in. } \\
0.025 \text { in. } \\
0.025 \text { in. } \\
0.025 \text { in. } \\
0.045 \text { in. } \\
0.045 \text { in. } \\
0.045 \text { in. } \\
0.045 \text { in. } \\
0.045 \text { in. } \\
0.045 \text { in. } \\
0.045 \text { in. } \\
0.045 \text { in. } \\
0.045 \text { in. } \\
0.080 \text { in. } \\
0.062 \text { in. } \\
0.062 \text { in. } \\
0.120 \text { in. } \\
0.062 \text { in. }\end{array}$ & $\begin{array}{r}(0.5 \mathrm{~mm}) \\
(1.0 \mathrm{~mm}) \\
(0.4 \mathrm{~mm}) \\
(0.64 \mathrm{~mm}) \\
(0.4 \mathrm{~mm}) \\
(0.64 \mathrm{~mm}) \\
(0.64 \mathrm{~mm}) \\
(0.64 \mathrm{~mm}) \\
(0.64 \mathrm{~mm}) \\
(1.1 \mathrm{~mm}) \\
(1.1 \mathrm{~mm}) \\
(1.1 \mathrm{~mm}) \\
(1.1 \mathrm{~mm}) \\
(1.1 \mathrm{~mm}) \\
(1.1 \mathrm{~mm}) \\
(1.1 \mathrm{~mm}) \\
(1.1 \mathrm{~mm}) \\
(1.1 \mathrm{~mm}) \\
(2.0 \mathrm{~mm}) \\
(1.55 \mathrm{~mm}) \\
(1.55 \mathrm{~mm}) \\
(3.0 \mathrm{~mm}) \\
(1.55 \mathrm{~mm})\end{array}$ & $\begin{array}{l}\text { F.946OPC } \\
\text { F-9469PC } \\
\text { F-9473PC }\end{array}$ & $\begin{array}{l}0.002 \text { in. } \\
0.005 \text { in. } \\
0.010 \text { in. }\end{array}$ & $\begin{array}{l}(0.05 \mathrm{~mm}) \\
(0.13 \mathrm{~mm}) \\
(0.25 \mathrm{~mm})\end{array}$ \\
\hline
\end{tabular}

•Film-linered versions are available as tapes 4936F, 4941F and 4956F. 


\section{Tapes and Adhesives Transfer Tapes}

\begin{tabular}{|c|c|c|c|c|c|c|c|}
\hline \multirow{2}{*}{\multicolumn{2}{|c|}{ Typical Physical Properties }} & \multicolumn{6}{|c|}{$\begin{array}{l}\text { Note: The following technical information and data should be considered } \\
\text { representative or typical only and should not be used for specification purposes }\end{array}$} \\
\hline & & \multicolumn{5}{|c|}{ Primary Tapes } & \multirow[b]{2}{*}{4930} \\
\hline Products & & F-9460PC & F-9469PC & F.9473PC & 4920 & 4929 & \\
\hline Adhesive Family: & & $A-10$ & A-10 & $A-10$ & VHB Tape & VHB Tapo & VHB Tape \\
\hline Adhesive Carrier: & & None & None & None & $\begin{array}{l}\text { Acrylic Foam } \\
\text { Closed Cell }\end{array}$ & $\begin{array}{l}\text { Acrylic Foam } \\
\text { Closed Cell }\end{array}$ & $\begin{array}{l}\text { Acrylic Foam } \\
\text { Closed Cell }\end{array}$ \\
\hline \multicolumn{8}{|l|}{ Thickness: } \\
\hline Nominal & in. & $\begin{array}{l}0.002 \\
(0.05)\end{array}$ & $\begin{array}{l}0.005 \\
(0.13)\end{array}$ & $\begin{array}{l}0.010 \\
(0.25)\end{array}$ & $\begin{array}{l}0.015 \\
(0.40)\end{array}$ & $\begin{array}{l}0.025 \\
(0.64)\end{array}$ & $\begin{array}{l}0.025 \\
(0.64)\end{array}$ \\
\hline Tolerance & & $\pm 20 \%$ & $\pm 10 \%$ & $\pm 5 \%$ & $\pm 15 \%$ & $\pm 15 \%$ & $\pm 15 \%$ \\
\hline Color: & & Clear & Clear & Clear & White & Black & White \\
\hline Release Liner: & in. & $\begin{array}{c}0.004 \\
(0.10) \\
\text { Printed } \\
\text { Paper }\end{array}$ & $\begin{array}{l}0.004 \\
(0.10) \\
\text { Printed } \\
\text { Paper }\end{array}$ & $\begin{array}{l}0.004 \\
(0.10) \\
\text { Prfinted } \\
\text { Paper }\end{array}$ & $\begin{array}{c}0.003 \\
(0.08) \\
\text { Printed } \\
\text { Paper }\end{array}$ & $\begin{array}{c}0.002 \\
(0.05) \\
\text { Clear } \\
\text { Polyester }\end{array}$ & $\begin{array}{c}0.003 \\
(0.08) \\
\text { Printed } \\
\text { Paper }\end{array}$ \\
\hline $\begin{array}{l}\text { Approximate Density: } \\
\text { (Foam Only) }\end{array}$ & $\begin{array}{l}\mathrm{lb} / \mathrm{ft}^{3} \\
\left(\mathrm{~kg} / \mathrm{m}^{3}\right)\end{array}$ & $\mathrm{NA}$ & NA & NA & $\begin{array}{c}50 \\
(800)\end{array}$ & $\begin{array}{c}50 \\
(800)\end{array}$ & $\begin{array}{c}50 \\
(800)\end{array}$ \\
\hline \multicolumn{8}{|l|}{ Roll Length: } \\
\hline Standard & $\begin{array}{l}\text { yds. } \\
(m)\end{array}$ & $\begin{array}{l}60 \\
(54.9)\end{array}$ & $\begin{array}{c}60 \\
(54.9)\end{array}$ & $\begin{array}{l}60 \\
(54.9)\end{array}$ & $\begin{array}{c}72 \\
(65.8)\end{array}$ & $\begin{array}{c}72 \\
(65.8)\end{array}$ & $\begin{array}{c}72 \\
(65.8)\end{array}$ \\
\hline \multicolumn{8}{|l|}{ Maximum } \\
\hline $\begin{array}{l}\text { Standard Units } \\
\text { a. } 1 / 4^{n} \text { up to } 1 / 2^{\prime \prime} \text { wide } \\
\text { b. } 1 / 2^{n} \text { and wider } \\
\text { c. } 1 / 4^{*} \text { to } 3 / 8^{n} \\
\text { d. } 3 / 8^{n} \text { up to } 1^{\prime \prime} \text { wide } \\
\text { e. } 1^{1 "} \text { up to } 3^{* \prime} \\
\text { f. } 3^{*} \text { and wider }\end{array}$ & $\begin{array}{l}\text { yd. } \\
\text { yd. } \\
\text { yd. } \\
\text { yd. } \\
\text { yd. } \\
\text { yd. }\end{array}$ & $\begin{array}{l}60 \\
240 \\
360 \\
360\end{array}$ & $\begin{array}{l}60 \\
240 \\
360 \\
360\end{array}$ & $\begin{array}{l}60 \\
120 \\
120 \\
180\end{array}$ & $\begin{array}{c}72 \\
216\end{array}$ & $\begin{array}{c}72 \\
216\end{array}$ & $\begin{array}{c}72 \\
216\end{array}$ \\
\hline $\begin{array}{l}\text { Metric Equivalents } \\
\text { a. } 6.4 \mathrm{~mm} \text { up to } \\
12.7 \mathrm{~mm} \text { wide } \\
\text { b. } 12.7 \mathrm{~mm} \text { and wider } \\
\text { c. } 6.4 \mathrm{~mm} \text { to } 9.5 \mathrm{~mm} \\
\text { d. } 9.5 \mathrm{~mm} \text { up to } 25.4 \mathrm{~mm} \\
\text { e. } 25.4 \mathrm{~mm} \text { up to } 76 \mathrm{~mm} \\
\text { f. } 75 \mathrm{~mm} \text { and wider }\end{array}$ & $\begin{array}{l}(m) \\
(m) \\
(m) \\
(m) \\
(m) \\
(m)\end{array}$ & $\begin{array}{l}(54.9) \\
(220) \\
(330) \\
(330)\end{array}$ & $\begin{array}{l}(54.9) \\
(220) \\
(330) \\
(330)\end{array}$ & $\begin{array}{l}(54.9) \\
(110) \\
(110) \\
(165)\end{array}$ & $\begin{array}{c}(65.8) \\
(197.5)\end{array}$ & $\begin{array}{c}(65.8) \\
(197.5)\end{array}$ & $\begin{array}{c}(65.8) \\
(197.5)\end{array}$ \\
\hline \multicolumn{8}{|l|}{ Roll Width: } \\
\hline Minimum & $\begin{array}{l}\text { in. } \\
\text { in. } \\
(\mathrm{mm})\end{array}$ & $\begin{array}{c}1 / 4 \\
0.25 \\
(6.4)\end{array}$ & $\begin{array}{c}1 / 4 \\
0.25 \\
(6.4)\end{array}$ & $\begin{array}{c}1 / 4 \\
0.25 \\
(6.4)\end{array}$ & $\begin{array}{c}1 / 4 \\
0.25 \\
(6.4)\end{array}$ & $\begin{array}{c}1 / 4 \\
0.25 \\
(6.4)\end{array}$ & $\begin{array}{c}1 / 4 \\
0.25 \\
(6.4)\end{array}$ \\
\hline Maximum & $\begin{array}{l}\text { in. } \\
(\mathrm{mm})\end{array}$ & $\begin{array}{c}60 \\
(1525)\end{array}$ & $\begin{array}{c}60 \\
(1525)\end{array}$ & $\begin{array}{c}60 \\
(1525)\end{array}$ & $\begin{array}{c}46 \\
(1170)\end{array}$ & $\begin{array}{c}46 \\
(1170)\end{array}$ & $\begin{array}{c}46 \\
(1170)\end{array}$ \\
\hline Slitting Tolerance: & $\begin{array}{l}\text { in. } \\
\text { in. } \\
(\mathrm{mm})\end{array}$ & \multicolumn{6}{|c|}{$\begin{array}{l} \pm 1 / 32 \\
\pm 0.031 \\
( \pm 0.8)\end{array}$} \\
\hline
\end{tabular}


$3^{\text {Tu }}$ VHB $^{\text {ru }}$ Double Coated Acrylic Foam

Tapes and Adhesives Transfer Tapes \begin{tabular}{ll}
\hline Typical Physical Properties & $\begin{array}{l}\text { Note: The following technical information and data should be considered } \\
\text { representative or typical only and should not be used for specification purposes. }\end{array}$
\end{tabular}

\begin{tabular}{ccccccccc}
\hline & & & \multicolumn{6}{c}{ Special Feature Tapes } \\
\hline 4949 & 4950 & 4955 & 4959 & 4905 & 4910 & 4925 & 4926 & 4932 \\
\hline VHB Tape & VHB Tape & VHB-Tape & VHB Tape & VHB Tape & VHB Tape & VHB Tape & VHB Tape & VHB Tape \\
\hline $\begin{array}{l}\text { Acrylic Foam } \\
\text { Closed Cell }\end{array}$ & $\begin{array}{c}\text { Acrylic Foam } \\
\text { Closed Cell }\end{array}$ & $\begin{array}{c}\text { Acrylic Foam } \\
\text { Closed Cell }\end{array}$ & $\begin{array}{c}\text { Acrylic Foam } \\
\text { Closed Cell }\end{array}$ & $\begin{array}{c}\text { Acrylic } \\
\text { Closed Cell }\end{array}$ & $\begin{array}{c}\text { Acrylic } \\
\text { Closed Cell }\end{array}$ & $\begin{array}{c}\text { Acrylic Foam } \\
\text { Closed Cell }\end{array}$ & $\begin{array}{c}\text { Acrylic Foam } \\
\text { Closed Cell }\end{array}$ & $\begin{array}{c}\text { Acrylic Foam Closed Cell } \\
\text { Closed }\end{array}$ \\
\hline
\end{tabular}

\begin{tabular}{|c|c|c|c|c|c|c|c|c|}
\hline $\begin{array}{l}0.045 \\
(1.1)\end{array}$ & $\begin{array}{l}0.045 \\
(1.1)\end{array}$ & $\begin{array}{l}0.080 \\
(2.0)\end{array}$ & $\begin{array}{l}0.120 \\
(3.0)\end{array}$ & $\begin{array}{l}0.020 \\
(0.5)\end{array}$ & $\begin{array}{l}0.040 \\
(1.0)\end{array}$ & $\begin{array}{l}0.025 \\
(0.64)\end{array}$ & $\begin{array}{l}0.015 \\
(0.40)\end{array}$ & $\begin{array}{l}0.025 \\
(0.64)\end{array}$ \\
\hline $\pm 10 \%$ & $\pm 10 \%$ & $\pm 10 \%$ & $\pm 10 \%$ & $\pm 10 \%$ & $\pm 10 \%$ & $\pm 15 \%$ & $\pm 15 \%$ & $\pm 15 \%$ \\
\hline Black & White & White & White & Clear & Clear & Lt. Gray & Gray & White \\
\hline $\begin{array}{c}0.002 \\
(0.08) \\
\text { Clear } \\
\text { Polyester }\end{array}$ & $\begin{array}{l}0.003 \\
(0.08) \\
\text { Printed } \\
\text { Paper }\end{array}$ & $\begin{array}{c}0.002 \\
(0.05) \\
\text { Clear } \\
\text { Polyester }\end{array}$ & $\begin{array}{c}0.002 \\
(0.05) \\
\text { Clear } \\
\text { Polyester }\end{array}$ & $\begin{array}{c}0.005 \\
(0.125) \\
\text { Red Poly- } \\
\text { ethylene }\end{array}$ & $\begin{array}{c}0.005 \\
(0.125) \\
\text { Red Poly- } \\
\text { ethylene }\end{array}$ & $\begin{array}{c}0.002 \\
(0.05) \\
\text { Clear } \\
\text { Polyester }\end{array}$ & $\begin{array}{l}0.003^{\circ} \\
(0.08) \\
\text { Printed } \\
\text { Paper }\end{array}$ & $\begin{array}{l}0.003 \\
(0.08) \\
\text { Prited } \\
\text { Paper }\end{array}$ \\
\hline $\begin{array}{c}50 \\
(800)\end{array}$ & $\begin{array}{c}50 \\
(800)\end{array}$ & $\begin{array}{c}45 \\
(720)\end{array}$ & $\begin{array}{c}45 \\
(720)\end{array}$ & $\begin{array}{c}60 \\
(960)\end{array}$ & $\begin{array}{c}60 \\
(960)\end{array}$ & $\begin{array}{c}50 \\
(800)\end{array}$ & $\begin{array}{c}45 \\
(720)\end{array}$ & $\begin{array}{c}50 \\
(800)\end{array}$ \\
\hline $\begin{array}{c}36 \\
(32.9)\end{array}$ & $\begin{array}{c}36 \\
(32.9)\end{array}$ & $\begin{array}{c}36 \\
(32.9)\end{array}$ & $\begin{array}{c}36 \\
(32.9)\end{array}$ & $\begin{array}{c}72 \\
(65.8)\end{array}$ & $\begin{array}{c}36 \\
(32.9)\end{array}$ & $\begin{array}{c}72 \\
(65.8)\end{array}$ & $\begin{array}{c}72 \\
(65.8)\end{array}$ & $\begin{array}{c}72 \\
(65.8)\end{array}$ \\
\hline $\begin{array}{l}72 \\
144\end{array}$ & $\begin{array}{l}72 \\
144\end{array}$ & $\begin{array}{l}36 \\
72\end{array}$ & $\begin{array}{l}36 \\
60\end{array}$ & $\begin{array}{l}72 \\
216\end{array}$ & $\begin{array}{c}72 \\
144\end{array}$ & $\begin{array}{c}72 \\
216\end{array}$ & $\begin{array}{c}72 \\
216\end{array}$ & $\begin{array}{l}72 \\
216\end{array}$ \\
\hline $\begin{array}{r}(65.8) \\
(131.6)\end{array}$ & $\begin{array}{l}(65.8) \\
(131.6)\end{array}$ & $\begin{array}{l}(32.9) \\
(65.8)\end{array}$ & $\begin{array}{l}(32.9) \\
(54.9)\end{array}$ & $\begin{array}{c}(65.8) \\
(197.5)\end{array}$ & $\begin{array}{c}(65.8) \\
(131.6)\end{array}$ & $\begin{array}{l}(65.8) \\
(197.5)\end{array}$ & $\begin{array}{r}(65.8) \\
(197.5)\end{array}$ & $\begin{array}{r}\text { (65.8) } \\
\text { (197.5) }\end{array}$ \\
\hline $\begin{array}{c}1 / 4 \\
0.25 \\
(6.4)\end{array}$ & $\begin{array}{c}1 / 4 \\
0.25 \\
(6.4)\end{array}$ & $\begin{array}{c}1 / 4 \\
0.25 \\
(6.4)\end{array}$ & $\begin{array}{c}1 / 2 \\
0.5 \\
(12.7)\end{array}$ & $\begin{array}{c}1 / 4 \\
0.25 \\
(6.4)\end{array}$ & $\begin{array}{c}1 / 4 \\
0.25 \\
(6.4)\end{array}$ & $\begin{array}{c}1 / 4 \\
0.25 \\
(6.4)\end{array}$ & $\begin{array}{c}1 / 4 \\
0.25 \\
\langle 6.4)\end{array}$ & $\begin{array}{c}1 / 4 \\
0.25 \\
(6.4)\end{array}$ \\
\hline \multirow[t]{2}{*}{$\begin{array}{c}46 \\
(1170)\end{array}$} & $\begin{array}{c}46 \\
(1170)\end{array}$ & $\begin{array}{c}46 \\
(1170)\end{array}$ & $\begin{array}{c}46 \\
(1170)\end{array}$ & $\begin{array}{c}46 \\
(1170)\end{array}$ & $\begin{array}{c}46 \\
(1170)\end{array}$ & $\begin{array}{c}46 \\
(1170)\end{array}$ & $\begin{array}{c}46 \\
(1170)\end{array}$ & $\begin{array}{c}46 \\
(1170)\end{array}$ \\
\hline & & & & $\begin{array}{c} \pm 1 / 32 \\
\pm 0.031 \\
\pm 0.8\end{array}$ & & & & \\
\hline
\end{tabular}

'Release Liner for tapes 4936F, 4941F and 4956F = 0.005 in $(0.125 \mathrm{~mm})$ Natural PE Film 


\section{M $M^{\mathrm{M}}$ VHB $^{\mathrm{m}}$ Double Coated Acrylic Foam \\ Tapes and Adhesives Transfer Tapes}

\begin{tabular}{ll}
\hline Typical Physical Properties & $\begin{array}{l}\text { Note: The following technical information and data should be considered } \\
\text { representative or typical only and should not be used for specification purposes. }\end{array}$
\end{tabular}

Special Feature Tapes

\begin{tabular}{|c|c|c|c|c|c|c|c|c|c|c|}
\hline $4936,4936 \mathrm{~F}$ & 4940 & $4941,4941 F^{\prime}$ & $4943 F$ & 4945 & $4946 \mathrm{~F}$ & 4951 & 4952 & $4956,4956 F^{*}$ & $4957 \mathrm{~F}$ & 4979F \\
\hline VHB Tape & VHB Tape & VHB Tape & VIB Tape & VHB Tape & VHB Tape & VHB Tape & VHB Tape & VHB Tape & VHB Tape & VHB Tape \\
\hline $\begin{array}{l}\text { Acrylic Foam } \\
\text { Closed Cell }\end{array}$ & $\begin{array}{l}\text { Acrylic Foam } \\
\text { Closed Cell }\end{array}$ & $\begin{array}{l}\text { Acrylic Foam } \\
\text { Closed Cell }\end{array}$ & $\begin{array}{l}\text { Acrylic Foam } \\
\text { Closed Cell }\end{array}$ & $\begin{array}{l}\text { Acrylic Foam } \\
\text { Closed Cell }\end{array}$ & $\begin{array}{l}\text { Acrylic Foam } \\
\text { Closed Cell }\end{array}$ & $\begin{array}{l}\text { Acrylic Foam } \\
\text { Closed Cell }\end{array}$ & $\begin{array}{l}\text { Acryic Foam } \\
\text { Closed Cell }\end{array}$ & $\begin{array}{l}\text { Acrylic Foam } \\
\text { Closed Cell }\end{array}$ & $\begin{array}{l}\text { Acrylic foam } \\
\text { Closed Cell }\end{array}$ & $\begin{array}{l}\text { Acrylic Foam } \\
\text { Closed Cell }\end{array}$ \\
\hline $\begin{array}{l}0.025 \\
(0.64)\end{array}$ & $\begin{array}{l}0.045 \\
(1.1)\end{array}$ & $\begin{array}{l}0.045 \\
(1.1)\end{array}$ & $\begin{array}{l}0.045 \\
(1.1)\end{array}$ & $\begin{array}{l}0.045 \\
(1.1)\end{array}$ & $\begin{array}{l}0.045 \\
(1.1)\end{array}$ & $\begin{array}{l}0.045 \\
(1.1)\end{array}$ & $\begin{array}{l}0.045 \\
(1.1)\end{array}$ & $\begin{array}{l}0.062 \\
(1.55)\end{array}$ & $\begin{array}{l}0.062 \\
(1.55)\end{array}$ & $\begin{array}{l}0.062 \\
(1.55)\end{array}$ \\
\hline $\pm 15 \%$ & $\pm 15 \%$ & $\pm 15 \%$ & $\pm 10 \%$ & $\pm 10 \%$ & $\pm 10 \%$ & $\pm 10 \%$ & $\pm 10 \%$ & $\pm 10 \%$ & $\pm 10 \%$ & $\pm 10 \%$ \\
\hline Gray & Lt. Gray & Gray & Gray & White & White & White & White & Gray & Gray & Black \\
\hline $\begin{array}{l}0.003^{*} \\
(0.08) \\
\text { Printed } \\
\text { Paper }\end{array}$ & $\begin{array}{c}0.002 \\
(0.05) \\
\text { Clear } \\
\text { Polyester }\end{array}$ & $\begin{array}{l}0.003 * \\
(0.08) \\
\text { Printed } \\
\text { Paper }\end{array}$ & $\begin{array}{l}0.005 \\
(0.125) \\
\text { Natural } \\
\text { PE Film }\end{array}$ & $\begin{array}{l}0.003 \\
(0.08) \\
\text { Printed } \\
\text { Paper }\end{array}$ & $\begin{array}{c}0.005 \\
(0.125) \\
\text { Natural } \\
\text { PE Film }\end{array}$ & $\begin{array}{c}0.002 \\
(0.05) \\
\text { Clear } \\
\text { Polyester }\end{array}$ & $\begin{array}{l}0.003 \\
(0.08) \\
\text { Printed } \\
\text { Paper }\end{array}$ & $\begin{array}{l}0.003^{*} \\
\text { (0.08) } \\
\text { Printed } \\
\text { Paper }\end{array}$ & $\begin{array}{l}0.005 \\
(0.125) \\
\text { Natural } \\
\text { PE Fllm }\end{array}$ & $\begin{array}{c}0.005 \\
(0.08) \\
\text { Red } \\
\text { PE Film }\end{array}$ \\
\hline $\begin{array}{c}45 \\
(720)\end{array}$ & $\begin{array}{c}50 \\
(800)\end{array}$ & $\begin{array}{c}45 \\
(720)\end{array}$ & $\begin{array}{c}45 \\
(720)\end{array}$ & $\begin{array}{c}50 \\
(800)\end{array}$ & $\begin{array}{c}50 \\
(800)\end{array}$ & $\begin{array}{c}50 \\
(800)\end{array}$ & $\begin{array}{c}50 \\
(800)\end{array}$ & $\begin{array}{c}45 \\
(720)\end{array}$ & $\begin{array}{c}45 \\
(720)\end{array}$ & $\begin{array}{c}45 \\
(720)\end{array}$ \\
\hline $\begin{array}{c}72 \\
(65.8)\end{array}$ & $\begin{array}{c}36 \\
(32.9)\end{array}$ & $\begin{array}{c}36 \\
(32.9)\end{array}$ & $\begin{array}{c}36 \\
(32.9)\end{array}$ & $\begin{array}{c}36 \\
(32.9)\end{array}$ & $\begin{array}{c}36 \\
(32.9)\end{array}$ & $\begin{array}{c}36 \\
(32.9)\end{array}$ & $\begin{array}{c}36 \\
(32.9)\end{array}$ & $\begin{array}{c}36 \\
(32.9)\end{array}$ & $\begin{array}{c}36 \\
(32.9)\end{array}$ & $\begin{array}{c}36 \\
(32.9)\end{array}$ \\
\hline $\begin{array}{c}72 \\
216\end{array}$ & $\begin{array}{l}72 \\
144\end{array}$ & $\begin{array}{l}72 \\
144\end{array}$ & $\begin{array}{l}72 \\
144\end{array}$ & $\begin{array}{l}72 \\
144\end{array}$ & $\begin{array}{l}72 \\
144\end{array}$ & $\begin{array}{l}72 \\
144\end{array}$ & $\begin{array}{l}72 \\
144\end{array}$ & $\begin{array}{c}72 \\
144\end{array}$ & $\begin{array}{l}72 \\
144\end{array}$ & $\begin{array}{l}72 \\
144\end{array}$ \\
\hline $\begin{array}{l}(65.8) \\
(197.5)\end{array}$ & $\begin{array}{l}(65.8) \\
(131.6)\end{array}$ & $\begin{array}{l}(65.8) \\
(131.6)\end{array}$ & $\begin{array}{l}(65.8 \\
(131.6)\end{array}$ & $\begin{array}{l}(65.8) \\
(131.6)\end{array}$ & $\begin{array}{l}(65.8) \\
(131.6)\end{array}$ & $\begin{array}{l}(65.8) \\
(131.6)\end{array}$ & $\begin{array}{l}(65.8) \\
(131.6)\end{array}$ & $\begin{array}{l}(65.8) \\
(131.6)\end{array}$ & $\begin{array}{l}(65.8) \\
(131.6)\end{array}$ & $\begin{array}{l}(65.8) \\
(131.6)\end{array}$ \\
\hline $\begin{array}{c}1 / 4 \\
0.25 \\
(6.4)\end{array}$ & $\begin{array}{c}1 / 4 \\
0.25 \\
(6.4)\end{array}$ & $\begin{array}{c}1 / 4 \\
0.25 \\
(6.4)\end{array}$ & $\begin{array}{c}1 / 4 \\
0.25 \\
(6.4)\end{array}$ & $\begin{array}{c}1 / 4 \\
0.25 \\
(6.4)\end{array}$ & $\begin{array}{c}1 / 4 \\
0.25 \\
(6.4)\end{array}$ & $\begin{array}{c}1 / 4 \\
0.25 \\
(6.4)\end{array}$ & $\begin{array}{l}1 / 4 \\
0.25 \\
(6.4)\end{array}$ & $\begin{array}{l}1 / 4 \\
0.25 \\
\langle 6.4\rangle\end{array}$ & $\begin{array}{l}1 / 4 \\
0.25 \\
(6.4)\end{array}$ & $\begin{array}{c}1 / 4 \\
0.25 \\
(6.4)\end{array}$ \\
\hline $\begin{array}{c}46 \\
(1170)\end{array}$ & $\begin{array}{c}46 \\
(1170)\end{array}$ & $\begin{array}{c}46 \\
(1170)\end{array}$ & $\begin{array}{c}46 \\
(1170)\end{array}$ & $\begin{array}{c}46 \\
(1170)\end{array}$ & $\begin{array}{c}46 \\
(1170)\end{array}$ & $\begin{array}{c}46 \\
(1170)\end{array}$ & $\begin{array}{c}46 \\
(1170)\end{array}$ & $\begin{array}{c}46 \\
(1170)\end{array}$ & $\begin{array}{c}46 \\
(1170)\end{array}$ & $\begin{array}{c}46 \\
(1170)\end{array}$ \\
\hline \multicolumn{11}{|c|}{$\begin{array}{c} \pm 1 / 32 \\
\pm 0.031 \\
( \pm 0.8)\end{array}$} \\
\hline
\end{tabular}

'Release Liner for tapes 4936F and 4941F $=0.005$ in $(0.125 \mathrm{~mm})$ Natural PE Film

(3) 
3M $M^{\text {m }}$ VHB $^{\text {mu }}$ Double Coated Acrylic Foam

Tapes and Adhesives Transfer Tapes

\begin{tabular}{|c|c|c|c|c|c|c|c|}
\hline \multirow{2}{*}{$\begin{array}{l}\text { Typical Performance } \\
\text { Characteristics } \\
\text { Products }\end{array}$} & \multicolumn{7}{|c|}{$\begin{array}{l}\text { Note: The following technical information and data should be considered } \\
\text { representative or typical only and should not be used for specification purposes. } \\
\text { Primary Tapes }\end{array}$} \\
\hline & & F-9460PC & F-9469PC & F-9473PC & 4920 & 4929 & 4930 \\
\hline \multicolumn{2}{|c|}{ 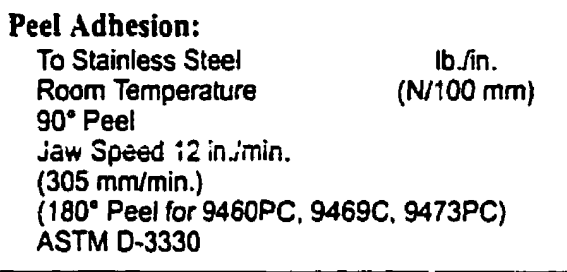 } & $\begin{array}{c}7 \\
(120)\end{array}$ & $\begin{array}{c}8 \\
(140)\end{array}$ & $\stackrel{9}{(160)}$ & $\begin{array}{c}15 \\
(260)\end{array}$ & $\begin{array}{c}20 \\
(350)\end{array}$ & $\begin{array}{c}20 \\
(350)\end{array}$ \\
\hline \multicolumn{2}{|l|}{$\begin{array}{l}\text { Normal Tensile: } \\
\text { (T-block) } \\
\text { To Aluminum } \\
\text { Room Temperature } \\
1 \text { in. }{ }^{2}\left(6.45 \mathrm{~cm}^{2}\right) \\
\text { Jaw Speed } 2 \text { in./min. } \\
\text { (50 mm/min.) ASTM D-897 }\end{array}$} & $\begin{array}{l}\text { 100" } \\
(690) \\
\text { 'Note: Te } \\
w\end{array}$ & $\begin{array}{c}100^{\circ} \\
(690) \\
\text { sile is highly } \\
\text { th can be diff }\end{array}$ & $\begin{array}{l}100^{\circ} \\
(690) \\
\text { gendent on g } \\
\text { It on rigid sur }\end{array}$ & $\begin{array}{l}160 \\
(1100) \\
\text { surface } c \\
\text { s with thit }\end{array}$ & $\begin{array}{c}160 \\
(1100)\end{array}$ & $\begin{array}{c}160 \\
(1100)\end{array}$ \\
\hline \multicolumn{2}{|l|}{$\begin{array}{l}\text { Static Shear: } \\
\text { Static Shear measured } \\
\text { at various temperatures } \\
\text { and gram loadings on } \\
\text { stainless steel. } 1 / 2 \mathrm{sq} \text {. in. } \\
\left(3.22 \mathrm{~cm}^{2}\right) \text { overlap. Will } \\
\text { hold listed weight for } \\
10.000 \text { min. ASTM D-3654 }\end{array}$} & $\begin{array}{r}1000 \\
1000 \\
1000 \\
1000 \\
500 \\
500\end{array}$ & $\begin{array}{r}1000 \\
1000 \\
1000 \\
1000 \\
500 \\
500\end{array}$ & $\begin{array}{r}1500 \\
1000 \\
1000 \\
1000 \\
1000 \\
500\end{array}$ & $\begin{array}{r}1500 \\
500 \\
500\end{array}$ & $\begin{array}{r}1500 \\
500 \\
500\end{array}$ & $\begin{array}{r}1500 \\
500 \\
500\end{array}$ \\
\hline \multicolumn{2}{|l|}{$\begin{array}{l}\text { Dynamic Shear: } \\
\text { To Stainless Steel } \\
1 \text { sq. in. }\left(6.45 \mathrm{~cm}^{2}\right) \text { overlap. } \\
\text { Room Temperature } \\
\text { Jaw Speed } 1 / 2 \text { in./min. } \\
\text { (12.7 mm/min.) ASTM D-1002 }\end{array}$} & $\begin{array}{l}80^{\circ} \\
(550) \\
\text { Note: D }\end{array}$ & $\begin{array}{l}80^{\circ} \\
(550) \\
\text { amic shear is } \\
\text { ch can be diff }\end{array}$ & $\begin{array}{l}80^{\circ} \\
(550) \\
\text { ighly depend }\end{array}$ & $\begin{array}{l}100 \\
(690) \\
\text { In good s } \\
\text { s with thi }\end{array}$ & $\begin{array}{l}100 \\
(690) \\
\text { contact } \\
\text { s. }\end{array}$ & $\begin{array}{c}100 \\
(690)\end{array}$ \\
\hline $\begin{array}{l}\text { Temperature Tolerance: } \\
\text { Short-Term } \\
\text { No change in room temperat } \\
\text { dynamic shear properties fol } \\
4 \text { hour conditioning at indica } \\
\text { temperature with } 100 \mathrm{~g} \text { static }\end{array}$ & $\begin{array}{l}\text { "F } \\
\text { ure } \\
\text { owing } \\
\text { ed } \\
\text { load }\end{array}$ & $\begin{array}{c}500 \\
(260)\end{array}$ & $\begin{array}{c}500 \\
(260)\end{array}$ & $\begin{array}{c}500 \\
(260)\end{array}$ & $\begin{array}{c}300 \\
(149)\end{array}$ & $\begin{array}{c}300 \\
(149)\end{array}$ & $\begin{array}{c}300 \\
(149)\end{array}$ \\
\hline $\begin{array}{l}\text { Temperature Tolerance: } \\
\text { Long-Term } \\
\text { Maximum temperature wher } \\
\text { tape supports } 250 \mathrm{~g} \text { in static } \\
\text { shear for } 10,000 \text { minutes. }\end{array}$ & $\begin{array}{l}{ }^{\circ} \mathrm{F} \\
{ }^{\circ} \mathrm{C}\end{array}$ & $\begin{array}{c}300 \\
(149)\end{array}$ & $\begin{array}{c}300 \\
(149)\end{array}$ & $\begin{array}{c}300 \\
(149)\end{array}$ & $\begin{array}{l}200 \\
(93)\end{array}$ & $\begin{array}{l}200 \\
(93)\end{array}$ & $\begin{array}{l}200 \\
(93)\end{array}$ \\
\hline \multicolumn{2}{|c|}{$\begin{array}{l}\text { Solvent Resistance: } \\
\text { Splash testing cycle }-20 \text { seconds } \\
\text { submersion, } 20 \text { sec. airdry, } 3 \text { cycles }\end{array}$} & \multicolumn{6}{|c|}{$\begin{array}{l}\text { No apparent degradation of any VHB Tapes when exposed ta splash testing of many - } \\
\text { common solvents, and fuels, including gasoline, JP-4 [et fuel, mineral spirts, motor oil, } \\
\text { ammonia cleaner, acetone, methyl ethyl ketone (MEK). }\end{array}$} \\
\hline \multicolumn{2}{|l|}{$\begin{array}{l}\text { Moisture Resistance: } \\
10 \text { years submersion in water. } \\
5 \% \text { salt water }\end{array}$} & \multicolumn{6}{|c|}{$\begin{array}{l}\text { Integrity of tape bond to aluminum for tapes } 4945 \text { and } 4950 \text { (also expected for other VHB } \\
\text { Tapes) remains excellent after } 10 \text { years submersion in water and salt water. Note: Continuous } \\
\text { submersion in liquids is not recommended and this information is provided to illustrate that } \\
\text { occasional contact with liquids should not be detrimental to tape performance in ordinary use. }\end{array}$} \\
\hline \multicolumn{2}{|l|}{ U.V. Resistance: } & \multicolumn{6}{|c|}{$\begin{array}{l}\text { This family of tapes has shown excellent U.V. resistance in outdoor weathering tests } \\
\text { and weather - - meter tests. }\end{array}$} \\
\hline \multicolumn{2}{|l|}{ Shelf Life: } & \multicolumn{6}{|c|}{$\begin{array}{l}24 \text { months from date of manufacture when stored in original cartons at } 70^{\circ} \mathrm{F}\left(21^{\circ} \mathrm{C}\right) \text { and } \\
50 \% \text { relative humidity. }\end{array}$} \\
\hline
\end{tabular}




\section{Tapes and Adhesives Transfer Tapes}

\begin{tabular}{|c|c|c|c|c|c|c|c|c|}
\hline \multirow{2}{*}{\multicolumn{2}{|c|}{$\begin{array}{l}\text { Typical Performance } \\
\text { Characteristics }\end{array}$}} & & \multicolumn{6}{|c|}{$\begin{array}{l}\text { Note: The following technical information and data should be considered } \\
\text { representative or typical only and should not be used for specification purposes. }\end{array}$} \\
\hline & & & $\longrightarrow$ Thick & \multicolumn{5}{|c|}{ Special Feature Tapes } \\
\hline 4949 & 4950 & 4955 & 4959 & 4905 & 4910 & 4925 & 4926 & 4932 \\
\hline $\begin{array}{c}25 \\
(440)\end{array}$ & $\begin{array}{c}25 \\
(440)\end{array}$ & $\begin{array}{c}20 \\
(350)\end{array}$ & $\begin{array}{c}20 \\
(350)\end{array}$ & $\begin{array}{c}12 \\
(210)\end{array}$ & $\begin{array}{c}15 \\
(260)\end{array}$ & $\begin{array}{c}17 \\
(300)\end{array}$ & $\begin{array}{c}12 \\
(210)\end{array}$ & $\begin{array}{c}20 \\
(350)\end{array}$ \\
\hline
\end{tabular}

$\begin{array}{ccccccccc}140 & 140 & 95 & 75 & 100 & 100 & 75 & 95 & 100 \\ (970) & (970) & (655) & (515) & (690) & (690) & (515) & (655) & (690)\end{array}$

\begin{tabular}{|c|c|c|c|c|c|c|c|c|}
\hline $\begin{array}{r}1500 \\
500 \\
500\end{array}$ & $\begin{array}{r}\mathbf{1 5 0 0} \\
\mathbf{5 0 0} \\
\mathbf{5 0 0}\end{array}$ & $\begin{array}{r}1500 \\
1000 \\
750 \\
750 \\
750 \\
750\end{array}$ & $\begin{array}{r}1500 \\
1000 \\
750 \\
750 \\
750 \\
750\end{array}$ & $\begin{array}{r}1000 \\
500 \\
500\end{array}$ & $\begin{array}{r}1000 \\
500 \\
500\end{array}$ & $\begin{array}{r}1000 \\
500 \\
500\end{array}$ & $\begin{array}{r}1000 \\
500 \\
500\end{array}$ & $\begin{array}{r}1500 \\
500\end{array}$ \\
\hline $\begin{array}{c}80 \\
(550)\end{array}$ & $\begin{array}{c}80 \\
(550)\end{array}$ & $\begin{array}{c}70 \\
(480)\end{array}$ & $\begin{array}{c}55 \\
(380)\end{array}$ & $\begin{array}{c}70 \\
(480)\end{array}$ & $\begin{array}{c}70 \\
(480)\end{array}$ & $\begin{array}{c}75 \\
(515)\end{array}$ & $\begin{array}{c}90 \\
(590)\end{array}$ & $\begin{array}{c}100 \\
(690)\end{array}$ \\
\hline $\begin{array}{c}300 \\
(149)\end{array}$ & $\begin{array}{c}300 \\
(149)\end{array}$ & $\begin{array}{c}400 \\
(204)\end{array}$ & $\begin{array}{c}400 \\
(204)\end{array}$ & $\begin{array}{c}300 \\
(149)\end{array}$ & $\begin{array}{c}300 \\
(149)\end{array}$ & $\begin{array}{c}300 \\
(149)\end{array}$ & $\begin{array}{c}300 \\
(149)\end{array}$ & $\begin{array}{l}200 \\
(93)\end{array}$ \\
\hline $\begin{array}{l}200 \\
(93)\end{array}$ & $\begin{array}{l}200 \\
(93)\end{array}$ & $\begin{array}{c}300 \\
(149)\end{array}$ & $\begin{array}{c}300 \\
(149)\end{array}$ & $\begin{array}{l}200 \\
(93)\end{array}$ & $\begin{array}{l}200 \\
(93)\end{array}$ & $\begin{array}{l}200 \\
(93)\end{array}$ & $\begin{array}{l}200 \\
(93)\end{array}$ & $\begin{array}{l}160 \\
(71)\end{array}$ \\
\hline
\end{tabular}

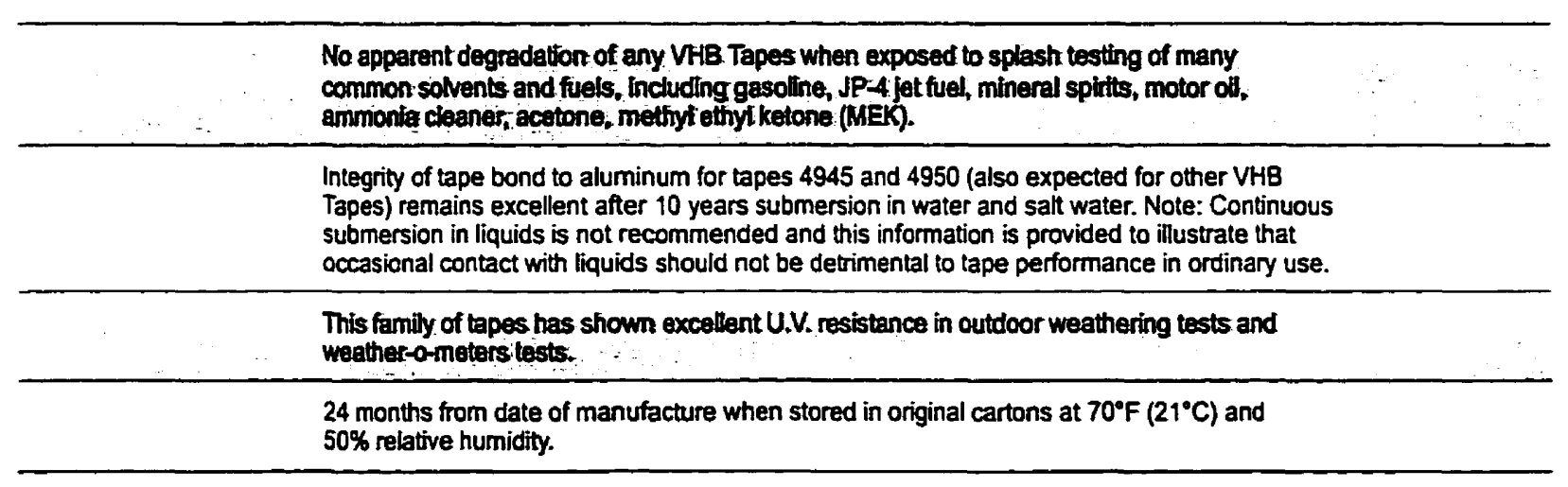




\section{$3_{M^{m}}$ VHB $^{\text {nu }}$ Double Coated Acrylic Foam Tapes and Adhesives Transfer Tapes}

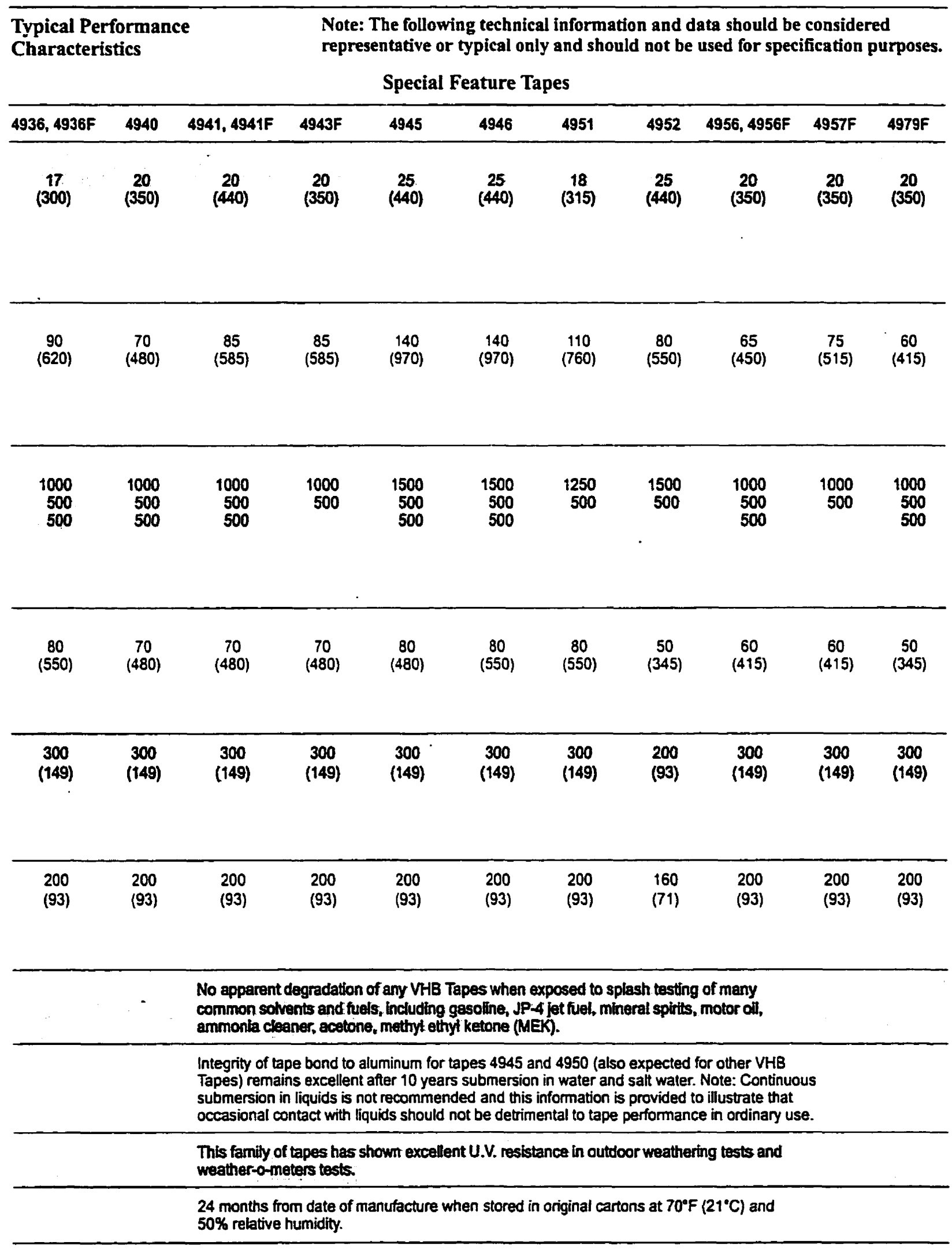




\section{Tapes and Adhesives Transfer Tapes}

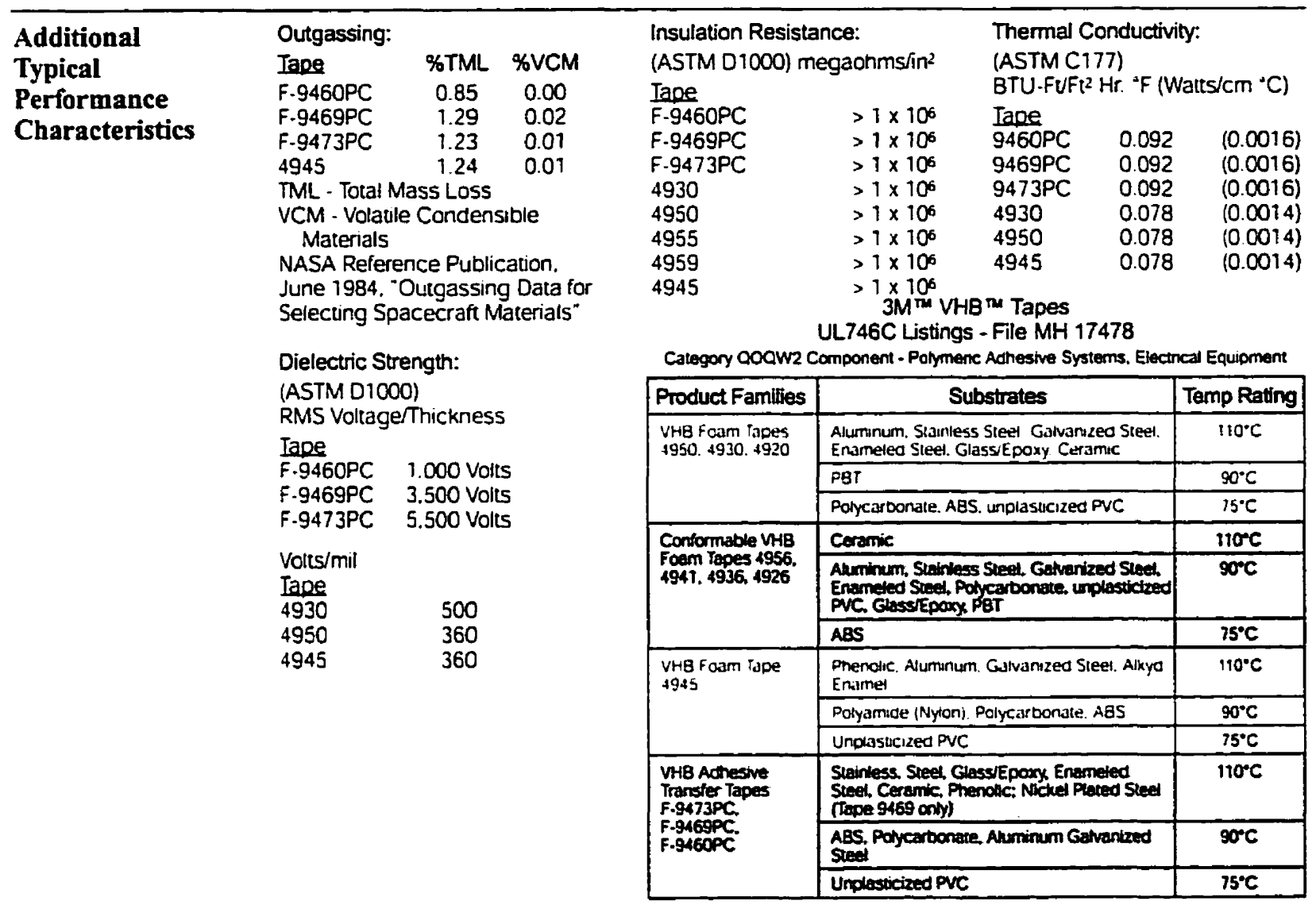

\section{Typical VHB Tape Properties for Modeling}

\author{
Thermal Coefficient \\ of Expansion \\ $1 \times 10^{.4} 1 \mathrm{n} / \mathrm{in} /{ }^{\circ} \mathrm{F}$ \\ $1.8 \times 10^{.4} \mathrm{~mm} / \mathrm{mm} /{ }^{\circ} \mathrm{C}$ \\ Young's Modulus $\left(25^{\circ} \mathrm{C}, 1 \mathrm{~Hz}\right)$ \\ (freq. and temp. dependent) \\ $5 \times 10^{3} \mathrm{kPa}$ \\ Poisson's Ratio \\ 0.5
}

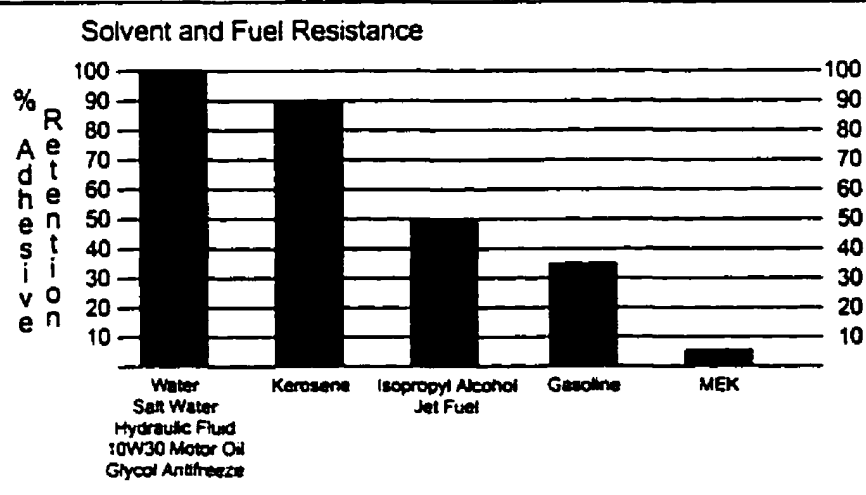

Test Method

- Tape between stainless steel and aluminum foil.

- 72 hours dwell at room temperature.

- Solvent immersion for 72 hours.

- Test within 45 minutes after removing from solvent

- $90^{\circ}$ peel for foam tapes. $180^{\circ}$ peel for transfer adhesives.

- 12 in./min. rate of peel.

- Peel adhesion compared to control.

Note: Continuous submersion in chemical solutions is not recommended. The above information is presented to illustrate that occasional chemical contact should not be detrimental to tape performance in most applications in ordinary use. 


\section{MT $^{\mathrm{TM}}$ VHB $^{\mathrm{TM}}$ Double Coated Acrylic Foam \\ Tapes and Adhesives Transfer Tapes}

\author{
Adhesion to a \\ Variety of Surfaces
}

\section{The Effect of Surface Energy on Adhesion}

Adhesion is basically the molecular force of attraction between unlike materials, similar to a magnetic force. The strength of attraction is determined by the surface energy of the material. The higher the surface energy, the greater the molecular attraction - the lower the surface energy, the weaker the attractive forces. Greater molecular attraction results in increased interfacial contact between an adhesive and a substrate. In other words, on a high surface energy material the adhesive can flow (or "wet-out") to assure a stronger bond.

Think of an automobile which has not been waxed for years. When water contacts the surface it spreads in large puddles. By comparison, on a freshly waxed car the water will bead up into small spheres.

The unwaxed car surface demonstrates high surface energy, the molecular attraction allows the water to flow. The waxed car is an example of low surface energy, where the liquid (or adhesive) does not flow-out.

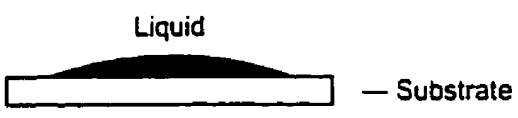

High surface energy

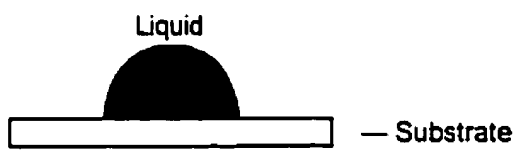

Low surface energy

This illustration demonstrates the effect of surface energy on adhesive interfacial contact. High surface energy materials draw the adhesive closer for high bond strength.

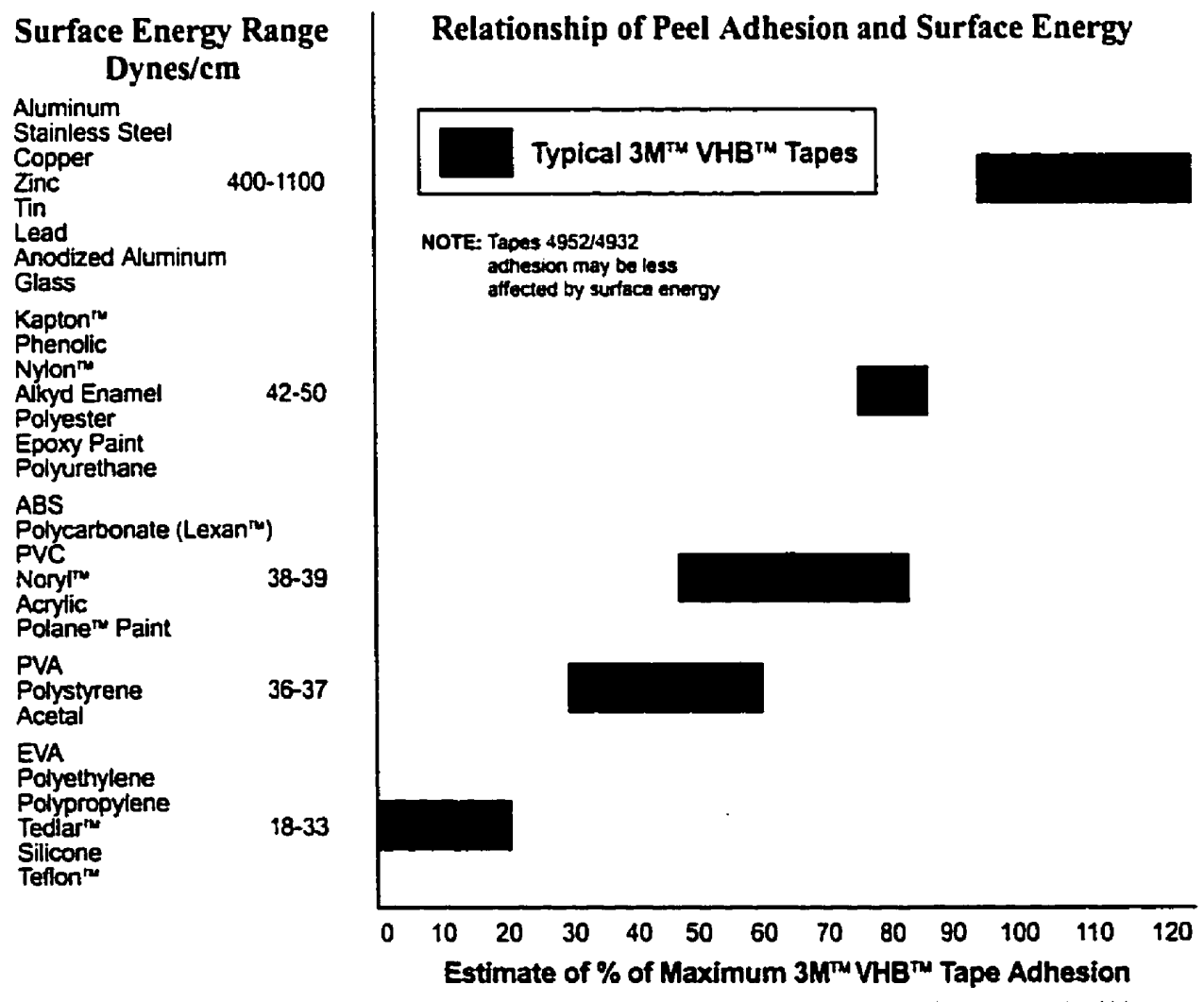

NOTES: There are a wide variefy of formulations, surfaces finishes and surface treatments available on substrate materiats which can affect adhesion. This chart is intended to provide only a rough estimate of the adhesion levelis which can be expected on some common materiats relative to a reference surface such as atuminum.

Light surface abrasion will significanty increase achesion levels on many materials, except when using Tapes 49524932. Kapton. Tedia, Nylon and Tefion are registered trademarks of EJ. Dupent De Nernours \& Ca. Inc

Lexan and Noryl are registered trademarks of General Electric $\mathrm{Co}$.

Potane is a registered trademark of Shenwin Witiams Co. 


\section{Design}

Considerations

\section{- How much tape area to use:}

As a general rule, four square inches of tape should be used for each pound of weight to be supported in static load. More or less tape may be required depending upon the particular application. User evaluation is, therefore, required to determine optimal tape usage.

\section{- Bonding to rigid surfaces}

The necessary thickness of tape depends on the rigidity of substrates, their irregularity, and the amount of application pressure which can be applied to mate the surfaces. The mismatch between surfaces must be less than half of the tape thickness, in conjunction with firm lamination pressure, to establish good surface contact. To iest for surface contaci problems, bond tape to the rigid or irregular surface, then laminate on a test piece of clear acrylic or polycarbonate ( $1 / 4$ " thick), and apply pressure. Observe the bond contact area through the clear substrate.

\section{- How much pressure to apply}

Typically, good surface contact can be attained by applying enough pressure to ensure that the tape experiences approximately $15 \mathrm{psi}(100 \mathrm{kPa})$. Rigid surfaces may require 2 or 3 times that much surface pressure to make the tape experience 15 psi.

\section{- Allow for thermal expansion/contraction and flexibility}

VHB Tapes can perform well in applications where two bonded surfaces may expand and contract differentially. The tapes can typically tolerate differential movement (shear or tensile) up to 3 times their thickness. Tape bonds are more flexible, so suitable design modifications or periodic use of rigid fasteners or adhesives may be needed to achieve required stiffness.

Application

Techniques
- To obtain optimum adhesion, the bonding surfaces must be well unified, clean and dry. Typical surface cleaning solvents are isopropyl alcoho//water mixture (rubbing alcohol) or heptane.

Note: Be sure to follow solvent manufacturer's precautions and directions for use when using solvents. (Steps A and B).

- Bond strength is dependent upon the amount of adhesive-to-surface contact developed. Firm application pressure develops better adhesive contact and helps improve bond strength. (Steps $C$ and D).

- After application, the bond strength will increase as the adhesive flows onto the surface. At room temperature approximately $50 \%$ of the ultimate strength will be achieved after 20 minutes, $90 \%$ after 24 hours and $100 \%$ after 72 hours. In some cases bond strength can be increased and ultimate bond strength can be achieved more quickly by exposure of the bond to elevated temperatures (e.g. $150^{\circ} \mathrm{F}$ $\left(66^{\circ} \mathrm{C}\right)$ for 1 hour). This provides better adhesive wetout onto the substrates.
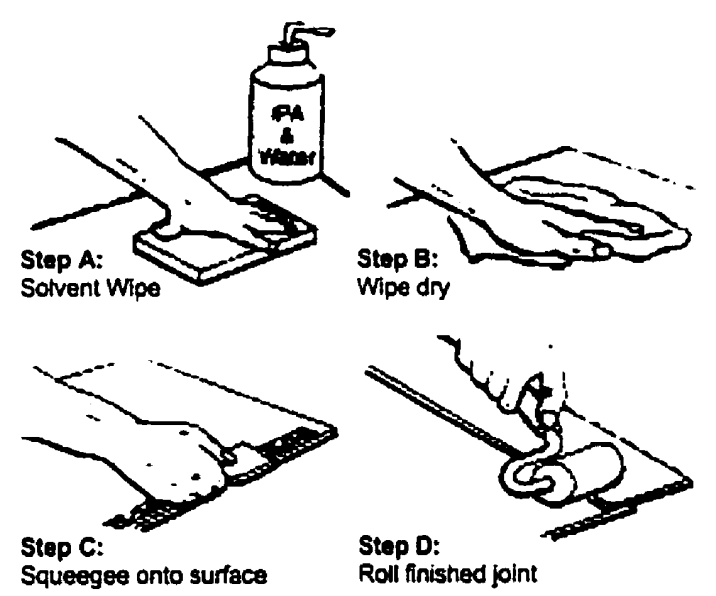

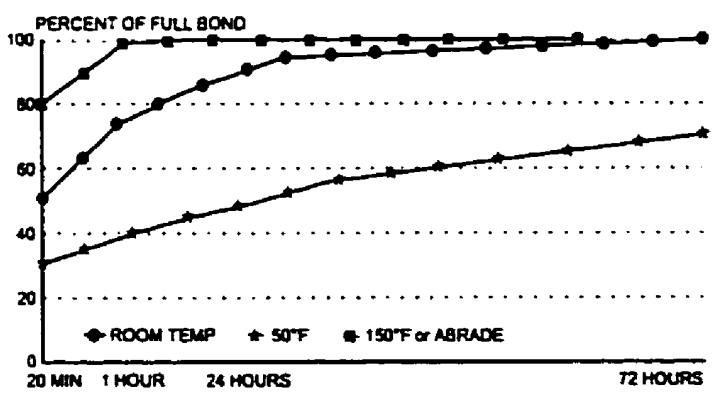




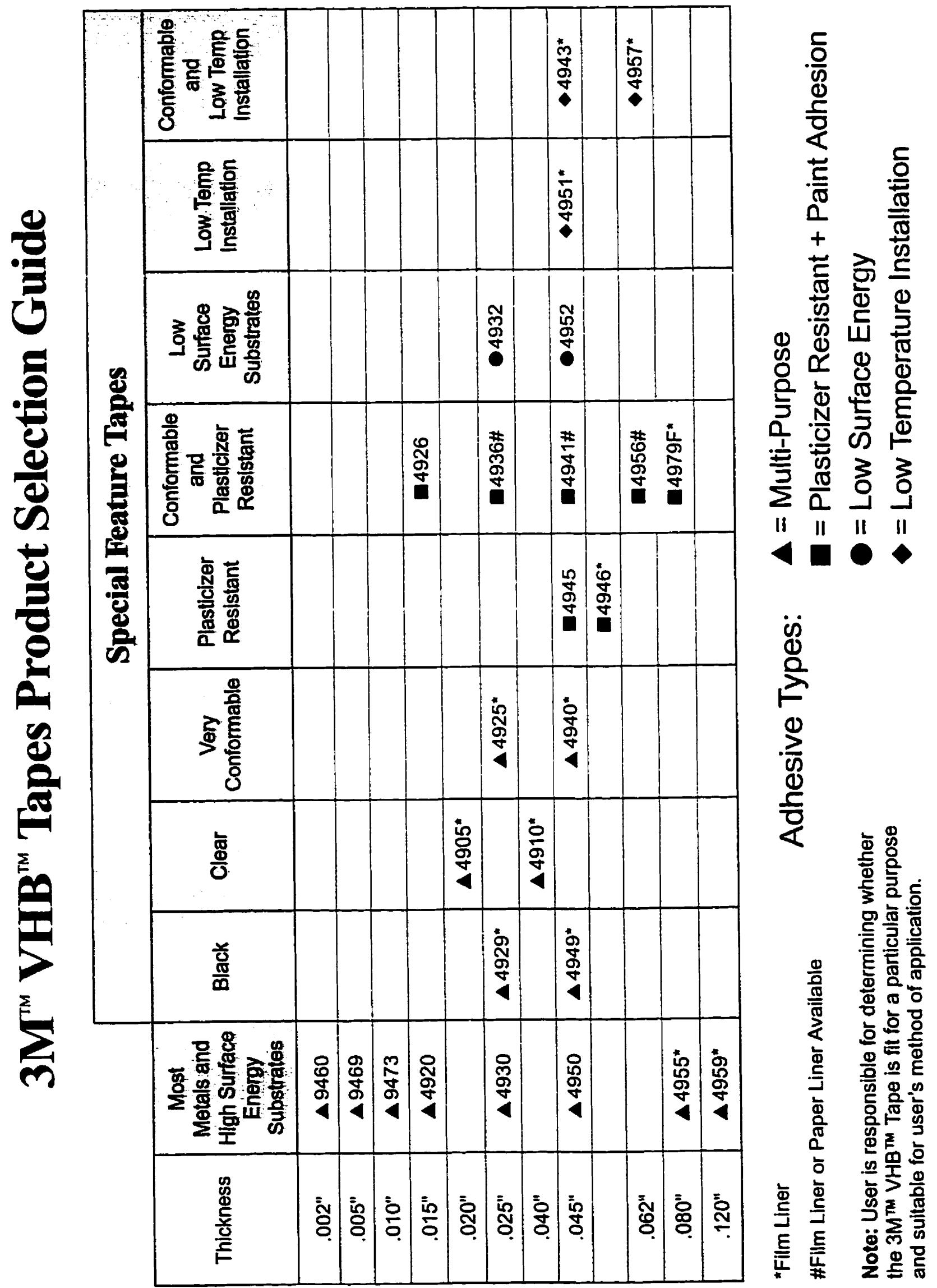


Application

Techniques
1. Ideal tape application temperature range is $70^{\circ} \mathrm{F}$ to $100^{\circ} \mathrm{F}\left(21^{\circ} \mathrm{C}\right.$ to $\left.38^{\circ} \mathrm{C}\right)$.

Minimum suggested application temperatures:

$50^{\circ} \mathrm{F}\left(10^{\circ} \mathrm{C}\right)$ - tapes F-9460PC, F-9469PC, F-9473PC, 4905, 4910, 4920, 4925 , $4929,4930,4932,4940,4949,4950,4952,4955,4959$

$60^{\circ} \mathrm{F}\left(16^{\circ} \mathrm{C}\right)$ - tapes 4926, 4936, 4936F, 4941, 4941F, 4945, 4946, 4956, 4956F, 4979F

$32^{\circ}\left(0^{\circ} \mathrm{C}\right)$ - tapes $4943 \mathrm{~F}, 4951,4957 \mathrm{~F}$

Note: Initial tape application to surfaces at temperatures below these suggested minimums is not recommended because the adhesive becomes too firm to adhere readily. However, once properly applied, low temperature holding is generally satisfactory.

To obtain good performance with all tapes VHB it is important to ensure that the surfaces are dry and free of condensed moisture.

2. It may be necessary to seal or prime some substrates prior to bonding. Consult $3 \mathrm{M}$ BSD Technical Bulletin on Primers for more information.

a. Most porous (e.g., concrete) or fibered materials (e.g., wood) will require sealing to provide a unified surface. Marine grade varnishes and high performance contact adhesives (such as $3 \mathrm{M}^{\mathrm{TM}} 80$ Neoprene Contact Adhesive or Scotch-Grip ${ }^{\mathrm{TM}} 1357$ Contact Adhesive) have been shown to produce good bond strengths with VHB tapes. Note: These primers must be tested by user for individual applications to determine suitability. Be sure to follow primer manufacturing precautions and directions for use when using primers.

b. Some materials (e.g., copper, brass, plasticized vinyl) may require priming or coating to prevent interaction between adhesive and substrate.

c. Bonding to glass, ceramic tile or other hydrophylic surfaces in a high humidity environment may require the use of a silane coupling agent to help ensure a longterm bond. Consult Silane Priming Technical Bulletin.
Important Application Considerations

\section{THE FOLLOWING APPLICATION CONDITIONS MUST BE EVALUATED THOROUGHLY BY THE USER TO DETERMINE WHETHER VHB TAPES ARE SUITABLE FOR THE INTENDED USE.}

\section{- Severe Cold Temperatures}

Applications which require performance at severe cold temperatures must be thoroughly evaluated by the user if the intended use will subject the VHB Tape product to high impact stresses.

\section{- Rigid Surfaces}

Applications of tapes F-9460PC, F-9469PC or F-9473PC involving two rigid surfaces must be evaluated by the user to ensure adequate adhesive contact and also to ensure that differences in thermal expansion rates of substrates do not adversely affect the bond line. 


\title{
Tapes and Adhesives Transfer Tapes
}

\author{
Important \\ Application \\ - Plasticized Vinyls \\ Considerations \\ Tapes $4926,4936,4941,4956,4945$ and $4946 \mathrm{~F}$ have very good plasticizer resistance \\ (continued) \\ and adhesion to many vinyls. Because of the wide variation in vinyl formulations, \\ however, evaluation by the user must be conducted with the specific vinyl used to \\ ensure that performance is satisfactory. Problems related to plasticizer migration can \\ often be predicted by accelerated aging of assembled parts at $150^{\circ} \mathrm{F}\left(66^{\circ} \mathrm{C}\right)$ for one \\ week. \\ - Rough surfaces. Tapes 4932 and 4952 were designed to adhere to many low surface \\ energy substrates. Rough surfaces ireated by light abrasion may actually be \\ detrimental to bond strength.
}




\section{M ${ }^{\text {tu }}$ VHB $^{\text {tu }}$ Double Coated Acrylic Foam Tapes and Adhesives Transfer Tapes}

\section{For Additional} Information
To request additional product information or to arrange for sales assistance. call toil free 1-800-362-3550. Address correspondence to: 3M Bonding Systems Division, 3M Center, Building 220-7E-01. St. Paul, MN 55144-1000. Our fax number is 612-733-9175. In Canada, phone: 1-800-364-3577. In Puerto Rico, phone 1-809-750-3000. In Mexico, phone: 5-728-2180.
Important Notice

The statements and technical information contained herein and based on tests and data which $3 \mathrm{M}$ believes to be reliable, but the accuracy or completeness of such statements and technical information is not guaranteed. User is responsible for determining whether a specific $3 \mathrm{M}^{\mathrm{w}} \mathrm{VHB} \mathrm{B}^{\mathrm{m}}$ Tape is fit for a particular purpose and suitable for user's method of application.

\section{Limited Warranty}

$3 M$ warrants for 12 months from the date of manufacture that $3 M^{\text {Tw }}$ VHB ${ }^{\text {ww }}$ Tape will be free of defects in material and manufacture. 3M MAKES NO OTHER WARRANTIES, EXPRESS OR IMPLIED. INCLUDING BUT NOT LIMITED TO. ANY IMPLIED WARRANTY OF MERCHANTABILITY OR FITNESS FOR A PARTICULAR PURPOSE. This Limited Warranty does not cover damage resulting from the use or inability to use $3 \mathrm{M}^{\text {TM }} \mathrm{VHB}^{\text {tw }}$ Tape due to misuse, workmanship in application, or application or storage not in accordance with $3 \mathrm{M}$ recommended procedures.

\section{Limitation of \\ Remedies and Liability}

If the $3 M^{\text {rw }} V H B^{\text {rw }}$ Tape is proved to be defective within the watranty period stated above. THE EXCLUSIVE REMEDY. AT 3M'S OPTION. SHALL BE TO REFUND THE PURCHASE PRICE OF OR TO REPAIR OR REPLACE THE DEFECTIVE $3 M^{\text {nu }}$ VHB ${ }^{n}$ TAPE. $3 M$ shall not otherwise be liable for loss or damages, whether direct, indirect. special, incidental, or consequential, regardless of the legal theory asserted, including negligence, warranty, or strict liability.

\section{Iso gaon}

This Bonding Systems Division product was manufactured under a 3M quality system registered to ISO 9002 standards.
Bonding Systems Division

$3 \mathrm{M}$ Center, Building 220-7E-01

St. Paul, MN 55144-1000

\section{$(3$}

VHB' and "Scoren-Gnp" are tracemans of $3 M$.

Prrued In U.SA

c3M 1998 70-07020266-1 